University of Redlands

\title{
Building a Carbon Dioxide Emissions Model for the City of Redlands
}

A Major Individual Project submitted in partial satisfaction of the requirements

for the degree of Master of Science in Geographic Information Systems

\author{
by \\ Sabina Giri
}

Fang Ren, Ph.D., Committee Chair

Mark Kumler, Ph.D.

August 2010 
Building a Carbon Dioxide Emissions Model for the City of Redlands

Copyright (C) 2010

by

Sabina Giri 
The report of Sabina Giri is approved.
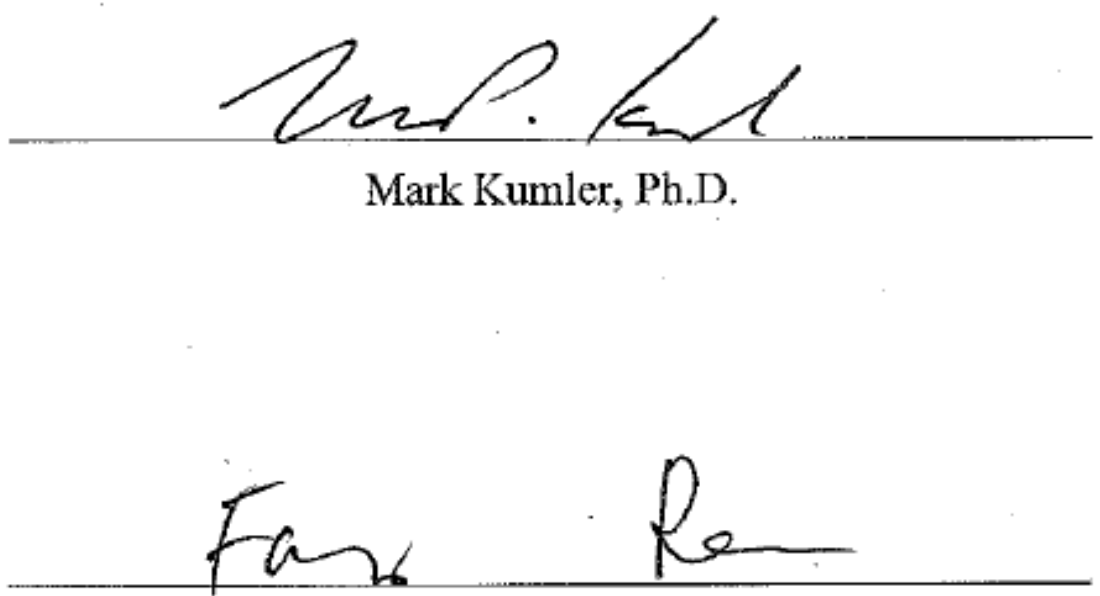

Fang Ren, Ph.D., Committee Chair

August 2010 



\section{Acknowledgements}

My project would not have been complete without the generous support of Mayor Jon Harrison (City of Redlands), Dr. Timothy Krantz (University of Redlands), Mr. Phil Mielke (City of Redlands), Ms. Linda La Pierre Ortiz (Southern California Edison), Ms. Becky R. Estrella (Southern California Gas Company), ESRI Instructors and the MS GIS Faculty. I would like to thank: Dr. Fang Ren for being my advisor and for spending long hours giving me ideas on how I could make this project successful; Dr. Mark Kumler for being my graduate committee second reviewer and for all the good advice on how I could improve my report, presentation and poster; Ms. Lynn Flewelling for reviewing my project report; Ms. Debra Riley, MS GIS Program Coordinator, for keeping us organized and for making us feel like we were at home; Nate Strout for helping me with programming; and John, Brandon and Ruben for supporting us with our computer problems. Thank you so much cohort 15 and 15.5 for all the help and support, for the cheerful faces and good times. To my dear family this is for you. Thank you for encouraging and supporting me along the way. 



\author{
Abstract \\ Building a Carbon Dioxide Model for the City of Redlands \\ by \\ Sabina Giri
}

Carbon dioxide is a major greenhouse gas associated with climate change and global warming. The California Global Warming Solutions Act of 2006 requires local governments, such as the City of Redlands, to plan and implement carbon dioxide emissions reduction programs by the year 2012, and reduce carbon emissions by the year 2020 to their 1990 level. Therefore, this project was developed as an initial assessment to analyze and estimate the distribution of indirect carbon dioxide emissions due to electricity and natural gas consumption from the residential and commercial sectors.

The most straightforward and accurate way to analyze the distribution of carbon dioxide emissions from end-use energy consumption is to examine the energy consumption data from the utility companies, such as the actual electricity meter readings of each household or each community. However, due to utility consumer confidentiality issues, only city-level aggregated data can be provided. This has made it difficult for local governments to determine indirect emissions at finer resolutions, such as parcel or building level. This project was designed to provide a tool to help city officials and planners estimate and analyze the spatial distribution of indirect carbon dioxide emissions.

A bottom-up approach was used to estimate the carbon dioxide emissions from the end-use energy consumption in the residential and commercial sectors. The $\mathrm{CO}_{2}$-Model application was built using ESRI's ArcGIS 9.3 ModelBuilder platform. Using energy intensity and unit energy consumption values with GIS parcels data is a cost effective way to estimate and analyze the change in carbon dioxide emissions over time. 



\section{Table of Contents}

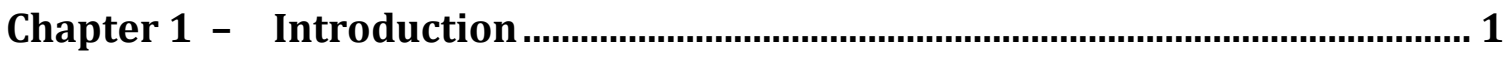

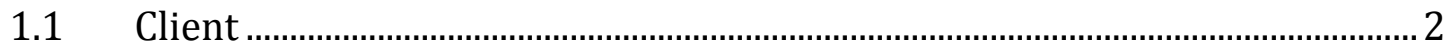

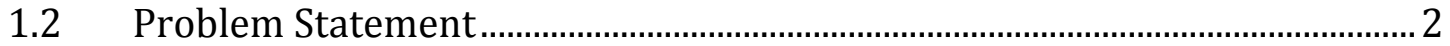

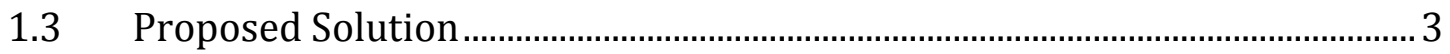

1.3.1 Goals and Objectives ……………………………………………………..... 3

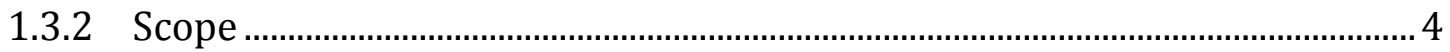

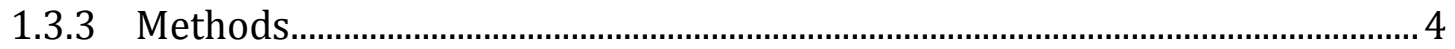

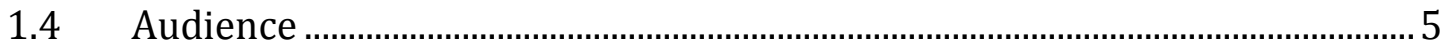

1.5 Overview of the Rest of this Report .................................................................. 5

Chapter 2 - Background and Literature Review.................................................... 7

$2.1 \quad$ Estimating Carbon Emissions.............................................................................

2.1.1 Global, National, and State Level Estimation.......................................................

2.1.2 Local Level Estimation .......................................................................................

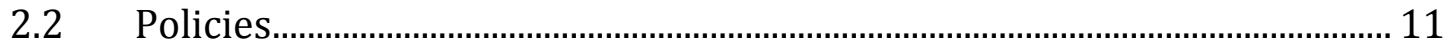

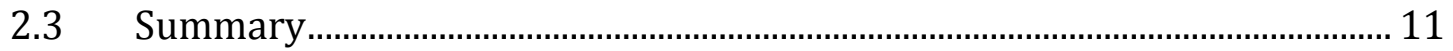

Chapter 3 - Systems Analysis and Design ……..................................................13

$3.1 \quad$ Problem Statement .......................................................................................... 13

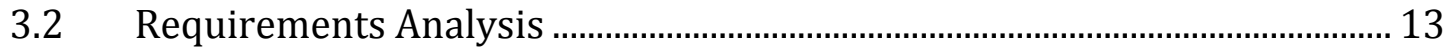

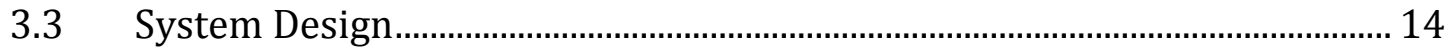

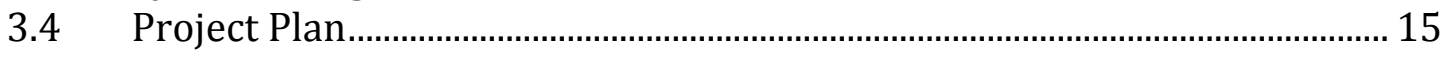

3.5 Summary …………………………………………………………………. 16

Chapter 4 - Database Design ........................................................................17

4.1 Conceptual Data Model ................................................................................ 17

4.2 Logical Data Model......................................................................................... 18

4.3 Data Sources and Collection............................................................................... 22

4.4 Data Scrubbing and Loading ………………………………………………. 23

4.4.1 Preprocessing Parcels Data ……………………………………………….... 23

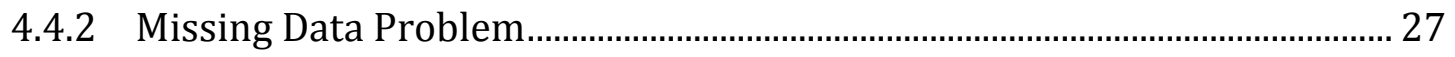

4.5 Summary …………………………………………………………………. 30

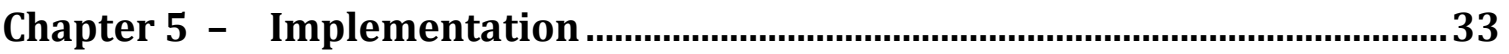

$5.1 \quad$ Project Workspace and Portability ………………………………………… 33

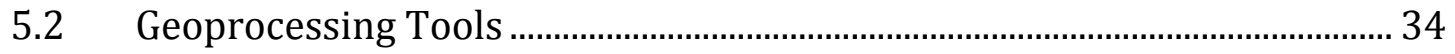

$5.3 \quad \mathrm{CO}_{2}$-Model Application ................................................................................. 35

5.3.1 Carbon Emissions Estimation Model for Commercial Sector ........................ 36

5.3.2 Carbon Emissions Estimation Model for Residential Sector ......................... 39

5.3.3 Carbon Dioxide Emission Factors ....................................................................... 41

$5.4 \quad$ Summary ...................................................................................................... 43

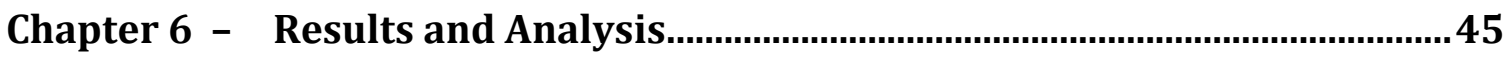

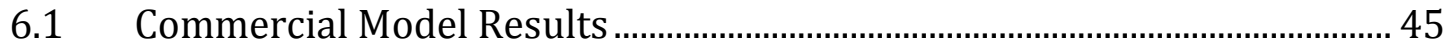

$6.2 \quad$ Residential Model Results.................................................................................. 48 


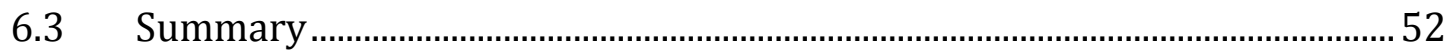

Chapter 7 - Conclusions and Future Work …........................................................53

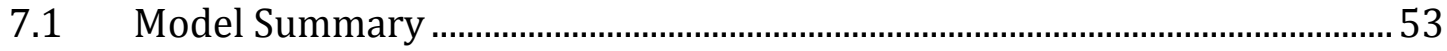

7.2 Model Enhancement and Future Studies .......................................................... 54

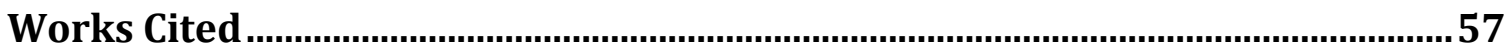

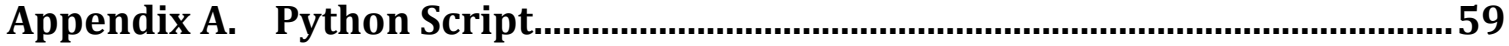

Appendix B. Criteria for dividing parcels dataset into different land use ......61

Appendix C. Utility provided data and 15/15 rule ............................................63

Appendix D. $\mathrm{CO}_{2}$-Model Application ModelBuilder Diagrams............................65

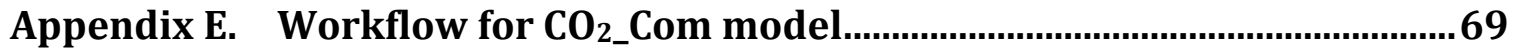

Appendix F. Workflow for $\mathrm{CO}_{2} \mathrm{SCE}$ and $\mathrm{CO}_{2}$ Zone10 model............................... 70

Appendix G. eGRID Subregions.............................................................................. 71 


\section{Table of Figures}

Figure 1-1: Carbon dioxide emissions and sources ................................................ 1

Figure 1-2: City of Redlands and surrounding cities ......................................... 2

Figure 2-1: Forecasting climate zone and utility region (CEC, 2006)...................... 10

Figure 3-1: Schematic of system design ......................................................... 14

Figure 4-1: Conceptual model of Redlands electricity and gas system .................. 17

Figure 4-2: Schematic of workspace and geodatabase ........................................ 19

Figure 4-3: Schema of input table required for the $\mathrm{CO}_{2}$-Model application ........... 21

Figure 4-4: Schema of output table generated by the $\mathrm{CO}_{2}$-Model application........ 22

Figure 4-5: Redlands city boundary and surrounding cities ...................................2. 24

Figure 4-6: Workflow automation built to preprocess parcels feature class ...........25

Figure 4-7: Original and processed parcel feature class ....................................26

Figure 4-8: Workflow automation to group data into different land use type .........27

Figure 4-9: Workflow automation to update missing floor area ...........................2 28

Figure 4-10: Workflow automation to update number of units ............................... 30

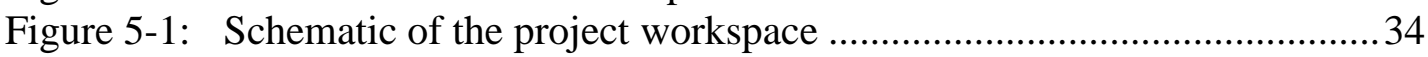

Figure 5-2: Schematic of custom and generic tools used in the sub-models ........... 35

Figure 5-3: Custom tool generated to add multiple fields to $\mathrm{CO}_{2}$-Models ............... 36

Figure 5-4: Energy intensities added as variables in $\mathrm{CO}_{2}$ Com model................... 38

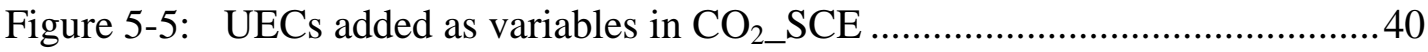

Figure 5-6: UECs added as variables in $\mathrm{CO}_{2} \_$Zone10 model ................................ 41

Figure 5-7: Electricity and natural gas emissions factors .................................. 42

Figure 6-1: Distribution of Carbon dioxide emissions from commercial sector .....45

Figure 6-2: Comparison of commercial building floor space and emissions ..........46

Figure 6-3: Commercial model result validation ................................................47

Figure 6-4: Carbon dioxide emissions distribution for residential sector predicted

using $\mathrm{CO}_{2} \_\mathrm{SCE}$ Model and $\mathrm{CO}_{2}$ ZZone10 .........................................................49

Figure 6-5: Percent of residential building type and carbon dioxide emissions ......50

Figure 6-6: Residential model result validation....................................................51 



\section{List of Tables}

Table 1. System design goals and requirements ......................................................14

Table 2. Feature classes and their attributes important for energy calculation.................20

Table 3. Parcel feature class showing different land use categories .............................29

Table 4. Annual electricity and gas intensity for SCE service area (CEC, 2006) ...........37

Table 5. Annual UEC values for SCE utility service areas by building age and type .......39

Table 6. Electricity and natural gas UEC used in $\mathrm{CO}_{2}$ Zone10 model ..........................41

Table 7. Carbon dioxide emissions factors for electricity and natural gas ......................42

Table 8. Comparison of actual and estimated natural gas consumptions ........................48

Table 9. Percent error for electricity and natural gas for the residential sector ................51 



\section{List of Acronyms and Definitions}

$\begin{array}{ll}\text { AAG-GCLP } & \text { Association of American Geographers-Global Change in Local Places } \\ \text { AB 32 } & \text { Assembly Bill 32 } \\ \text { APN } & \text { Assessor's Parcel Number } \\ \text { CCA } & \text { California Climate Action } \\ \text { CEC } & \text { California Energy Commission } \\ \text { CO } 2 & \text { Carbon Dioxide } \\ \text { DOE } & \text { Department of Energy } \\ \text { EIA } & \text { Energy Information Administration } \\ \text { EPPA } & \text { Emission Prediction and Policy Analysis } \\ \text { ESRI } & \text { Environmental Systems Research Institute } \\ \text { FCZ } & \text { Forecasting Zone } \\ \text { GDP } & \text { Gross Domestic Product } \\ \text { GIS } & \text { Geographic Information Systems } \\ \text { ICLEI-CCP } & \text { International Council for Local Environmental Initiatives-Cities for } \\ & \text { Climate Protection } \\ \text { IGSM } & \text { Integrated Global Systems Model } \\ \text { IPCC } & \text { Intergovernmental Panel on Climate Change } \\ \text { KWh } & \text { Kilowatt Hour } \\ \text { LEED } & \text { Leadership in Energy and Environmental Design } \\ \text { NAICS } & \text { North American Industrial Classification System } \\ \text { RASS } & \text { Residential Appliance Saturation Study } \\ \text { SCAG } & \text { Southern California Association of Governments } \\ \text { SCE } & \text { Southern California Edison } \\ \text { UC Davis } & \text { University of California at Davis } \\ \text { UEC } & \text { Unit Energy Consumption } \\ \text { UML } & \text { Unified Modeling Language } \\ \text { USEPA } & \text { United States Environmental Protection Agency } \\ & \end{array}$ 



\section{Chapter 1 - Introduction}

Carbon dioxide $\left(\mathrm{CO}_{2}\right)$ is a major greenhouse gas associated with climate change and global warming. $\mathrm{CO}_{2}$ is part of a complex system in the global environment and modeling it requires an understanding of physical and ecological systems that interprets emissions into levels of greenhouse gases, climate change, and global warming (Schmalensee, Stoker, \& Judson, 1998). Basically, environmental and man-made sources are the main contributors of carbon dioxide. Among various man-made sources, burning of fossil fuels for energy to support the residential, commercial, industrial, and transportation sectors is considered to be the main cause of increasing carbon dioxide emissions in the atmosphere (Figure 1-1). Since emissions from natural sources cannot be controlled, efforts are being made to reduce carbon emissions from man-made sources.

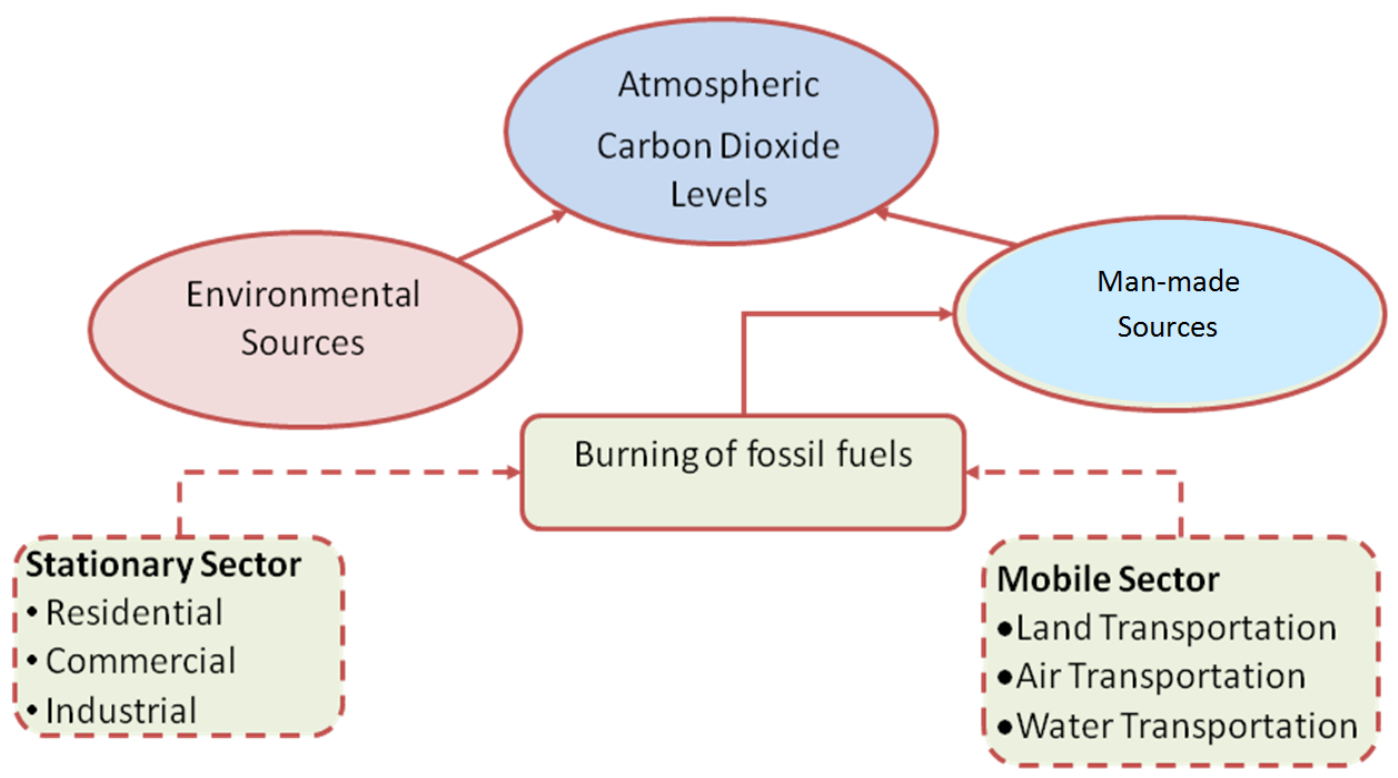

\section{Figure 1-1: Carbon dioxide emissions and sources}

California is taking a leading role in reducing greenhouse gas emissions at a statewide level under the California Global Warming Solutions Act of 2006, Assembly Bill 32 (AB 32) (California Environmental Protection Agency Air Resources Board, 2006). This bill provides local governments with the authority to enact and adopt greenhouse gas reduction plans that are more stringent than State and Federal plans. The goal of the plan is to reduce carbon emissions by 2020 to a baseline target year of 1990 (California Public Utilities Commission, 2008). Therefore, the California Global Warming Solutions Act of 2006 is focusing on reducing greenhouse gases at the local city level.

According to the State Climate Action Task Force, major local governments need to prepare carbon emissions reduction plans and implement them by 2012 (California Public Utilities Commission, 2008). In order to plan carbon reduction programs, local governments need to identify and analyze carbon emission patterns. There are several 
models to aggregate carbon emissions at different resolutions, such as global, national, and state levels using different methods, but these are not spatially integrated at the local government level. Therefore, this project developed a carbon dioxide emission model $\left(\mathrm{CO}_{2}\right.$-Model $)$ to analyze and estimate the geographic distribution of indirect carbon dioxide emissions due to electricity and gas consumption from the residential and commercial sectors for the City of Redlands (Figure 1-2) using existing data.

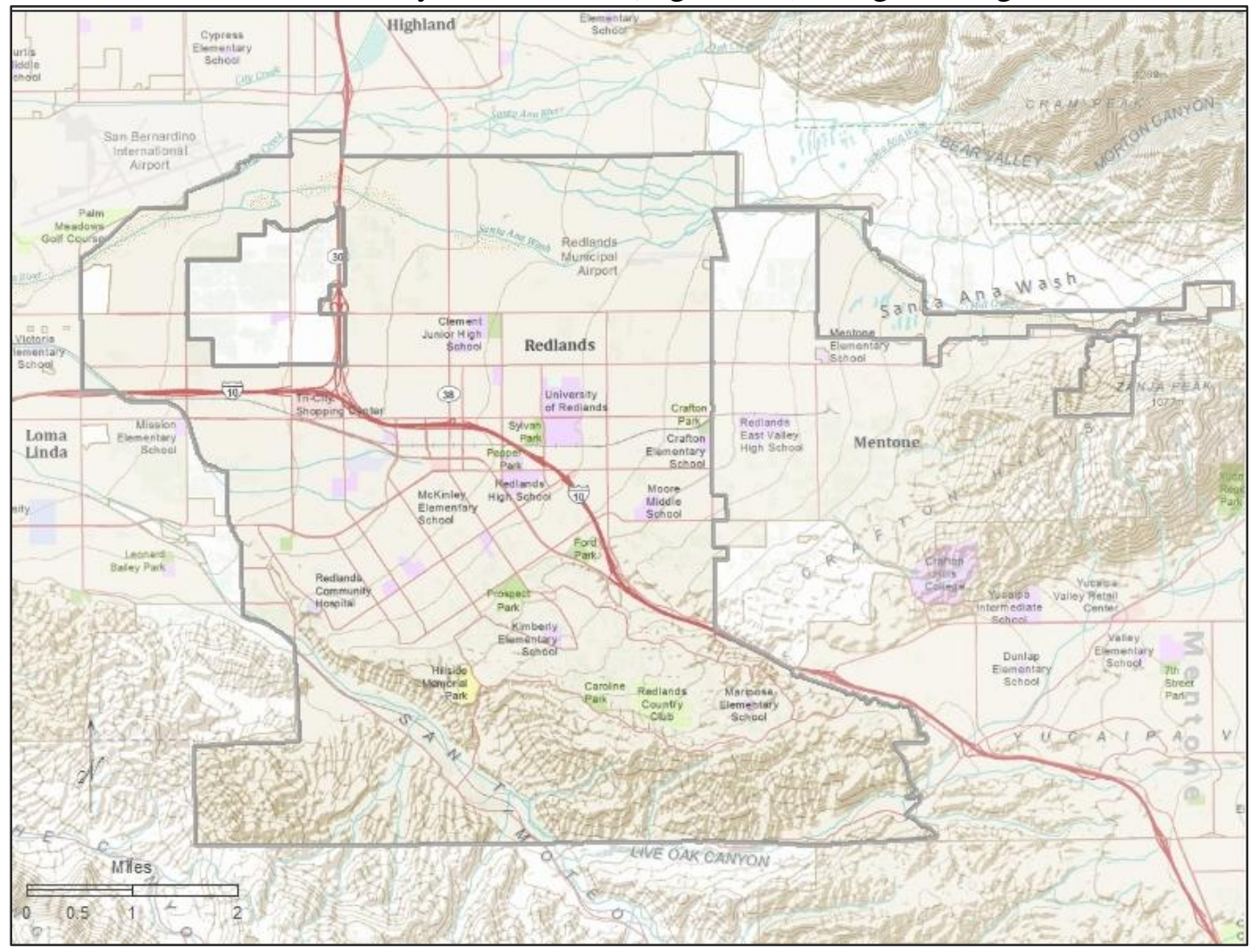

Figure 1-2: City of Redlands and surrounding cities

The rest of this chapter will introduce the client, the problem statement, a proposed solution, the audience for this project, and a general overview of the rest of this report.

\subsection{Client}

The client for this project is Mayor Jon Harrison of the City of Redlands. This project was commissioned to estimate and analyze the spatial distribution of carbon emissions from residential and commercial land uses using GIS. The client plans to use the outcome of the project to design carbon emission reduction programs, and to pursue Leadership in Energy and Environmental Design (LEED) development in the City of Redlands.

\subsection{Problem Statement}

To meet the demands of the California Global Warming Solutions Act of 2006, local governments need to quantify and analyze carbon emissions in order to implement carbon 
emissions reduction plans. The most straightforward and accurate way to analyze the spatial pattern of carbon dioxide emissions from end-use energy consumption would be to examine the energy consumption data from the utility companies, such as the actual electricity meter readings of each household or each community. However, due to utility consumer confidentiality issues, only the aggregated data, such as total electricity consumption for the entire commercial sector or residential sector, can be provided. This has made it difficult for local governments to determine indirect emissions from end-use energy consumption at finer resolutions, such as parcel or building levels. Therefore, recognizing the need to address and manage the emissions spatially at a local government level, the client requested a method to assess the carbon emission for residential and commercial land use for the City of Redlands.

\subsection{Proposed Solution}

To provide a basis for carbon emissions reduction policies and plans for the City of Redlands, this project proposed to develop an automated $\mathrm{CO}_{2}$-Model by using GIS techniques and various spatial analytical tools. The $\mathrm{CO}_{2}$-Model makes it possible to estimate and analyze the distribution of indirect carbon emissions from residential and commercial land uses.

The model was created using the Environmental Systems Research Institute's (ESRI) ModelBuilder extension that is available with ArcGIS 9.3 software. The carbon emissions calculations for the $\mathrm{CO}_{2}$-Model were based on an alternative California Registry-approved method for estimating electricity use (California Climate Action Registry, 2009). This method is recommended to organizations having difficulty obtaining actual metered readings of their purchased electricity. A similar method was followed to calculate emissions from natural gas use in residential and commercial buildings. The model was developed using the ArcGIS ModelBuilder platform because of the flexibility it provides to automate and repeat the work flow.

\subsubsection{Goals and Objectives}

The overall goal of this project was to develop an automated $\mathrm{CO}_{2}$-Model to estimate and analyze the indirect carbon emissions from residential and commercial energy consumption for the year 2008. The information products produced by the $\mathrm{CO}_{2}$-Model would help the client plan carbon emissions reduction programs. There were four specific objectives identified for the development of the automated $\mathrm{CO}_{2}$-Model:

1. Investigate methodologies to estimate end-use energy consumption for the residential and commercial sector

2. Estimate energy consumption for residential and commercial sectors

3. Estimate and analyze indirect carbon emission distribution from estimated energy consumption data

4. Identify areas of high carbon emissions and produce information products such as maps and a user manual. 


\subsubsection{Scope}

The four specific objectives identified above helped define the scope of this project, which was to quantify and analyze the indirect carbon emissions distribution from the consumption of electricity and gas in the residential and commercial land use sectors in the City of Redlands. Mobile sources, such as transportation, were beyond the scope of this project because of the time limitation. Large stationary sources, including powerplants, refineries, manufacturing facilities, and other industries were also beyond the scope of this project because these facilities are required to follow industry-specific reporting guidelines and California Registry protocols.

Thus, there are two components of the $\mathrm{CO}_{2}$-Model: residential and commercial. A bottom-up approach was taken to estimate energy consumption based on the investigated methods. The data acquisition process was complicated and time consuming. The data provided by the utility companies were aggregated at levels that were not useful to the client to make planning decisions and were not suitable for spatial analysis purposes. Therefore, an automated $\mathrm{CO}_{2}$-Model application was developed based on previous studies on estimating end-use energy consumptions to predict the spatial distribution of indirect emissions from commercial and residential sectors.

\subsubsection{Methods}

Several procedures and models have been developed by other organizations for estimating carbon emissions for reporting purposes. The first step for this project was to identify the method that would support the purpose of the study, making use of the data available. This project drew upon a method based on an alternative California Registryapproved method for estimating electricity use developed by the California Climate Action Registry (California Climate Action Registry, 2009).

The second step in building the $\mathrm{CO}_{2}$-Model was to create a workspace that would contain all the related documents, applications, and file geodatabases provided by the client and created while running the model. The third step was building the $\mathrm{CO}_{2}$-Model itself in ArcGIS 9.3 using the ModelBuilder extension to automate the workflow. The geoprocessing tools provided in ArcGIS 9.3 were used to build the model in ModelBuilder and to calculate carbon emissions using spatial and non spatial data. ModelBuilder was chosen to automate the estimation of carbon emissions due to its simplicity and the capability to insert and change variables. Most of the functions to automate the $\mathrm{CO}_{2}$-Model were available via the ArcToolbox and programming was not required. The emissions factors used in the $\mathrm{CO}_{2}$-Model were added to the ModelBuilder to convert electric and gas consumption data to equivalent carbon emissions. The factors were obtained from the 2009 California Climate Action Registry Protocol. The calculated energy consumption for the different sectors was then multiplied by the emissions factor to calculate the total emissions per parcel per sector in the $\mathrm{CO}_{2}$-Model.

In addition to the steps detailed above, data collection and processing was one of the most important and time consuming steps. Aggregated energy consumption data for the City were collected from the electric and gas companies, and parcel level data were collected from the City of Redlands GIS department. The parcels data was used to calculate energy consumption per parcel based on existing methods; the aggregated 
electricity and gas data provided by the utility companies were used to verify the estimated energy consumption at city level.

\subsection{Audience}

This project may interest a wide variety of people interested in global warming and climate change. The targeted audiences of this project are planning and management professionals who are familiar with GIS. Planning groups with a basic knowledge of the ArcGIS 9.x application may also benefit from the implementation of the project.

\subsection{Overview of the Rest of this Report}

This report consists of seven chapters. The foundation of the $\mathrm{CO}_{2}-\mathrm{Model}$ was built on previously conducted studies, which are outlined in Chapter 2. Chapter 3 describes the system analysis and design by discussing the analysis requirements. Chapter 4 provides the database design, which incorporates the conceptual and logical data model, as well as data sources, data collection, scrubbing, and loading methods used for this study. The implementation processes are described in Chapter 5 and the results and analysis of the implementation of $\mathrm{CO}_{2}$-Model are discussed in Chapter 6. Chapter 7 presents the findings and recommendations for future work. 



\section{Chapter 2 - Background and Literature Review}

This chapter provides background and answers questions as to why estimating $\mathrm{CO}_{2}$ emissions at local levels is important; what kind of estimation methods have been used previously and at what scale; what are the policies that drive $\mathrm{CO}_{2}$ emissions reduction programs; and what methodologies should be used. There are three sections in this chapter. The first section provides a general overview of different types of research and models that exist for estimating $\mathrm{CO}_{2}$ emissions, and their weaknesses and strengths. The second section explains the policies that mandate emissions reduction, and the methods recommended at the local level. The last section of this chapter provides a summary of the literature that supports the methods of this project.

\subsection{Estimating Carbon Emissions}

Carbon dioxide is one of the major greenhouse gases and is studied extensively in research related to greenhouse gas emissions, climate change, and global warming. According to the Energy Information Administration (EIA), 80 percent of the U.S. greenhouse gas emissions are energy-related carbon dioxide emissions (Energy Information Administration, 2007).

Although emission sources are local, research is focused intensively at a global level (Kates, Mayfield, Torrie, \& Witcher, 1998). The literatures on carbon emissions estimation can be divided into global, national, state, and local levels.

\subsubsection{Global, National, and State Level Estimation}

Several studies conducted at the national and global levels have associated increases in carbon emissions directly with the economic growth of a region. The EIA states that the energy use in the United States is primarily driven by economic growth in the long term, and is affected by fluctuations in weather patterns (e.g., number of cooling and heating days) and energy generation sources in the short-term (Energy Information Administration, 2007).

The Department of Energy (DOE) has designed an energy indicators system which provides a hierarchal structure to generate indexes that explain the change in energy use over time (U.S. Department of Energy, 2003). Three types of indexes are developed in a hierarchical structure to measure the change in energy use: economy-wide energy consumption is in the highest aggregation level, and the unit defined to measure the activity at this level (intensity indicator) is defined by gross domestic product (GDP); the second level of the hierarchical system includes the residential, commercial, industrial, and transportation sectors, and the indicators defined to measure the activity were divided into different categories. The energy intensity indicators for the residential category, which could be further divided into different housing types, are household size and floor space (in square feet); for the commercial category the indicator identified is floor space (in square feet) only.

Other studies have been conducted to estimate carbon emissions at global and national levels. For example, Schmalensee, Stoker and Judson (1998) constructed carbon emission models using an econometric model to compare the emissions at both national 
and global levels. Fossil fuel combustion, population growth, and income from 1950 to 1990 were taken into account in their models. Researchers at the Massachusetts Institute of Technology have developed a system as a part of an Integrated Global Systems Model (IGSM) to project the effects of economic growth on man-made greenhouse gas emissions and aerosols. The newer version of the IGSM, the Emission Prediction and Policy Analysis (EPPA) model, also includes regional and sector details, and land use to represent energy flow of the "earth system" as a whole (Paltsev, et al., 2005).

The United States Environmental Protection Agency (USEPA) has developed methodologies to compile a comprehensive greenhouse gases inventory at the state level, based upon approaches established by the Intergovernmental Panel on Climate Change (IPCC) to inventory greenhouse gases at the national level (Kates, Mayfield, Torrie, \& Witcher, 1998). According to Kates, Mayfield, Torrie, and Witcher (1998), the EPA and IPCC-based emissions calculation method is very detail-oriented and may be beneficial and applicable to nations that have consumption or activity level data.

Most of the above mentioned research relates carbon emissions from energy consumption at the global, national, and state levels to economic and demographic patterns. The methods developed to estimate emissions at the global and national level cannot be applied at the local level due to the complexities associated with disaggregated data (Kates, Mayfield, Torrie, \& Witcher, 1998). The problems related to emissions allocation decrease as spatial aggregation increases; in part it is also because there is more data collected at the national level than the local levels (Kates, Mayfield, Torrie, \& Witcher, 1998).

\subsubsection{Local Level Estimation}

Since this project focuses on carbon emissions at a city scale or local level, it is also important to understand the complexities associated with carbon emissions estimation methods at the local level.

There are several methods for estimating and reporting carbon emissions at local levels. The best methods identified were simple, replicable, and maintainable with the least effort. There were several top-down and bottom-up approaches identified in the literature. The top-down approaches, developed by the electric utility industry, predict the end-use electricity for buildings based on historical data loads (Heiple \& Sailor, 2008). The bottom-up approaches, in contrast, use individual building energy consumption per hour to estimate city-level consumption. The energy calculations for some of the bottomup approaches are estimated using pre-existing building simulation software like EQUEST and DOE 2.2, developed by the U.S. Department of Energy. Buildings are divided into different categories based on their characteristics and the simulation software is used to predict the energy consumption for a set of prototype buildings representative of buildings in a particular city (Heiple \& Sailor, 2008).

Two organizations have independently developed methods to calculate greenhouse emissions at the local level, though with different objectives: the International Council for Local Environmental Initiatives-Cities for Climate Protection (ICLEI-CCP) campaign, and the Association of American Geographers-Global Change in Local Places (AAG-GCLP). The objective of AAG-GCLP is to understand the causes of greenhouse gas emissions and their impact at the local level. The ICLEI-CCP method looks at the total fuel and electricity sales per sector to predict total emissions in cities (Kates, 
Mayfield, Torrie, \& Witcher, 1998). ICLEI-CCP and AAG-GCLP are not GIS-oriented. Both methods are used to inventory greenhouse gas emissions at the city level.

The University of California at Davis (UC Davis) has developed a GIS-based land use planning and forecasting model for regional or county-level analysis. The model has several components to predict suitable areas for future urban growth. One of the components of the model is a greenhouse gas calculator, which allows users to calculate energy demands and resulting greenhouse gases from new developments. The total energy (electricity and gas) demand in a residential category is calculated by multiplying the number of residential households by an average number of square feet of a building in the residential land use category and by the energy intensity for the residential land use type (University of California at Davis, 2008). The total energy demand in a commercial land use category is calculated by multiplying the number of square feet of a building by the average energy intensity for the land use category.

A similar method was developed by the California Climate Action (CCA) Registry for estimating electricity use for commercial sectors. The only difference is that the CCA Registry recommends estimating end-use energy consumption for commercial sectors based on the average electricity intensity of comparable facilities, instead of that for the land use category. The study recommends deriving the average electricity intensity of comparable facilities from the results of an extensive survey and analysis administered and supported by California Energy Commission (CEC) for forecasting end-use energy demand and assessing energy efficiency market activities (California Energy Commission, 2006). The California Commercial End-Use Survey divided and analyzed end-use energy demand according to CEC forecasting zone (FCZ) and electricity utility region (Figure 2-1). 


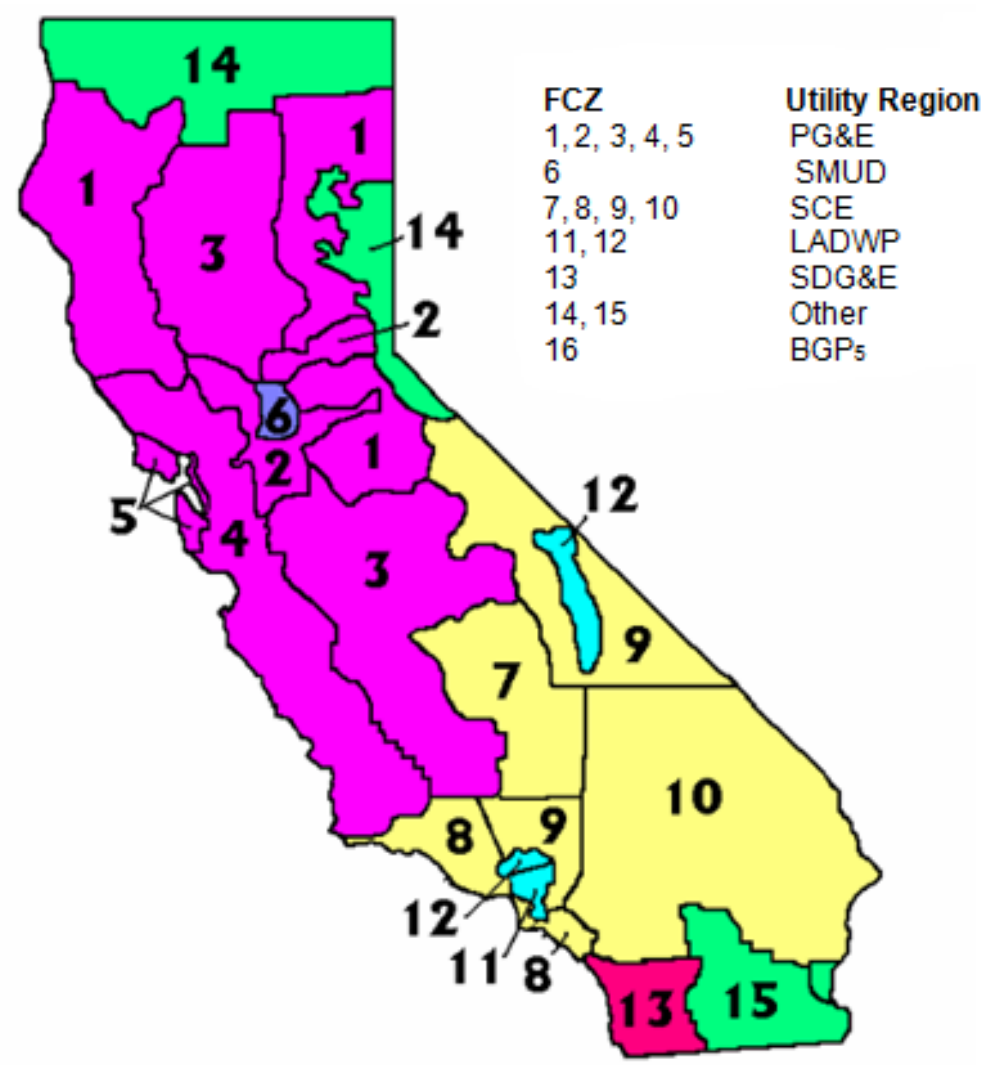

Figure 2-1: Forecasting climate zone and utility region (CEC, 2006)

As for the residential sector, the CEC commissioned a Unit Energy Consumption (UEC) study by teaming up with the investor owned utilities. UEC is defined as the average energy consumed by a household in a year. There were two sets of UEC values produced by the survey that were applicable for the estimation of energy consumption for the City of Redlands. One set of the UEC values was the result of the survey from the SCE utility region and the other set was the result of the survey from the climate zone 10 region. The California Statewide Residential Appliance Saturation Study (RASS) was conducted to allow comparison of end-use energy consumption across utilities service regions and climate zones similar to the commercial survey explained above. The results also provide UEC based on variables, such as dwelling type, dwelling vintage, and income for different climate zones and utility regions (California Energy Commission, 2004). The RASS study was revised and the UEC results were updated using updated billing and weather data in 2006. The average UEC results per household from the revised study for the SCE Utility region and Zone 10 region were used in the $\mathrm{CO}_{2}$-Model to estimate end-use energy consumption for resident type and dwelling vintage (California Energy Commission, 2006).

Several factors, including economic, demographic, building structure, and weather, play significant roles in assessing unit energy consumption for a building. For example, Arronruengswat \& Auffhammer (2009), in their study for the California Climate Change Center, simulated and provided an estimation of California's residential electricity 
demand based on climate change. Their findings showed direct effects of climate on electricity demand for residential customers and varied greatly among climate zones. However, due to the time and cost budget, not all of these factors can be exhaustively examined. The level of sophistication used to inventory and calculate emissions depends on the amount of resources and time local organizations are willing to spend (Kates, Mayfield, Torrie, \& Witcher, 1998). In addition, these factors may not be equally important in determining the local energy consumption. For example, in a region that has not experienced much economic growth, economic factors may not influence the change in energy consumption when compared to other factors. Therefore, it is possible that factors which need to be considered may vary across different study areas.

\subsection{Policies}

In 1988, due to increasing awareness and warnings from climatologists and scientists about the effects of greenhouse gases, the World Meteorological Organization and the United Nations Environment Program established the IPCC. In 1993, President Clinton established the Climate Change Action Plan, asking for voluntary reduction to stabilize and reduce the greenhouse gas emissions in the United States. In 2006, the Governor of California, Arnold Schwarzenegger, signed the California Global Warming Solutions Act (Assembly Bill (AB) 32) into law. The bill has provided local governments with initiatives to voluntarily cut carbon dioxide emissions by implementing energy reduction and efficiency efforts to meet the greenhouse gas emission reduction goal. The state plans on reducing the overall emissions by the year 2020 to a base line target year of 1990 (California Public Utilities Commission, 2008). Therefore, several local governments are committed to energy leadership in local communities and at government facilities to meet the target goal of AB 32 (California Public Utilities Commission, 2008).

\subsection{Summary}

Although climate change is related to human activities performed at local levels, the majority of the efforts to quantify and analyze greenhouse gases are done at the global level (Kates, Mayfield, Torrie, \& Witcher, 1998). There are many datasets and research results at the national and state level, but converting data from these two levels to the local level would introduce significant errors if local weather variability is not accounted for during the conversion.

For this project, the methods to estimate energy consumption were simplified based on past research. Recent methodologies used for energy consumption modeling at local levels helped define the $\mathrm{CO}_{2}$-Model. The literature has shown evidence linking energy consumption to population growth, climate change, economy (per capita income of household), and building characteristics at different scales. Most of the models implemented to perform carbon inventories and assessments at the regional and local scale are Microsoft Excel-based and have no GIS or spatial component.

According to the Department of Energy and the EIA, aggregated energy intensities are considered as useful summary indicators for calculating energy consumption to track changes over time. Therefore, the $\mathrm{CO}_{2}$-Model uses energy intensity drawn from California Commercial End-Use Survey (California Energy Commission, 2006) and uses average UEC drawn from the California State Wide Residential Appliance Saturation 
Study (RASS) (California Energy Commission, 2004) to predict end-use energy consumption from common commercial buildings and residential buildings, respectively. The provider for electricity is Southern California Edison (SCE) and for natural gas is the Southern California Gas Company (SoCalGas). Since the study area falls under the SCE utility region and FCZ 10, the results from the California Commercial End-Use Survey for the SCE region were used in the $\mathrm{CO}_{2}$-Model to characterize energy consumption for common commercial buildings in the service area; the results from the RASS for SCE region and FCZ 10 were used in the $\mathrm{CO}_{2}$-Model to characterize energy consumption for residential buildings.

The effects of economic variables on energy consumption were ignored in the $\mathrm{CO}_{2}$ Model because the California energy consumption per capita basis has remained constant since the 1970s (Arronruengswat \& Auffhammer, 2009). In the case of the $\mathrm{CO}_{2}$-Model, weather doesn't play a role in analyzing energy consumption because the analysis for this project is not based on monthly consumption, but rather annual consumption, and the study area is within a single climate zone. 


\section{Chapter 3 - Systems Analysis and Design}

The first section of this chapter defines the problem statement and the second section describes the process of requirements analysis, which identifies non-functional and functional requirements based on the client's needs. The third section provides details about the systems design, based on the client's existing technology and data. The last section, the project plan, provides an overview of the initial project plan and the changes made during the development of the project. The major tasks included in the completion of this project are also discussed in the project plan.

\subsection{Problem Statement}

The California Global Warming Solutions Act of 2006 (AB 32) requires local governments to cut carbon emissions by the year 2020 to a baseline target year of 1990 (California Public Utilities Commission, 2008). Local governments need to plan and implement emissions reduction programs by the year 2012. To support the decision to reduce greenhouse gases at local level, the Climate Action Task Force was created for the City of Redlands. The client of this project, Mayor Jon Harrison, required a method for estimating and analyzing carbon emissions for the residential and commercial sectors in Redlands. The client needed the estimation products for planning and implementing carbon emissions reduction programs in the city.

\subsection{Requirements Analysis}

A requirements analysis was conducted during the project development phase to guarantee that the project would meet all of the client's needs; that is, the $\mathrm{CO}_{2}$-Model developed in this project should allow the client to estimate and analyze carbon dioxide emissions using GIS with available data and methodologies for monitoring purposes in the future.

Several functional and nonfunctional requirements were developed (Table 1). The nonfunctional requirements were to make the $\mathrm{CO}_{2}$-Model application simple, replicable, maintainable, and less time consuming in order for it to be widely used. The functional requirements, in chronological order as shown in Table 1 were: data preprocessing, which included cleaning and identifying important attributes as indicators necessary for the modeling; building a file geodatabase to house the data provided by the different sources and produced from the model application; automating the workflow and calculation methods using the ModelBuilder platform in the Environmental Systems Research Institute's (ESRI) ArcGIS 9.3 software application; and producing useful information products, such as maps, a desktop application, and a user manual. 
Table 1. System design goals and requirements

\begin{tabular}{|l|l|}
\hline Nonfunctional & Functional \\
Identify indicators & Data preprocessing \\
Central storage unit & Design file geodatabase \\
$\begin{array}{l}\text { Simple, reliable, repeatable, } \\
\text { automated }\end{array}$ & Design and build model \\
$\begin{array}{l}\text { Easy to understand, use and } \\
\text { follow }\end{array}$ & $\begin{array}{l}\text { Produce information products } \\
\text { (maps, desktop application, } \\
\text { user manual) }\end{array}$ \\
\hline
\end{tabular}

\subsection{System Design}

The system design of the $\mathrm{CO}_{2}$-Model was divided into three general components (Figure 3-1). The existing geospatial data, provided by different sources such as city and county, were stored in a database to keep them organized. The file geodatabase model was chosen not only to house the existing geospatial data, but also to be compatible with the client's existing technology.

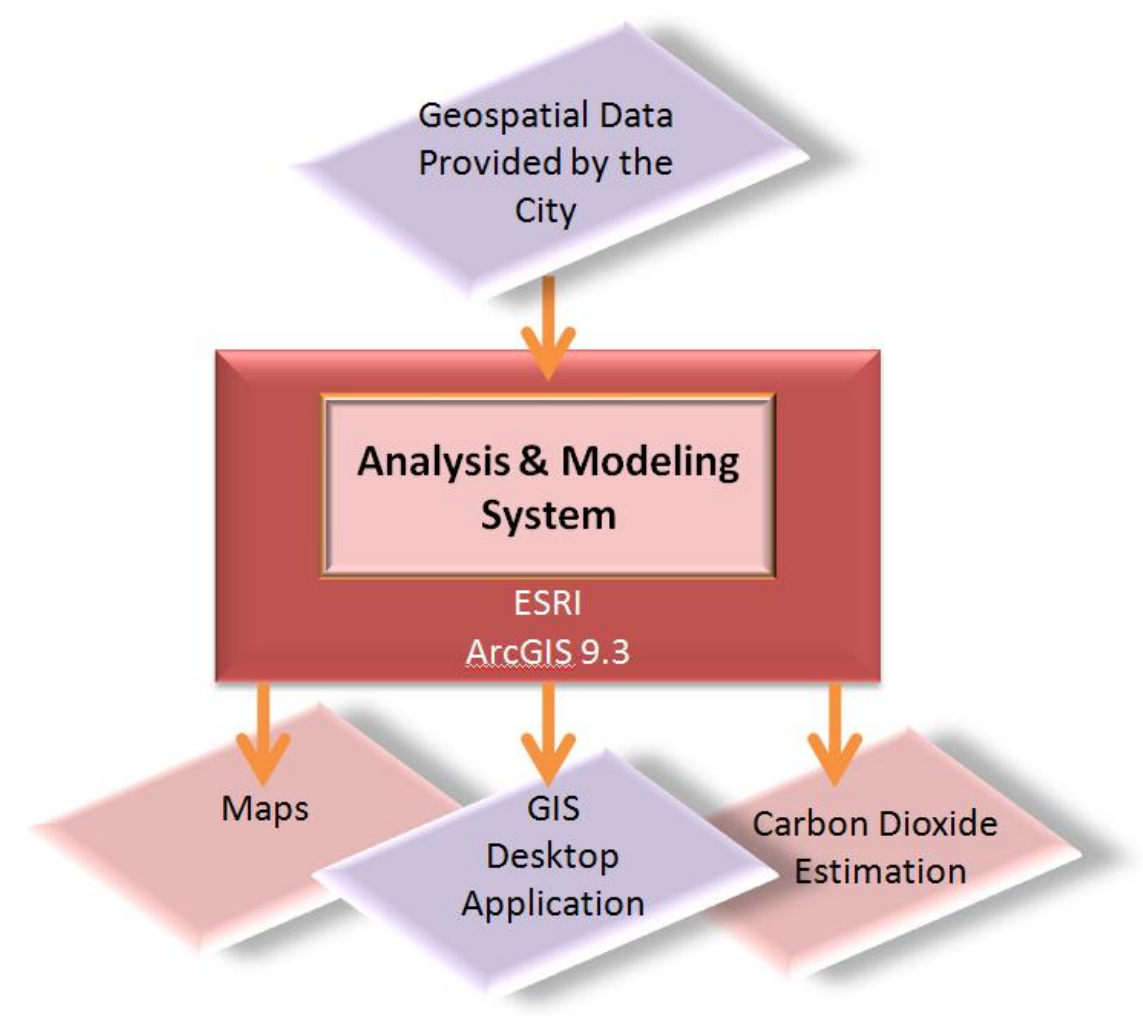

Figure 3-1: Schematic of system design 
The second component of the system is the $\mathrm{CO}_{2}$-Model, which was designed to automate the carbon emission calculation using ESRI's ModelBuilder extension available with ArcGIS (9.3) software. ArcGIS was chosen as a platform due to its single user capability to support a desktop application for data compilation, query, spatial analysis, image visualization and exploitation, modeling, and data management.

In addition to the existing tools available from ArcToolbox, a custom tool was developed using Python scripting for compiling multiple step processes, such as adding multiple fields to the attribute table in a feature class (Appendix A). A detailed explanation of the model implementation can be found in Chapter 5. Python scripting was the desired programming language because it requires more basic programming skills than Visual Basic and is free to use because of its open source license (Python Software Foundation, 2009).

A desktop application that houses the model and supporting data files was provided to the client, along with the maps and carbon emissions estimation results. With the output, the client would be able to examine the distribution of the carbon emissions of different types of buildings and estimate the total carbon emissions of the entire city for commercial and residential sectors. Along with the model output, the documentation of this GIS desktop application was also delivered to the client.

In general, any computer system consisting of ESRI ArcGIS 9 at the ArcInfo license level and PythonWin 2.5 should be able to successfully run the $\mathrm{CO}_{2}$-Model. PythonWin software can be downloaded from Python Software Foundation website free of cost. A copy is also provided with the ESRI installation disk.

\subsection{Project Plan}

The primary objective of this project was to develop a carbon emissions model for the City of Redlands to quantify and analyze carbon emissions distribution based on existing data. The model was designed to calculate indirect carbon emissions from small stationary emission sources, specifically the residential and commercial sectors. Other stationary sources, including power plants, refineries, manufacturing facilities, and other industries were not included in this project because they are required to follow industryspecific reporting guidelines and California Registry protocols.

The major tasks involved in completing this project were divided into four phases. All the project phases were executed as originally planned except for the first phase. The first phase involved researching existing methodologies and guidelines to identify feasible ways to estimate carbon emissions, and to indentify and collect data required for each approach. Approximately 35 percent of project time was invested in this phase due to the limited data information. Two different approaches were identified to calculate end-use energy consumption from past research. The first approach was based on Heiple and Sailor's research (2008) to predict energy consumption using available simulation software, such as EQUEST, DOE2, or Energy Plus, and a second approach based on the California Registry protocol and EIA's method. The second approach provided simple methodologies to estimate carbon dioxide emissions from an end-use energy consumptions perspective.

The plan to use the preexisting software to estimate energy consumption for buildings was changed because the existing geospatial data provided by the city did not have enough building characteristics information to support the simulation model to 
predict energy consumption of the buildings. Instead, the second approach was followed to calculate carbon emissions. Details about calculation methodologies, data collection, scrubbing, and loading can be found in Chapter 4. The $\mathrm{CO}_{2}$-Model building process and analysis worked as planned and are explained in detail in Chapter 5 and 6.

The second phase of the project was system design, and included requirements analysis, system architecture design, and conceptual and logical data modeling. The third phase involved developing the physical database and implementing the $\mathrm{CO}_{2}$-Model in ArcGIS. Verification of the results was also conducted after calculating the energy consumption in the model by comparing the results to the total energy consumptions data provided by the utility companies. The fourth phase involved presenting the project and its results to the Climate Action Task Force and preparing documents and deliverables required to meet the client's request.

Scheduling and budgeting were also performed as part of the second phase. A project schedule was designed to identify the high level tasks, milestones, and duration. However, the actual project schedule diverged from the initial plan due to the extended time spent on requesting and acquiring data from the utility companies. Not knowing the format and resolution at which the utility company would provide the data made it difficult to build the model as proposed in the initial work plan. Therefore, the schedule had to be adjusted to accommodate the time lost, although the scope of the project and major tasks remained the same.

\subsection{Summary}

This chapter provided information about the problem statement, requirements analysis, system design, schedule, and budget as defined in the scope and initial project plan. The requirements analysis consisted of six non-functional and functional requirements. The system was designed to support the functional and nonfunctional requirements and the technology on which the model would be based. The last section identified the major tasks to be completed in different phases, milestones, deliverables, and documentation required for the completion of this project. Although scheduling had to be adjusted to accommodate the delays introduced during data collection, the deliverables and major tasks remained the same through the project. 


\section{Chapter 4 - Database Design}

The database design for the $\mathrm{CO}_{2}$-Model is explained in this chapter by using vector data models to represent the geographic features. The first section of this chapter provides a conceptual overview of the energy consumption sector at the city level. The second section of this chapter explains the logical and physical design by identifying the feature classes and their attributes important for building the $\mathrm{CO}_{2}$-Model in the simplest form. The purpose of building a geodatabase for the $\mathrm{CO}_{2}$-Model application was to simply organize and manage the data files associated with the application and was not intended to build any structured relationships between features. The third and fourth sections provide information about the data sources, collection methods, and scrubbing and loading procedures, respectively. The preprocessing steps and the missing data problems and solutions are included in Section 4.5. The chapter concludes with a summary of the whole database design process and the workflow.

\subsection{Conceptual Data Model}

Designing the conceptual model started by identifying the concepts or entities and the relationships critical for the $\mathrm{CO}_{2}$-Model application. Modeling carbon dioxide emissions may appear difficult and complex because there are many factors contributing to the carbon dioxide emissions, but the modeling can be simplified by dividing carbon emission sources into several categories, such as stationary and mobile, which can be further divided into sub-categories, and by modeling each category separately. A simplified conceptual model provided in Figure 4-1 illustrates the energy characteristics and system for the stationary sector in the City of Redlands.

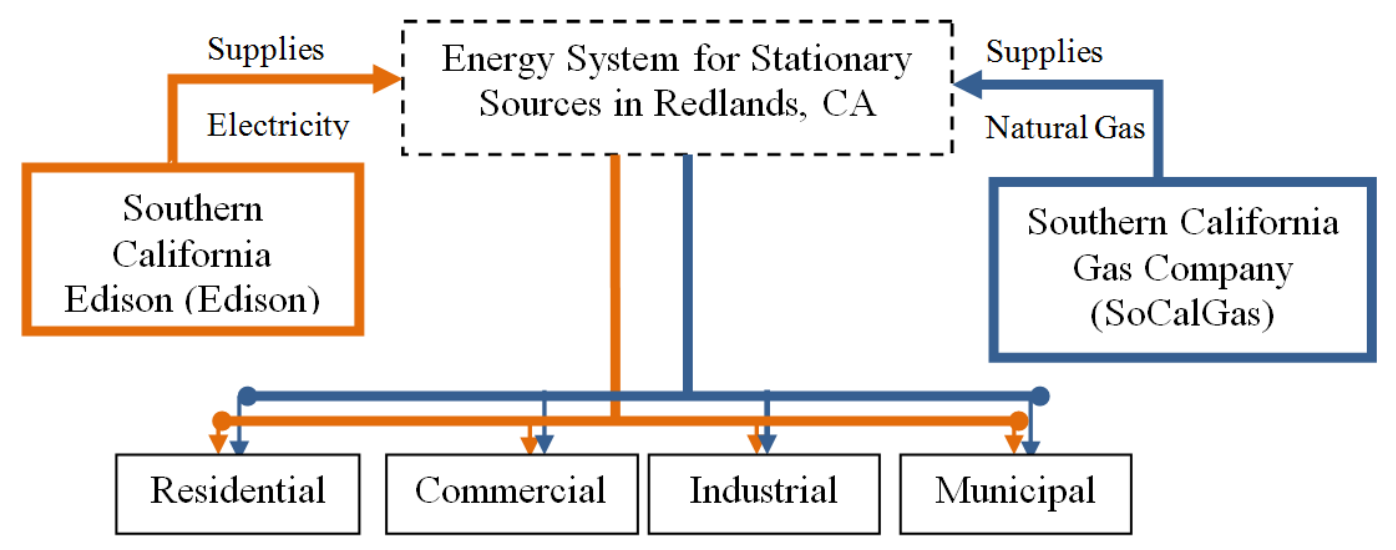

Figure 4-1: Conceptual model of Redlands electricity and gas system

Electricity and natural gas are supplied by two utility companies in Redlands. Southern California Edison provides the electricity, and SoCalGas provides the natural gas to meet the demands of the residential, commercial, industrial and municipal sectors. Almost all of the electricity and gas consumed by the different sectors in Redlands are actually generated outside the city's boundary and are brought to the city via transmission 
and distribution lines. Therefore, the amount of carbon emissions is largely determined by the end-user energy consumption, such as for cooling, heating, and cooking, rather than by the energy generation at the power plants. However, following the California General Reporting Protocol, the on-site (consumer) and off-site (producer) carbon dioxide emissions are counted at the location where the energy is consumed, rather than where the energy is produced.

The carbon dioxide emissions from electricity and gas usage in the residential and commercial sectors were the main focus of this project and were estimated at the parcel level. Carbon dioxide emissions from energy use in the industrial sector, such as power plants, refineries, and production and manufacturing facilities were outside the scope of this project because they are required to follow industry-specific reporting guidelines and the California Registry protocols. Carbon dioxide emissions from energy consumption in the municipal sector (for example, energy used for street lighting and construction) were also not included in this project.

\subsection{Logical Data Model}

The logical data model provided details about the important feature classes and their attributes linked to the analysis of carbon emissions. The logical data model helped identify the feature classes and their attributes needed for building the $\mathrm{CO}_{2}$-Model. A feature class is the most basic component of a geodatabase and it contains features of the same geometric type, such as point, line and polygon. The purpose of building a geodatabase was simply for data management and organization.

Since the model was implemented with ArcGIS software, the file geodatabase model was chosen for the logical design. The file geodatabase is an object-relational database, which is used for its capabilities to store spatial relationships, add behavior, and improve data integrity and management. It is recommended for storing file-based feature classes and managing various types of GIS feature classes. Two file geodatabases, $\mathrm{CO}_{2^{-}}$ Model1.gdb and $\mathrm{CO}_{2}$-Workspace.gdb, were created to manage and organize the feature classes needed and produced while implementing the $\mathrm{CO}_{2}$-Model application. Figure 4-2 shows the schematics of the workspace and the two geodatabases created to store and manage the files related to this project. The $\mathrm{CO}_{2} \_$Model1.gdb was set as the main workspace, where the client's feature class and the final feature class generated by the $\mathrm{CO}_{2}$-Model application were stored: The $\mathrm{CO}_{2} \_$Workspace.gdb was set as the scratch workspace, where all the intermediate feature classes created while running the model are saved. 


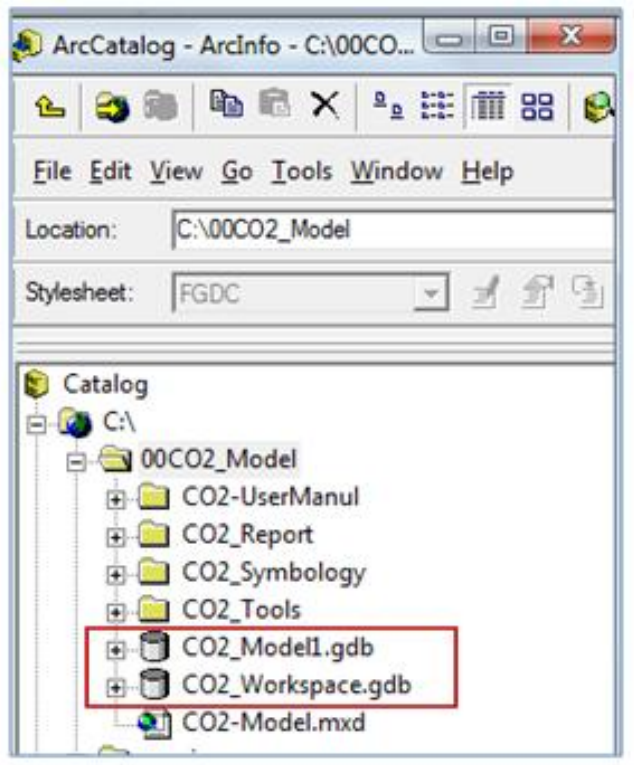

Figure 4-2: Schematic of workspace and geodatabase

Although the energy flow shown in Figure 4-1 is a top-down approach, the calculation of carbon dioxide emissions was based upon the bottom-up approach. Ideally, the carbon emissions from residential and commercial sectors are best calculated using the direct electricity and gas consumption data, such as billing data for individual buildings or parcels. Unfortunately, such information was not available. Thus, the amount of energy usage was estimated based on the building category and floor size. Since most of the attributes of buildings needed to determine the energy consumption were available at the parcel level, the decision to use the parcels feature class was made. The parcels feature class is the single required data file for estimating energy consumption and carbon emissions at the parcels level. The parcels feature class was divided into three new feature class according to the land use - commercial, single family, and multifamily residential - using the preprocessing models. The general selection criteria for differentiating the records into commercial, single family, and multifamily are provided in Table 2. The detailed expressions used in the preprocessing model to differentiate the parcels into the commercial and residential (single and multifamily) were based on the USECODE and LANDUSE fields and are provided in Appendix B. 
Table 2. Feature classes and their attributes important for energy calculation

\begin{tabular}{|l|l|}
\hline Categories & Description \\
\hline Commercial & $\begin{array}{l}\text { Cemeteries, Commercial Storage, Communication Facilities, } \\
\text { Elementary Schools, Hotels \& Motels, Junior High Schools, } \\
\text { Non-Attended Public Parking, Open Storage, Police \& Sheriff } \\
\text { Stations, Pre-Schools/Day Care Centers, Religious Facilities, } \\
\text { Retail Centers, Senior High Schools, and Special Care Facilities, } \\
\text { Colleges \& Universities, Fire Stations, Government Offices, } \\
\text { Low-Med Rise Major Office, Major Medical Health Care, } \\
\text { Mixed Commercial \& Industrial, Modern Strip Development, } \\
\text { Older Strip Development, Packing Houses \& Grain Elevators, } \\
\text { Regional Shopping Center, and Wholesaling \& Warehousing. } \\
\text { Single family (SF) } \\
\text { Multifamily (MF) } \\
\text { Attached single family residence(SFR), Duplexes \& Triplexes, } \\
\\
\text { Low-Rise Apartments \& Condos, Med-Rise Apartments \& } \\
\text { Condos, and Mixed Residential, Multi-family apartments }\end{array}$ \\
\hline
\end{tabular}

All the data used and produced were in feature class format. The feature classes saved in the geodatabase were all stand alone and were not grouped into a feature dataset, although they shared the same coordinate system and geographic extent.

The input and output feature classes related to the $\mathrm{CO}_{2}$-Model application were imported to ArcGIS Diagrammer simply to display the schema of the feature classes used in the toolset. The ArcGIS Diagrammer is also an ESRI product developed to create, edit, or analyze geodatabase schema (Environmental Systems Research Institute, 2009). Figure 4-3 provides the schema of the input tables: All_Commercial, All_MFRes, and All_SFRes derived from the parcel feature classes used to estimate the carbon emissions from commercial, multi-family, and single-family structures respectively. 

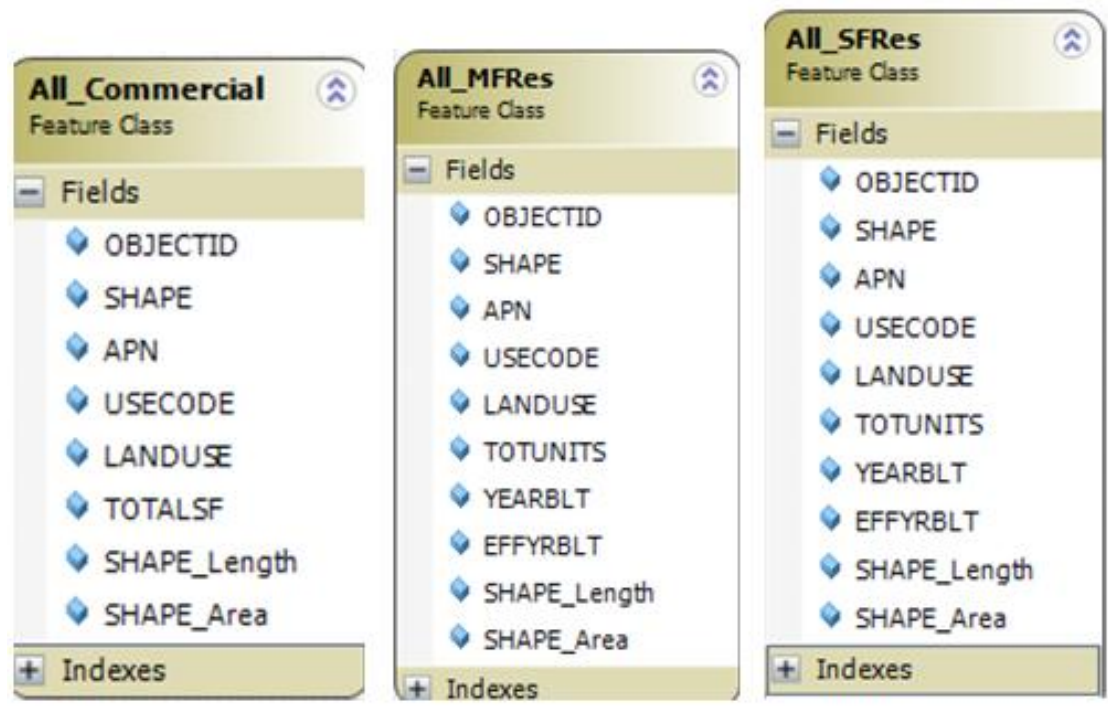

\section{Figure 4-3: Schema of input table required for the $\mathrm{CO}_{2}$-Model application}

The assessor's parcel number (APN) attribute is optional for all three input feature classes. It exists in the tables for record identification purposes only. Use code (USECODE) and land use (LANDUSE) are two important attributes for selecting and dividing the residential and commercial parcels into different land use types. The total square feet (TOTALSF) is important for calculating carbon dioxide emissions for commercial structures. The total number of units (TOTUNITS) and year when buildings were built (YEARBLT) are used for calculating carbon dioxide emissions for residential structures. The effective year built (EFFYRBLT) attribute is used as an alternative when the year when buildings were built is missing for some parcels.

In addition to the attributes that came with the original parcel data, six new attributes were added automatically to the input parcels feature class and populated by running the $\mathrm{CO}_{2}$-Model applications: Electric_kwh, Gas_therms, CO2lb_Elect, CO2lb_Gas, TotalCO2_lb, and MetricTon_CO2. The attributes are created to hold values calculated by the models to estimate electricity and natural gas consumptions, carbon dioxide emissions in pounds from the estimated electricity and natural gas consumptions, and the sum of the carbon dioxide emissions in both pounds and metric tons. The schema of the output feature class, including the data type and attributes, are provided in Figure 4-4. The design of the $\mathrm{CO}_{2}$-Model application from which the output feature classes shown in Figure 4-4 were generated is discussed in Chapter 5. 


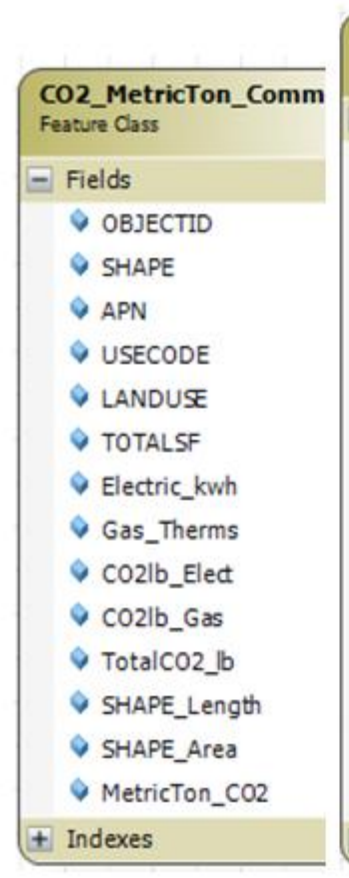

\begin{tabular}{|c|c|}
\hline \multicolumn{2}{|c|}{$\begin{array}{l}\text { CO2_MetricTon_SCE } \\
\text { Feature Class }\end{array}$} \\
\hline \multicolumn{2}{|c|}{ - Fields } \\
\hline & $\checkmark$ OBJECTID \\
\hline & $\checkmark$ SHAPE \\
\hline & $\checkmark$ APN \\
\hline & $\checkmark$ USECODE \\
\hline & $\checkmark$ LANDUSE \\
\hline & $\checkmark$ TOTUNITS \\
\hline & $\checkmark$ YEARBLT \\
\hline & EFFYRBLT \\
\hline & Electric_kwh \\
\hline & Gas_Therms \\
\hline & CO2lb_Elect \\
\hline & $\checkmark$ CO2lb_Gas \\
\hline & TotalCO2_b \\
\hline & $\checkmark$ SHAPE_Length \\
\hline & $\checkmark$ SHAPE_Area \\
\hline & MetricTon_CO2 \\
\hline+ & Indexes \\
\hline
\end{tabular}

\begin{tabular}{|c|}
\hline $\begin{array}{l}\text { CO2_MetricTon_Zone10 } \\
\text { Feature Class }\end{array}$ \\
\hline - Fields \\
\hline$\checkmark$ OBJECTID \\
\hline$\checkmark$ SHAPE \\
\hline$\checkmark$ APN \\
\hline$\checkmark$ USECODE \\
\hline$\checkmark$ LANDUSE \\
\hline$\checkmark$ TOTUNITS \\
\hline$\checkmark$ TOTALSF \\
\hline$\diamond$ YEARBLT \\
\hline EFFYRBLT \\
\hline$\checkmark$ Globald \\
\hline Electric_kwh \\
\hline Gas_Therms \\
\hline$\checkmark$ CO2lb_Elect \\
\hline$\checkmark \mathrm{CO} 2 \mathrm{lb}$ _Gas \\
\hline TotalCO2_lb \\
\hline$\checkmark$ SHAPE_Length \\
\hline$\checkmark$ SHAPE_Area \\
\hline Metricton_CO2 \\
\hline
\end{tabular}

Figure 4-4: Schema of output table generated by the $\mathrm{CO}_{2}$-Model application

\subsection{Data Sources and Collection}

The City of Redlands, SoCalGas, and SCE were the three primary data sources for this project. The city's GIS department provided the parcel and city boundary data in a file geodatabase format compatible with ArcGIS 9.3. Information about buildings required for the carbon dioxide emissions analysis, such as land use type, number of units, total square feet of floor area (square footage), and the year when the buildings were built are the attributes associated with the parcel feature class. The city also provided another GIScompatible database containing land use information about San Bernardino County. This feature class can also be downloaded from the Southern California Association of Governments (SCAG) website (http://www.scag.ca.gov/planning.htm). Compared to the city parcel data, the SCAG land use data was less accurate. The city's parcel feature class was based on the information collected by the county tax assessor's office and had more detailed information about land use and property than the SCAG land use data, which was collected and updated using 2005 digital aerial imagery. For example, a feature may be characterized as multifamily land use in the SCAG database if the parcel falls in the multifamily zoned area, but in reality it may be a school. Since SCAG uses aerial imagery, it may not capture the information as accurately as the city parcel database.

Unlike obtaining parcel and land use feature classes directly from the city, collecting energy consumption data from the utility companies was much more difficult. Due to confidentially issues, acquiring energy usage data for individual buildings was not possible. The data were initially requested at the census block group aggregation level. However, due to the $15 / 15$ rule the electric company was not able to provide the data at 
such a fine resolution. The details regarding the 15/15 rule are also provided in Appendix C.

The most challenging and time consuming part of this project was finding common ground to acquire the energy consumption data that would satisfy the utility company's requirements and the project needs. After several emails and phone calls, both utility companies could only provide the total amount of energy consumption across different categories of buildings (as mentioned earlier). Therefore, the aggregated energy consumption data provided by the utility companies were mainly used to verify the calculated energy consumption.

SCE provided the four categories of aggregated annual electricity consumption data in the unit of kilowatt hours (KWhs) for the City of Redlands, including agricultural and open space, residential, commercial, and others. The aggregation conducted by SCE was based on the SCAG land use data, which are not as accurate as the city parcel data. A request was made to SCE to use the land use type or usecode from the cities parcel feature class for the electricity consumption. However, SCE agreed to only use the SCAG feature class for aggregating the electricity consumption data. Therefore, the SCAG feature class provided by the client was provided to SCE. Further discussion of the land use type based on the SCAG feature class that was included in each category can be found in Appendix C.

SoCalGas Company provided aggregated residential and commercial gas consumption data at the zip code level in a Microsoft Excel format. The commercial data were also aggregated according to North American Industrial Classification System (NAICS) code. The electric and gas consumption data provided by the utility company were only for the year 2008. Therefore, this project only estimated the carbon emissions for the year.

Another very important data input for the model was estimating energy use intensity across buildings of different categories, because the detailed individual building level data were not available. The energy consumption per household and building type was extracted from the results of Statewide Residential Appliance Saturation Study report of 2004 and 2006. The energy consumption per square foot data for different commercial building type were extracted from the results of the California Commercial End-Use Survey (California Energy Commission, 2006). Both the studies were conducted by the California Energy Commission.

\subsection{Data Scrubbing and Loading}

This section is divided into two subsections: preprocessing of parcel data, and missing data problems, and solutions. The last section of this chapter provides a brief summary of this chapter and introduces the following chapter.

\subsubsection{Preprocessing Parcels Data}

The City of Redlands planning boundary encompasses 52 square miles and includes parcels that are unincorporated or are outside the territory of the city limits (City of Redlands, 2006). The city provides services to these unincorporated planning areas within and outside the city boundaries. The unincorporated area outside the city boundary, also known as the Sphere of Influence (or sphere), is not included in the $\mathrm{CO}_{2-}$ 
Model. The unincorporated area northwest of the city center is popularly known as the 'donut hole'. The client wished to include the donut hole in the $\mathrm{CO}_{2}$-Model and all analysis (Figure 4-5). The information about the incorporated and unincorporated areas within and outside the city boundary was located in the parcel feature class provided by the client. The parcels feature class consisted of 154 attributes and 49,846 records, which included records of parcels within the Redlands city boundary as well as surrounding cities (Figure 4-5).

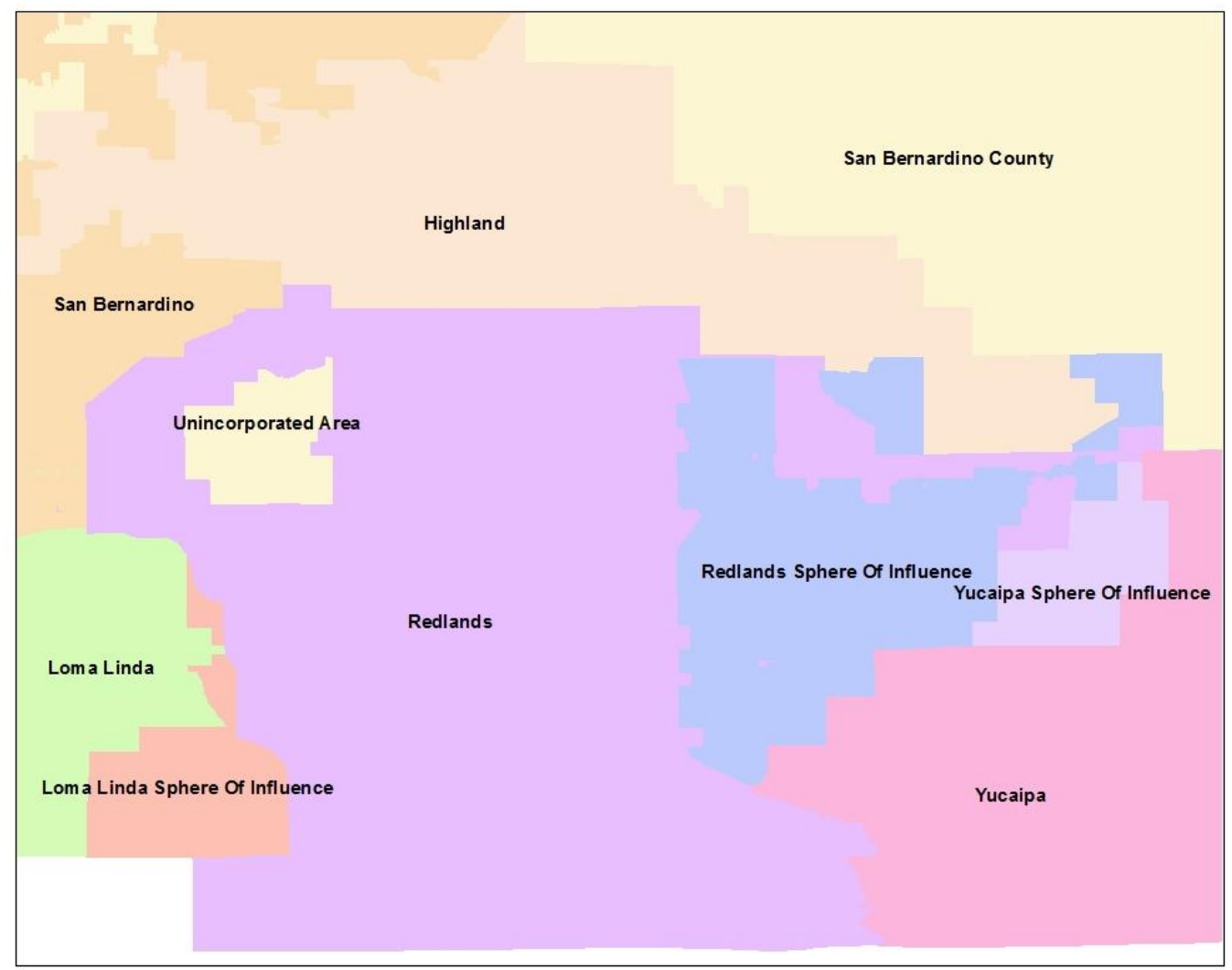

Figure 4-5: Redlands city boundary and surrounding cities

A series of preprocessing steps were developed and automated using ModelBuilder. The most common tools used in the preprocessing models were select, clip, append, erase, and delete fields. Preprocessing of the data helped reduce the file size and made the system run faster and more effectively. There were three preprocessing models developed to get the data ready for the $\mathrm{CO}_{2}$-Model. The first automated model (A1P_Parcel) shown in Figure 4-6 selects all the incorporated and unincorporated parcels within the Redlands city limits from the original city parcel feature class. 


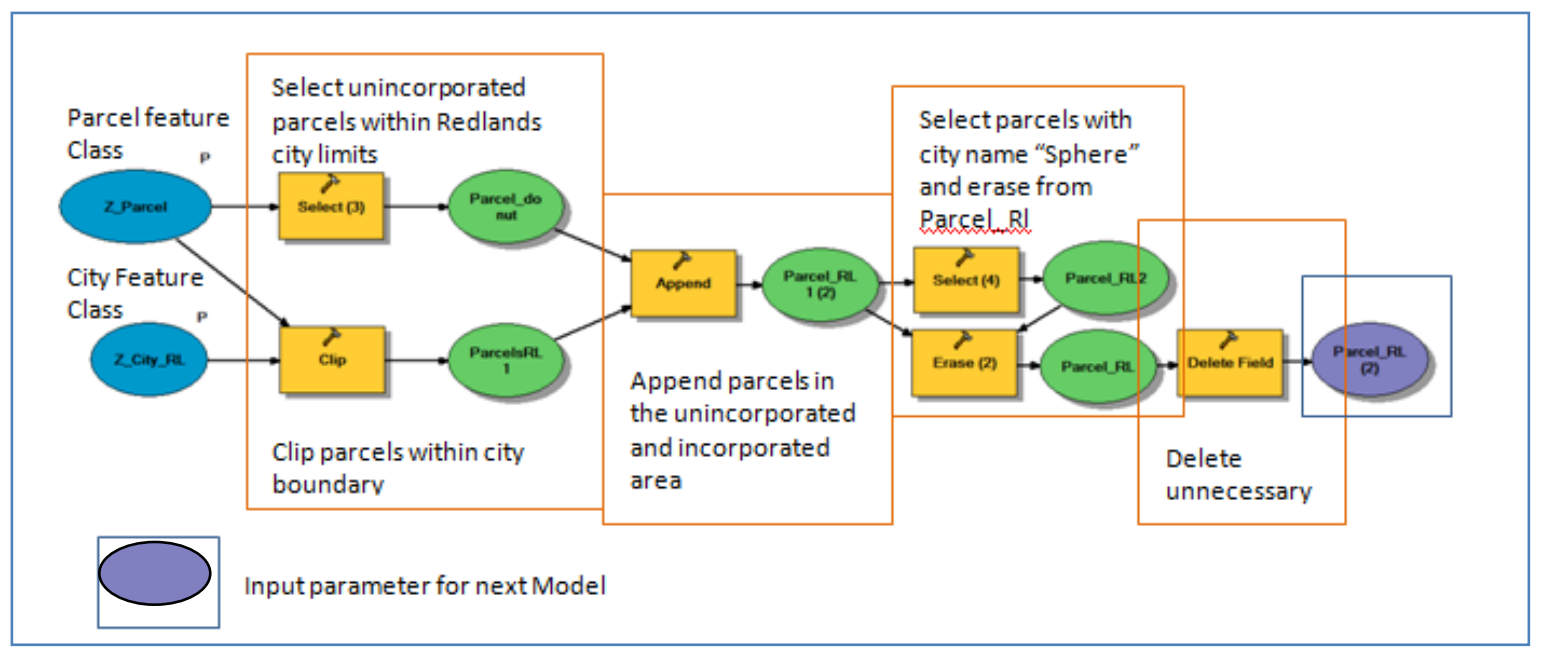

Figure 4-6: Workflow automation built to preprocess parcels feature class

The first step in the preprocessing model was to clip the parcel feature class using the city limit feature class. This retains only the parcels that are within the actual city limits of Redlands, thus excluding the donut hole. Therefore, the second step was to use the select tool to select the unincorporated parcels within the donut hole. In the third step, the two feature classes were appended into a new Redlands parcel feature class (Parcel_RL) to represent all the parcels within the city limits and the donut hole. Since some parcels in the sphere of influence were still included, these records were erased from the Parcel_RL feature class by selecting records with city name equal to sphere. The Parcel_RL feature class was then saved in the scratch workspace geodatabase unit $\left(\mathrm{CO}_{2}\right.$ Workspace.gdb) where all the other intermediate files created were saved. After deleting the unnecessary parcels from Parcel_RL, the attributes considered unnecessary for carbon dioxide estimation were also deleted using delete field toolset. The original parcels feature class provided by the client contained 154 attributes and 49,846 features, which were eventually narrowed down to 15 attributes and 22,629 features by the first preprocessing model (Figure 4-7). This model can be used repeatedly with the parcels data when it is updated. 


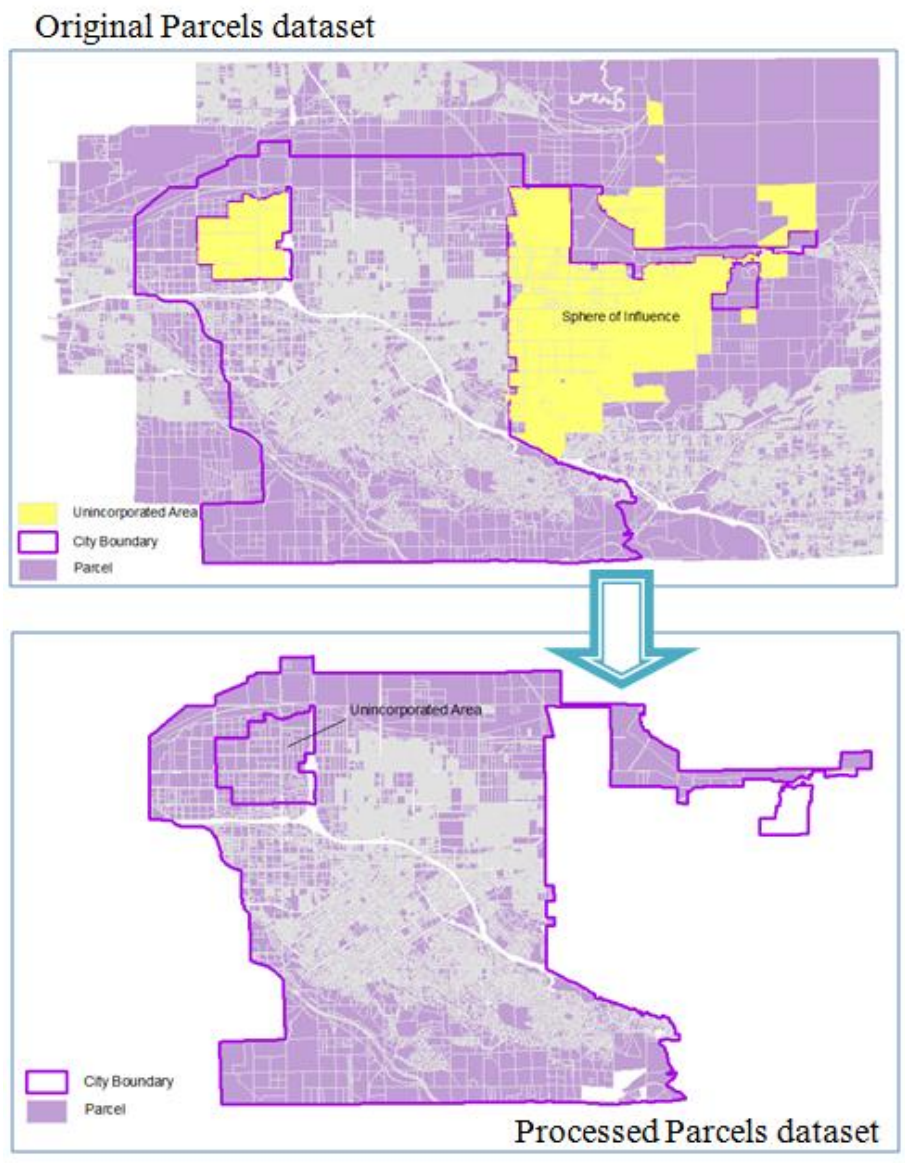

\section{Figure 4-7: Original and processed parcel feature class}

The second preprocessing model, A2P_LandUse, uses the output, Parcel_RL, from the first model, A1P_Parcel, as an input model parameter (Figure 4-8). The second model selects and aggregates parcels based on land use type into different feature classes. 


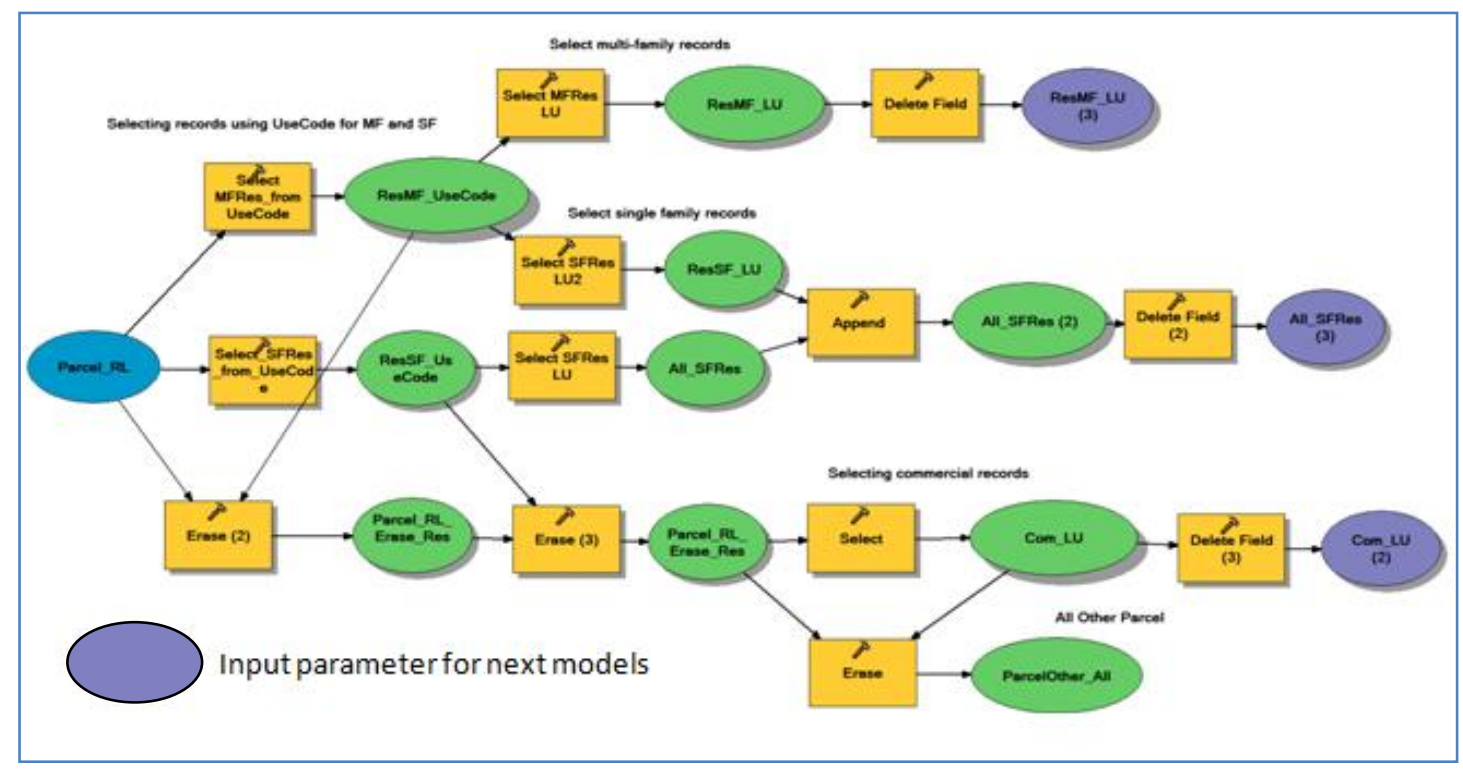

Figure 4-8: Workflow automation to group data into different land use type

The first selection in the model is based on the USECODE attribute and the second is based on LANDUSE attribute. The USECODE attribute provided a more generalized land use code for the parcel, and helped divide the parcels into single family and multifamily. Once the parcels were separated using the USECODE, the land use attribute was used to aggregate the different types of buildings on parcels. The original parcel feature class contained a field with web links, which connected to the San Bernardino County Assessor's property information website (http://nppublic.co.sanbernardino.ca.us/newpims/). The web links were used to verify the use code and land use attribute category in the parcels feature class. The decision to use both the USECODE and LANDUSE attribute was made to improve and ease the selection procedure for differentiating the parcels. The final categories produced from the model are single family residential (All_SFRes), multifamily residential (ResMF_LU), and commercial (Com_LU), which are automatically saved in the workspace geodatabase $\left(\mathrm{CO}_{2} \_\right.$WorkSpace.gdb). The remaining parcels not categorized under the above mentioned three categories were not used in the $\mathrm{CO}_{2}$-Model but were selected and saved as ParcelOther_All in the workspace geodatabase.

The output feature class for single family residential parcels' (All_SFRes) was used directly in the $\mathrm{CO}_{2}$-Model to calculate carbon dioxide emissions. The output feature classes for multifamily residential parcels (ResMF_LU) and commercial parcels (Com_LU) goes through other preprocessing model B1_MF and B2_Com, respectively, which deals with missing data problem, and is explained below in Section 4.4.2.

\subsubsection{Missing Data Problem}

Missing data was an issue during the data preparation for the model application. There were 419 records out of 1160 records in the Com_LU feature class that were missing building floor space values. The square foot data of building floor space was required to calculate the energy consumptions and carbon dioxide emissions for commercial 
buildings. Two approaches were identified to solve the missing floor area problem for the buildings on commercial parcels. The first approach was to estimate the missing floor areas by using the average floor space of the commercial buildings of the same type. However, since a lot of data for similar structures were missing-for example most of the square feet data for government owned buildings, schools and universities, and fire stations - it was not ideal to use the average to estimate the missing values. The second approach was based on the assumption that most of the commercial buildings in Redlands consisted of a single floor; the missing floor area problem for commercial buildings could be solved by substituting the floor area with the building footprint. Therefore, the B2_Com model substitutes the missing floor area values in the commercial parcel feature class (Com_LU) by the area of the building footprint from the buildings feature class (Z_Building) by performing a spatial join between the two feature classes (Figure 4-9).

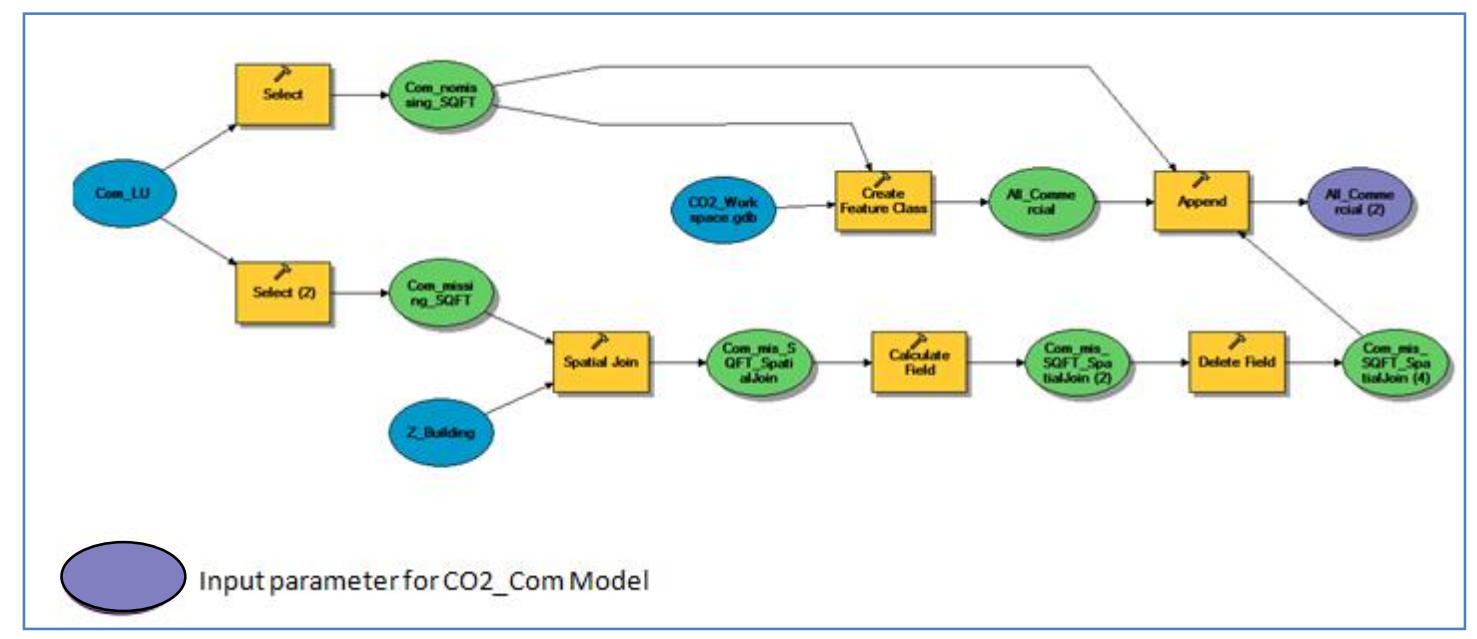

Figure 4-9: Workflow automation to update missing floor area

If the buildings consisted of more than one floor, then the resulting energy consumptions and carbon dioxide emissions from these buildings were underestimated by the model. Out of 419 records with missing floor area, 188 records had no building structure or footprint on them. Therefore, the 188 records were assumed to be vacant. The final output of the B2_Com model, All_Commercial, gets stored in the workspace geodatabase to be used in the carbon dioxide emissions calculation for commercial buildings, which is explained in detail in Chapter 5 .

Similarly, for residential feature classes, a total of 16,395 and 2,272 parcel records were identified as single family and multifamily residential, respectively. Out of 2,272 multifamily residential records 22 records had missing number of units (Table 3 ). 
Table 3. Parcel feature class showing different land use categories

\begin{tabular}{|llc|}
\hline Feature class & Land use type & Number of records \\
\hline All_SFRes & Single Family & 16,395 \\
ResMF_LU & Duplex or 2 & 324 \\
ResMF_LU & Triplex or 3 & 84 \\
ResMF_LU & Quadruplex or 4 & 304 \\
ResMF_LU & Res, Pud, or Condo & 1,410 \\
ResMF_LU & 5 - 14 Apartment & 87 \\
ResMF_LU & 15+ Apartment & 62 \\
ResMF_LU & Government Assisted Apartment & 1 \\
\hline
\end{tabular}

Upon visual analysis of several parcels and building structures using ArcMap and verifying with the city's GIS Supervisor, the Condos or Res, Pud (planned unit developments) were identified as attached single family residential units. Hence, the decision to replace the missing values of number of units with one was made.

The single family unit number was solved in the $\mathrm{CO}_{2}$-Model but the values for multifamily was solved by developing the B1_MF model (Figure 4-10). Running the model populates the number of units value for multifamily residential with low uncertainty and risk. Out of all the data for multifamily land use complexes, 22 complexes with 5 to 14 units and 4 complexes with 15 and more units were missing precise unit numbers. The 5 to 14 unit complexes with missing number of units were assumed to be 9.5 units per parcel. The missing data problem for the four 15 or more unit complexes was solved by calling the facilities and updating the parcels feature class with precise unit data. 


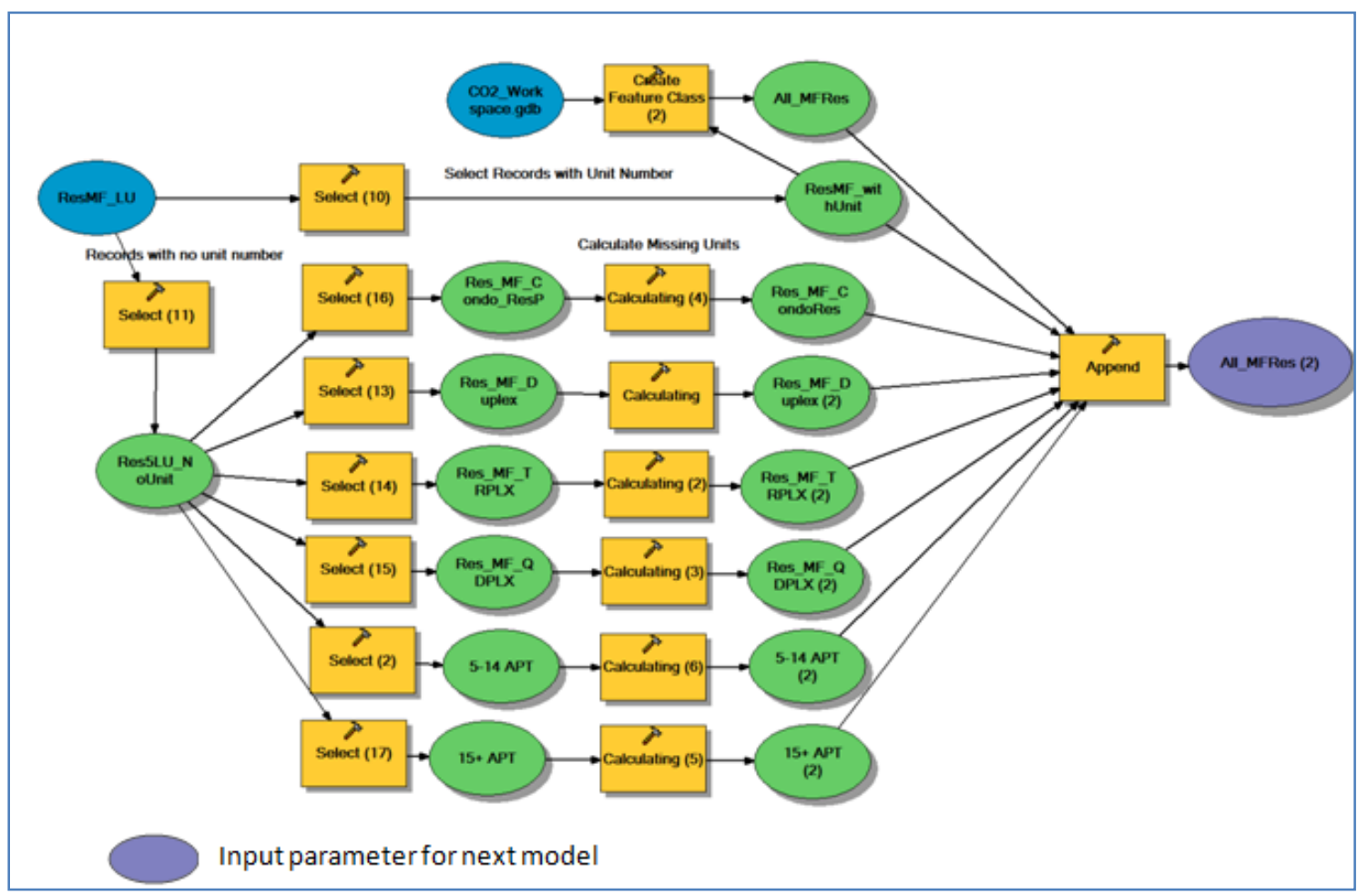

Figure 4-10: Workflow automation to update number of units

There are several potential sources of error in this dataset. Some of the land use codes may have been recorded incorrectly. Some of the parcels coded as single family may have detached units that are occupied with or without county approval. Some parcels indicated or assumed to be vacant may in fact now be occupied. While significant effort was expanded to interpret the data accurately and make reasonable assumptions, the model's accuracy could be improved by a record-by record verification/validation process. This data validation process was beyond the scope of this project.

Two other important attributes for residential sector carbon emissions estimation, EFFYRBLT or YEARBUILT (information on the year when buildings were built), were not fully populated. Although the missing data problems for these two attributes were unsolved, the records were still used to estimate carbon emissions and the details can be found in Chapter 5. The updated multifamily residential feature class, All_MFRes, was saved in the work space geodatabase to be used in the $\mathrm{CO}_{2}$-Model application.

\subsection{Summary}

The conceptual model provides a general understanding of carbon dioxide emissions from end-use energy consumption perspective at the city level by identifying the entities and relationship using a top-down approach. The logical data model was built to understand the classes and attributes that were important in building the $\mathrm{CO}_{2}$-Model using a bottom-up approach since the direct energy consumption data were not available. The two geodatabases provided a foundation for managing and organizing the feature classes required for estimating carbon dioxide emissions for the City of Redlands. In 
addition to the conceptual and logical data model, this chapter also provided information about data sources, data collection methods, and data scrubbing and loading. In order to make the data ready for the $\mathrm{CO}_{2}$-Model, three preprocessing models were also developed using ModelBuilder to make the preprocessing data consistent, replicable, and automated. The preprocessed feature classes were then loaded to the geodatabase for the $\mathrm{CO}_{2}$-Model implementation, which is explained in the following chapter. 



\section{Chapter 5 - Implementation}

This chapter explains the processes involved in building the $\mathrm{CO}_{2}$-Model application using ESRI ArcGIS ModelBuilder tools. The $\mathrm{CO}_{2}$-Model was developed to work with Redlands parcels data but can easily be modified to work with other cities parcel data.

The model's objective was to estimate carbon emissions from commercial and residential land use. These objectives were met by building three sub-models: the $\mathrm{CO}_{2}$-Com model for commercial parcels; the $\mathrm{CO}_{2}$-SCE model for residential parcels; and the $\mathrm{CO}_{2}-\mathrm{Z}$ one 10 model for residential parcels. The implementation processes for the $\mathrm{CO}_{2}$-Model is discussed in three sections: Project Workspace and Portability; Geoprocessing Submodels; and $\mathrm{CO}_{2}$-Model Application. The $\mathrm{CO}_{2}$-Model can be replicated by following the steps described in each section below. This chapter concludes with a summary of the important components of the $\mathrm{CO}_{2}$-Model.

\subsection{Project Workspace and Portability}

A new workspace was created as a project folder $(00 \mathrm{CO} 2)$ in the $\mathrm{C}: \backslash$ drive to hold all data, applications and documentation (Figure 5-1). Several sub folders were contained in the project folder. The three carbon emissions sub-models are housed under the CO2_Tools folder and the documentation is in the CO2_Report folder for easy access. The project folder also houses the two geodatabases, the $\mathrm{CO}_{2}-$ Model1.gdb and the $\mathrm{CO} 2$ _Workspace.gdb, for managing and organizing all the feature classes. The $\mathrm{CO}_{2-}$ Modell.gdb is the main unit that holds the data provided by the client (file names starting with the letter $\mathrm{Z}$ ), and the output feature classes (file names starting with CO2_MetricTon). The rest of the feature classes generated while running the model are stored in the scratch workspace, the CO2_Workspace.gdb. 


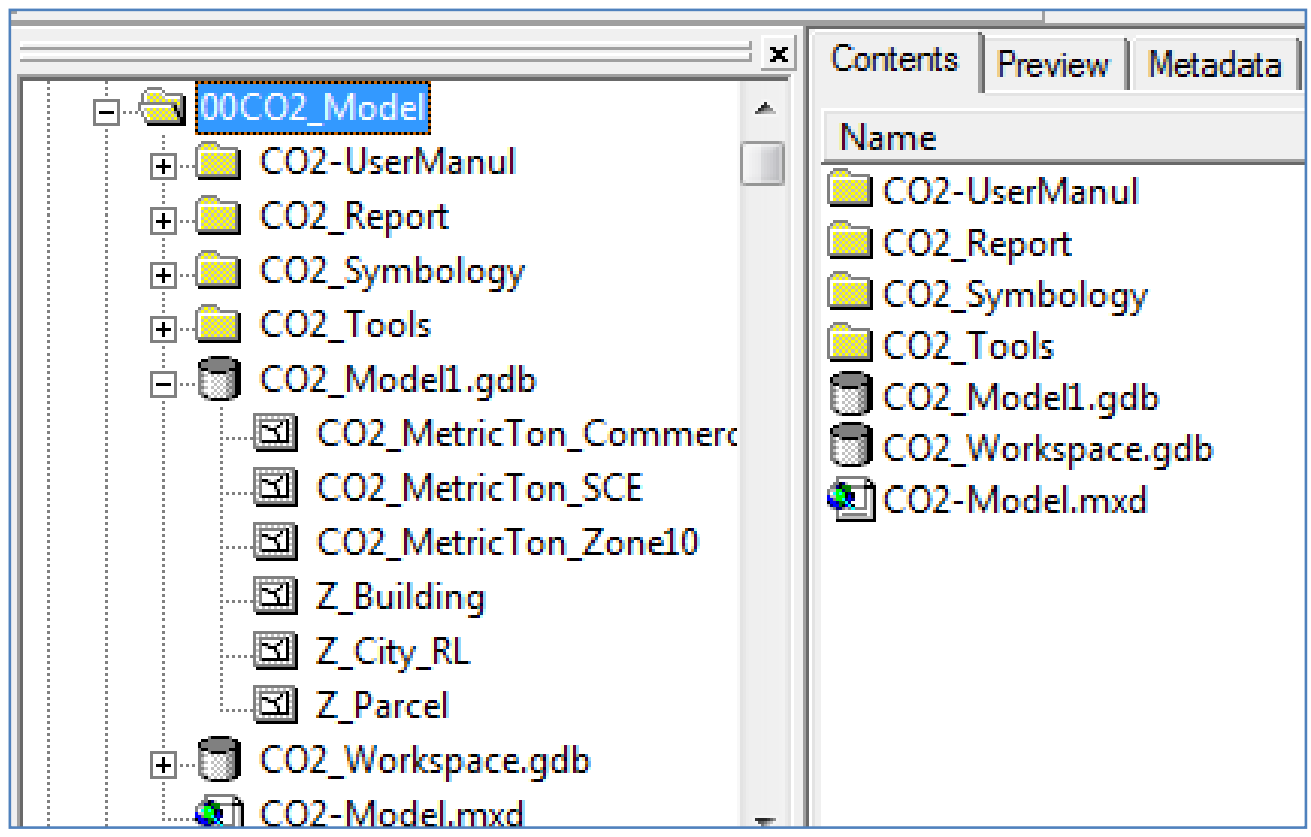

Figure 5-1: Schematic of the project workspace

The $\mathrm{CO}_{2}$-Model.mxd is an ArcMap document that contains all the toolsets and the sub-models. When users run the sub-models from the map document file (.mxd), the final feature classes are added and symbolized automatically. The symbols are saved under the CO2_Symbology folder in the project folder and can be imported using the properties window to display carbon emissions results in different classes.

The project workspace makes it easy to manage, organize, and transfer the $\mathrm{CO}_{2}$ Model application for sharing. For easy sharing of geoprocessing tools, data, and the ArcMap document (.mxd), ArcGIS gives an option to save the data as absolute or relative pathnames. The relative pathnames option allows sharing of the tools and data in different user environments. Therefore, all the tools, data, and scripts related to the $\mathrm{CO}_{2}$ Model were saved using the relative pathname option.

\subsection{Geoprocessing Tools}

A number of geoprocessing tools were used in the $\mathrm{CO}_{2}$-Model to automate the carbon emission estimation workflow in the ModelBuilder environment. There are two types of tools used: generic and custom tools. Generic tools refer to the ones available with ArcToolbox, including select, erase, append, create feature class, calculate field, and add field (Figure 5-2). Custom tools refer to the ones that must be programmed to perform special operations. The custom tool developed in this project (Add fields) was used in all three sub-models to add five new fields to the input feature class attribute table. The custom tool was developed using Python and the script was named S1_Addfields (Appendix A). 

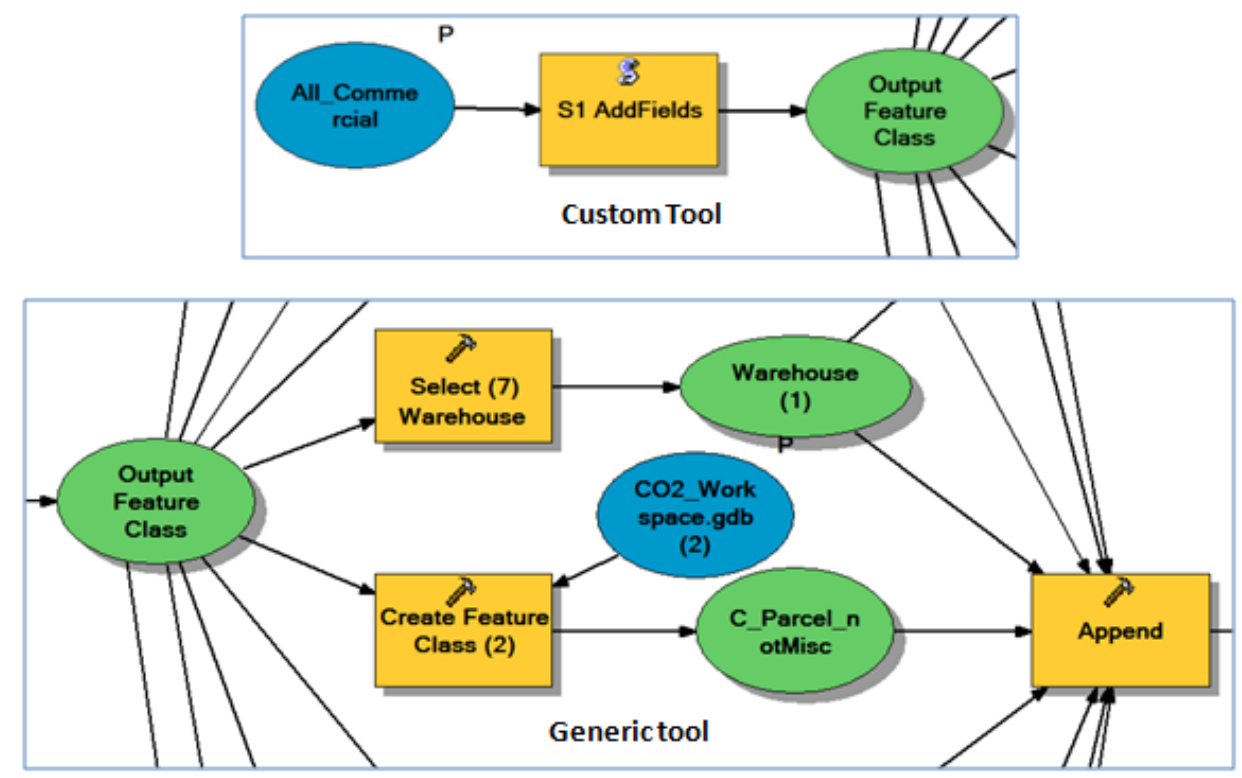

Figure 5-2: Schematic of custom and generic tools used in the sub-models

\section{$5.3 \quad \mathrm{CO}_{2}$-Model Application}

ArcGIS ModelBuilder was used to automate and develop the $\mathrm{CO}_{2}$-Model application to estimate the total carbon dioxide emissions from end-use energy consumptions. The model works for the commercial and residential sectors at the city parcel level. Specifically, three models were developed to estimate the carbon dioxide emissions from the commercial and residential sectors: $\mathrm{CO}_{2}$ Com; $\mathrm{CO}_{2}$ SCE; and $\mathrm{CO}_{2}$ Zone10. The $\mathrm{CO}_{2}$ Com estimates carbon dioxide emissions from the commercial sector and the other two models estimate carbon dioxide emissions from the residential sector. The ModelBuilder automation process and diagrams for the three models are provided in Appendix D.

To build the models, several steps were shared by all the sub-models. First, the custom tool (Addfield) was added to the model by dragging the Python script $S 1$ AddFields from the ArcToolbox to the model. This tool generates multiple fields, including Electric_kwh, Gas_Therms, CO2lb_Elect., CO2lb_Gas, and TotalCO2_lb (Figure 5-3). These attributes were created to hold values generated by the model. 


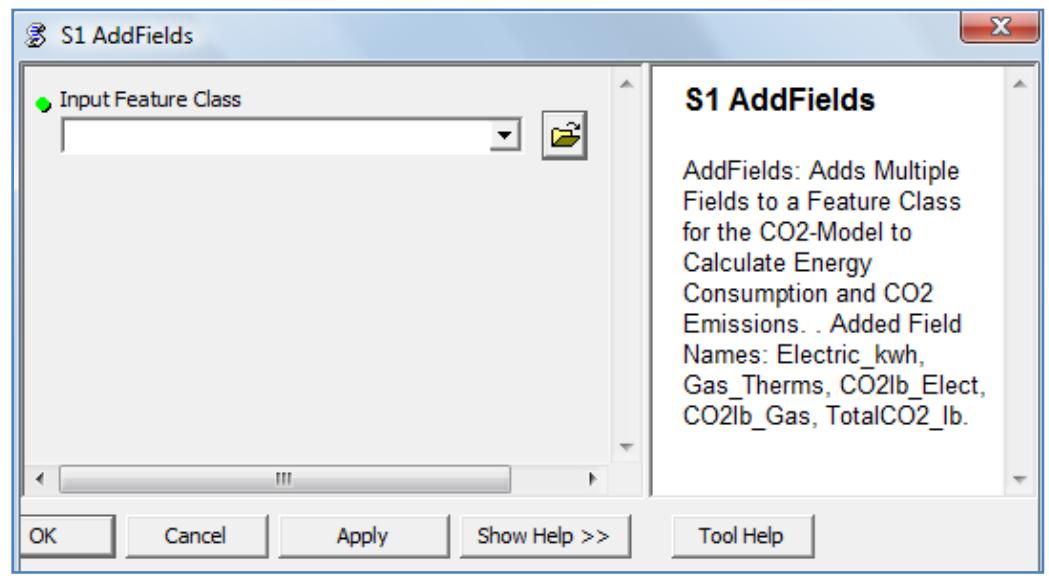

Figure 5-3: Custom tool generated to add multiple fields to $\mathrm{CO}_{2}$-Models

After adding multiple fields, the following key steps were implemented using different generic tools from the ArcToolbox.

1. Selecting and creating new feature classes of building types based on land use and use code. For example, it was required to classify all the commercial buildings into eleven categories, including Small office (less than 30,000 square feet of floor space), large office (greater than 30,000 square feet of floor space), restaurant, retail, food store, school, college, health, lodging, warehouse, and miscellaneous buildings.

2. Estimating electricity/gas consumption for facilities by using annual energy intensity or unit energy consumptions applicable for the building types based on CEC (California Energy Commission) survey and studies.

3. Determining the annual carbon emissions from the facility by using the following formula:

$\begin{aligned} & \text { Annual indirect } \\ & \begin{array}{c}\text { carbon dioxide } \\ \text { emissions }\end{array}\end{aligned}=\begin{gathered}\text { Annual electric/gas } \\ \text { consumption } \\ \text { (Estimated in step 2) }\end{gathered} \quad \mathrm{X} \quad \begin{gathered}\text { Carbon dioxide } \\ \text { emission factor }\end{gathered}$

4. Adding carbon dioxide emissions (in pounds) from electricity and gas consumption.

5. Converting the annual carbon dioxide emissions calculated in pounds to metric tons by dividing the annual emissions (in pounds calculated in step 5) by 2,204.62 lbs/metric ton.

More detailed discussion on the sub-models is provided in the following sections.

\subsubsection{Carbon Emissions Estimation Model for Commercial Sector}

The $\mathrm{CO}_{2}$ Com model estimates carbon dioxide emissions from the commercial sector. This model design was based on the California Climate Action Registry General Reporting Protocol (2009), following the recommendation for estimating indirect emissions for organizations unable to obtain energy use information from their utility 
companies. For a particular commercial building, the protocol suggests the square footage and average electricity intensity of comparable facilities be used to estimate the carbon emissions. Energy intensity is defined as energy consumption per unit square foot and these are directly extracted from the California Commercial End-Use Survey Report produced by CEC (California Energy Commission) in 2006 (Table 4).

Table 4. Annual electricity and gas intensity for SCE service area (CEC, 2006)

\begin{tabular}{|lcc|}
\hline Building Type & $\begin{array}{c}\text { Electricity } \\
\left(\mathrm{KWh} / \mathrm{ft}^{2}\right)\end{array}$ & $\begin{array}{c}\text { Natural Gas } \\
\left(\text { therms } / \mathrm{ft}^{2}\right)\end{array}$ \\
Small Office $\left(<30 \mathrm{kft}{ }^{2}\right)$ & 13.25 & 0.08 \\
Large Office $\left(>=30 \mathrm{kft}^{2}\right)$ & 17.91 & 0.13 \\
Restaurant & 46.19 & 2.49 \\
Retail & 15.36 & 0.02 \\
Food Store & 41.71 & 0.22 \\
School & 8.22 & 0.12 \\
College & 13.62 & 0.24 \\
Health & 20.3 & 0.68 \\
Lodging & 13.28 & 0.41 \\
Miscellaneous & 9.87 & 0.24 \\
All Warehouses & 5.71 & 0.03 \\
\hline
\end{tabular}

Based on this method, the parcel data for commercial land use was first selected and divided into the eleven categories shown in Table 4 above. This input feature class was the output feature class of the second preprocessing model (Section 4.4.1). Then the electricity and natural gas intensities were added in the $\mathrm{CO} 2$-Com model as model parameters and can be updated when necessary (Figure 5-4). 


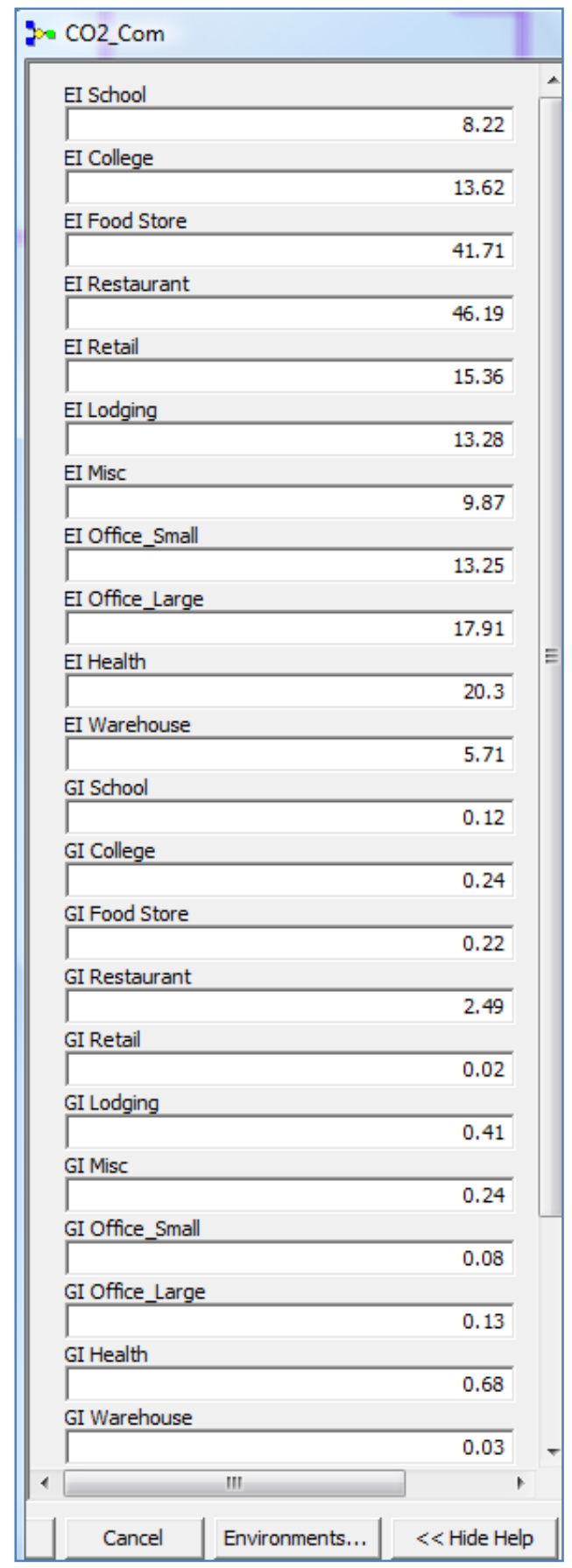

\section{Figure 5-4: Energy intensities added as variables in $\mathrm{CO}_{2}$ Com model}

The Calculate Field tool was then used to calculate the total electricity and gas consumption. The entire procedure in the CO2-Com model is summarized in Appendix E. 


\subsubsection{Carbon Emissions Estimation Model for Residential Sector}

Carbon dioxide emissions estimation for the residential sector was based on the results of the California Statewide Residential Appliance Saturation Study (California Energy Commission, 2004) and California Statewide Residential Appliance Saturation Study Update to Air Conditioning Unit Energy Consumption Estimates Using 2004 Billing Data (California Energy Commission, 2006). The carbon dioxide emissions estimations for the residential sector were calculated using annual UEC (Unit Energy Consumption) per household data provided by the CEC study.

As discussed in Chapter 2, CEC has published two sets of annual UEC values: one set includes annual UEC values based on the SCE (Southern California Edison) utility region survey, which covers $\mathrm{CEC}$ forecast climate zones 7, 8, 9, and 10; the other includes annual UEC values based on the CEC forecast climate zone 10 only. Thus, there are two sub-models designed to estimate the carbon dioxide emissions from the residential sector- $\mathrm{CO}_{2} \_\mathrm{SCE}$ and $\mathrm{CO}_{2}$ Zone 10 - as part of the $\mathrm{CO}_{2}$-Model application. The $\mathrm{CO}_{2} \_\mathrm{SCE}$ model uses the annual UEC values for the entire SCE region and is more generalized compared to the $\mathrm{CO}_{2}$ Zone10 model, which uses annual UEC values specifically for zone 10 .

Although $\mathrm{CO}_{2} \_\mathrm{SCE}$ and $\mathrm{CO}_{2} \_$Zone 10 models use different UEC values, the carbon dioxide emissions estimation methods are the same and are summarized in Appendix F. Both models multiply the UEC value of a particular type of residential building by the number of households in that parcel as the total energy consumptions for the buildings in that parcel.

Two feature classes_-All_SFRes and All_MFRes_-were added as input model parameters for both the models. The first step of the $\mathrm{CO}_{2} \mathrm{SCE}$ model includes selecting and creating new feature classes to group the different types of buildings based on residence type (single family vs. multifamily) and the building age (new vs. old). According to the California Statewide Residential Appliance Saturation Study, buildings built prior to 1997 are considered old and buildings built during or after 1997 are considered new (California Energy Commission, 2004). The electricity and natural gas annual UECs for SCE utility service area by residence age and type are shown in Table 5.

Table 5. Annual UEC values for SCE utility service areas by building age and type

\begin{tabular}{|lcccc|}
\hline & Energy Type & $\begin{array}{c}\text { New } \\
\text { Household } \\
\text { UEC (CEC, } \\
\text { 2006) }\end{array}$ & $\begin{array}{c}\text { Old } \\
\text { Household } \\
\text { UEC (CEC, } \\
\text { Utility }\end{array}$ & $\begin{array}{c}\text { Unknow) } \\
\text { age (CEC, } \\
\text { 2004) }\end{array}$ \\
\hline All SCE & Electricity & 8,106 & 6,385 & $6,473^{*}$ \\
SF SCE & Electricity & 8,998 & 7,515 & \\
MF SCE & Electricity & 4,695 & 4,336 & \\
All SoCalGas & Gas & 457 & 443 & $443^{*}$ \\
SF SoCalGas & Gas & 508 & 529 & \\
MF SoCalGas & Gas & 243 & 283 & \\
\hline
\end{tabular}

* Electricity and gas UECs for all households in SCE region 
The annual UEC values were added to the model in ModelBuilder as variables (Figure 5-5) and were defined as the model parameters. Once the input variables are defined as parameters, they can be easily updated by the users when new values are available.

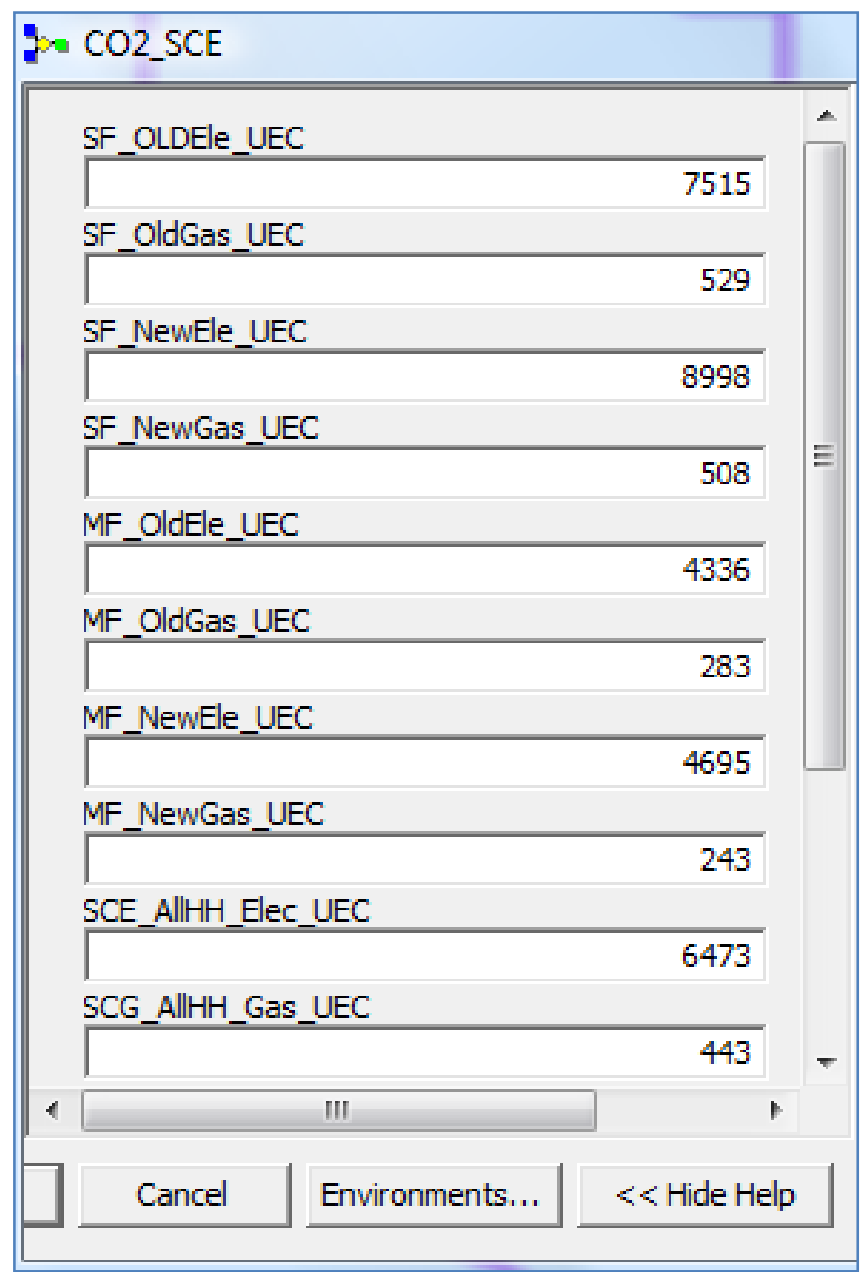

\section{Figure 5-5: UECs added as variables in $\mathrm{CO}_{2} \_\mathrm{SCE}$}

The single family and multifamily records with unknown age (year the building was built or effective) were categorized as unknown age groups and all household UEC values were used to calculate their total energy consumption in the $\mathrm{CO}_{2}$ SCE model.

For the $\mathrm{CO}_{2}$-Zone10 model, the first step was to create a new feature class from the two input feature classes to distinguish the residential buildings by the following four categories: single family homes, 2-4 unit apartments, 5+ apartments, and mobile homes (Table 6). 
Table 6. Electricity and natural gas UEC used in $\mathrm{CO}_{2} \_$Zone10 model

\begin{tabular}{|lcl|}
\hline Resident Type & $\begin{array}{c}\text { Electric } \\
\text { UEC }\end{array}$ & $\begin{array}{c}\text { Gas } \\
\text { UEC }\end{array}$ \\
\hline All Household & 7,978 & 528 \\
Single Family & 8,850 & not available \\
2-4 Unit Apt & 5516 & not available \\
5+ Unit Apt & 4950 & not available \\
Mobile Home & 5963 & not available \\
\hline
\end{tabular}

The annual UEC values shown in Table 6 were added to the $\mathrm{CO}_{2}$ Zone10 ModelBuilder as model parameters (Figure 5-6), where users can easily update them when new values are available.

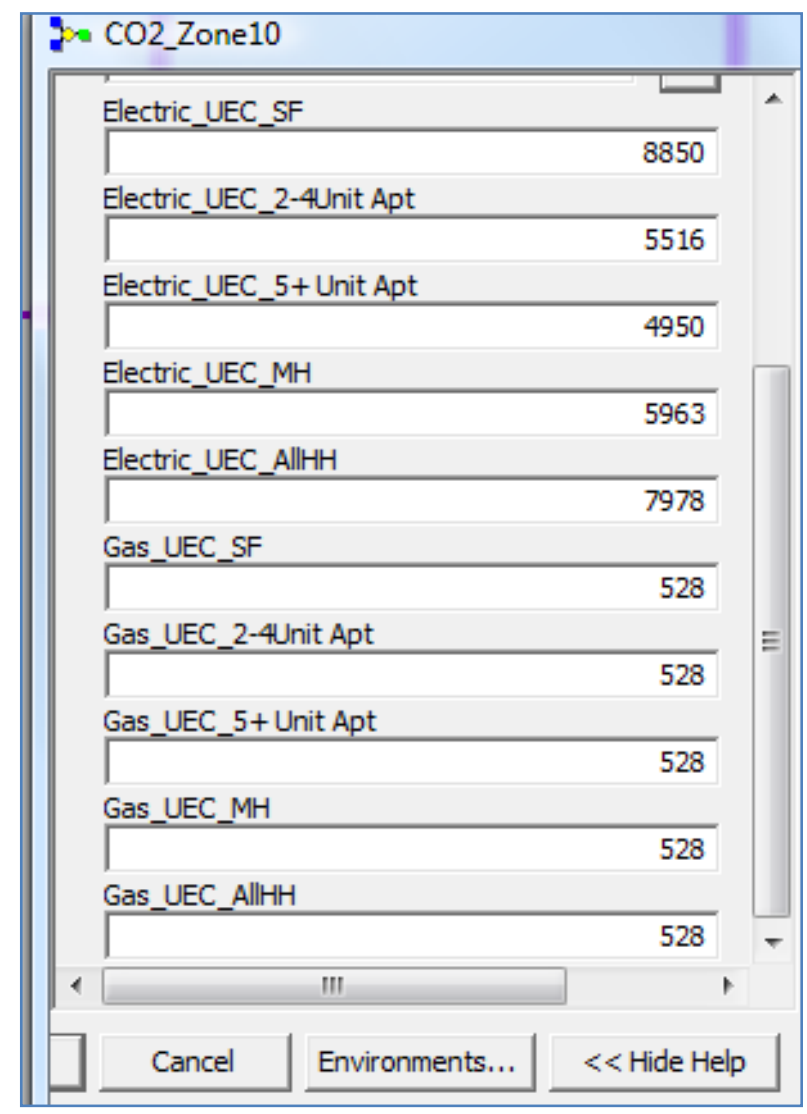

Figure 5-6: UECs added as variables in $\mathrm{CO}_{2} \_$Zone10 model

\subsubsection{Carbon Dioxide Emission Factors}

The carbon dioxide emissions calculations in the $\mathrm{CO}_{2}$-Models (step 3) converted annual kilowatt hours $(\mathrm{KWh})$ of electricity and therms of natural gas consumption to pounds of carbon dioxide emissions using carbon dioxide emissions factors. The factors used in the 
sub-models of the $\mathrm{CO}_{2}$-Model application were derived from the California Climate Action Registry General Reporting Protocol (2009) and are provided in Table 7.

Table 7. Carbon dioxide emissions factors for electricity and natural gas

\begin{tabular}{|lll|}
\hline & $\mathrm{CO}_{2}$ Emission Factor & Descriptions \\
\hline Electricity & $724.12(\mathrm{lb} / \mathrm{MWh})$ & eGRID Subregion: CAMX \\
Natural Gas & $53.06\left(\mathrm{~kg} \mathrm{CO}_{2} / \mathrm{MMBtu}\right)$ & Weighted U.S. average \\
\hline
\end{tabular}

The carbon dioxide emissions rate from the electricity consumptions were based on eGRID factors developed by the U.S. EPA (United States Environmental Protection Agency). The California Climate Action Registry General Reporting Protocol (2009) recommends using eGRID factors for calculating emissions from indirect electricity consumption. Since Redlands is located in California, CAMX eGRID Subregion (Appendix $\mathrm{G}$ ) values are used as the carbon emissions factor in the $\mathrm{CO}_{2}$-Models. The carbon emissions factor to convert natural gas consumptions to carbon dioxide emissions was not available for California. Therefore, the weighted U.S. average was used to calculate carbon dioxide emissions from natural gas consumption (Table 7). The carbon dioxide emissions factor for natural gas was extracted from the California Climate Action Registry General Reporting Protocol (2009), as well. The carbon emissions factors were added to all three sub-models as variables and their values as model parameters, so users can change the values as new values are produced by the U.S. EPA (Figure 5-7).
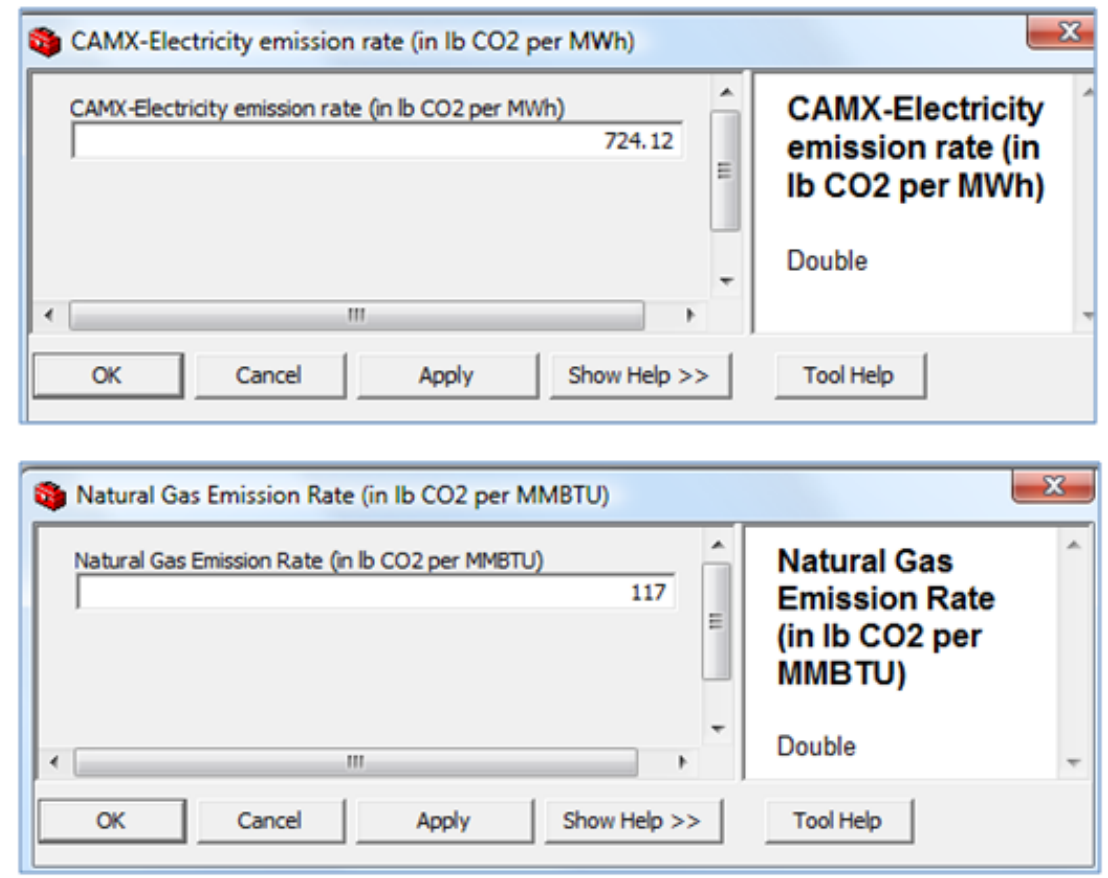

Figure 5-7: Electricity and natural gas emissions factors 


\subsection{Summary}

The $\mathrm{CO}_{2}$-Model application consists of three sub-models: $\mathrm{CO} 2 \_\mathrm{Com}, \mathrm{CO}_{2} \_\mathrm{SCE}$, and $\mathrm{CO}_{2}$ ZZone10. The ESRI ArcGIS ModelBuilder environment was chosen to develop all three models because it allows consistency and repeatability in estimating carbon dioxide emissions. During implementation of the three models, users are provided with a parameter window to update the input variables, and input feature class. The implementation of the $\mathrm{CO}_{2}$ CCom toolset yields an estimation of the carbon dioxide emissions from the commercial sector and the implementation of the $\mathrm{CO}_{2}$ SCE and $\mathrm{CO}_{2}$ ZZone10 yields an estimation of the carbon dioxide emissions from the residential sector. All the models were designed to be updated and easily run from the Open Model dialog box or from the edit model windows. The sub-models, data, and the ArcMap document (.mxd) are portable and easy to transfer to other users' systems. The results of the three sub-models are explained in detail in Chapter 6. 



\section{Chapter 6 - Results and Analysis}

This chapter presents the results of the different components of $\mathrm{CO}_{2}$-Model application: $\mathrm{CO}_{2}$ Com, $\mathrm{CO}_{2} \_\mathrm{SCE}$, and $\mathrm{CO}_{2} \_$Zone 10. The electricity and gas consumptions calculated by the models were aggregated at the city level and compared to the aggregated electricity and gas consumptions data provided by the utility company for the year 2008 , respectively to ensure the accuracy of the model in predicting energy consumptions. This chapter is divided into three sections to discuss the results from the commercial and residential models and a summary of the results is provided at the end.

\subsection{Commercial Model Results}

This section provides the results and analysis of the $\mathrm{CO}_{2}$ Com model. The $\mathrm{CO}_{2}$ Com model estimates the energy consumptions and carbon dioxide emissions for the commercial sector. Figure 6-1 shows the distribution of carbon dioxide emissions due to end-use energy consumption from the commercial sector. The variation in the distribution is largely dependent on the variation of building floor space and the type of building. The highly concentrated areas in the northwest corner of city are warehouses. Although the warehouse is not the building type that has highest energy consumption intensity, the generally large floor space of these warehouses makes them contribute more carbon emissions than other commercial buildings.

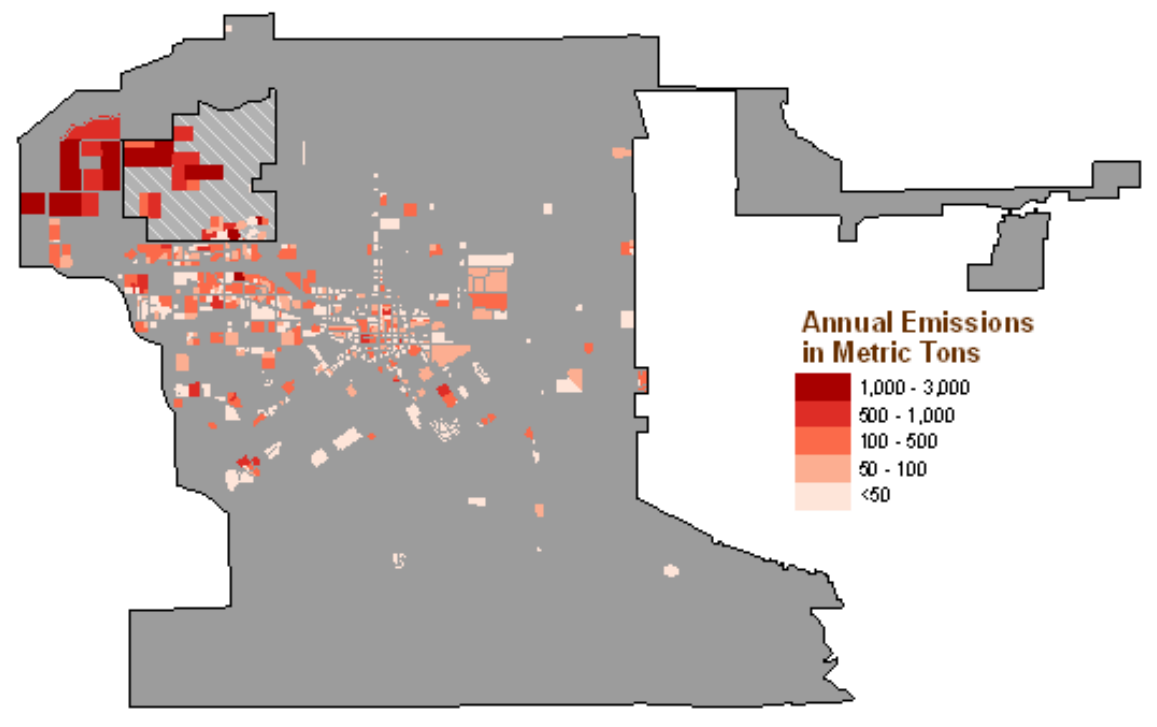

Figure 6-1: Distribution of Carbon dioxide emissions from commercial sector

To further illustrate the relationship between floor size and carbon emissions, Figure 6-2 shows a comparison between average building size and average carbon dioxide emissions by building type. On average, food store buildings generate the most carbon emissions across the various commercial structures, while small office space generates the least. In terms of floor space, warehouses have the largest average floor space and 
restaurants have the smallest average floor space. Thus, the average carbon emissions are not proportional to the average floor spaces, because the carbon emissions also depend on the energy intensity of a particular type of building. For example, although the average sizes of the food stores and large offices are less than the average size of the warehouses, the average emissions rates for both food stores and offices are much higher than warehouses. This is because food stores and large offices have greater energy consumption intensities $(41.71 \mathrm{KWh}$ per sq $\mathrm{ft}$ and 0.22 therms per sq $\mathrm{ft}$ for food stores, $17.91 \mathrm{KWh}$ per sq ft and 0.13 therms per sq ft for large offices, and 5.71 and 0.03 therms per sq $\mathrm{ft}$ for warehouses). It is also worth pointing out that the results shown here are generalized and cannot be used to compare individual buildings. For example, two food stores with the same floor space will very likely have different energy usages and this difference cannot be reflected by the model results.

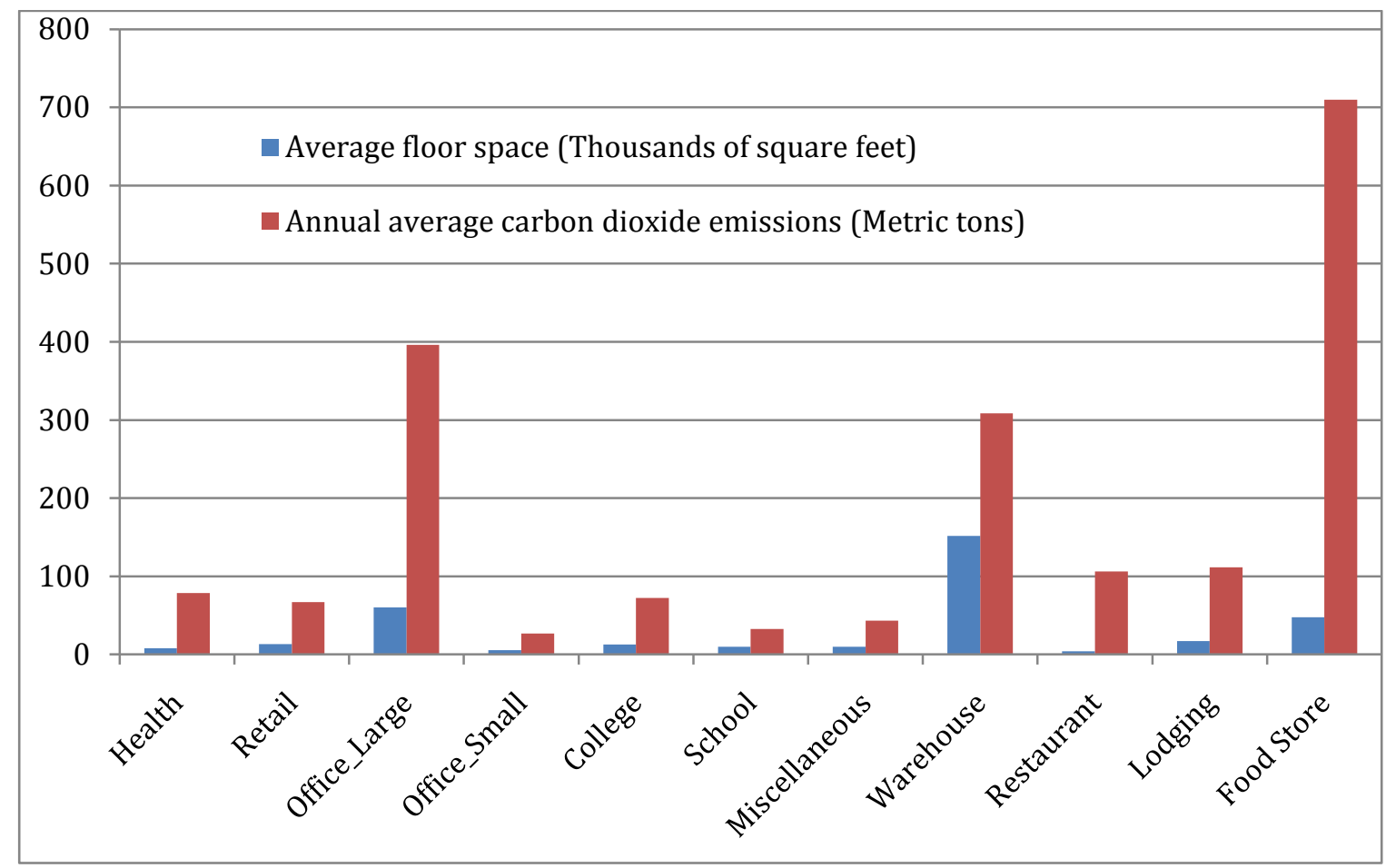

\section{Figure 6-2: Comparison of commercial building floor space and emissions}

The total annual electricity and gas consumption calculated from the model was aggregated at the city level and compared with the actual electricity and gas consumption data provided by the utility companies for the year 2008 (Figure 6-3). The comparison shows that the estimation for electricity consumption is much more accurate than that for gas consumption. Prediction for city-wide annual electricity consumptions is about 17 percent above the utility provided value. However, the discrepancy between the prediction for city-wide annual gas consumptions and the true value is rather large, about 47 percent underestimation. 


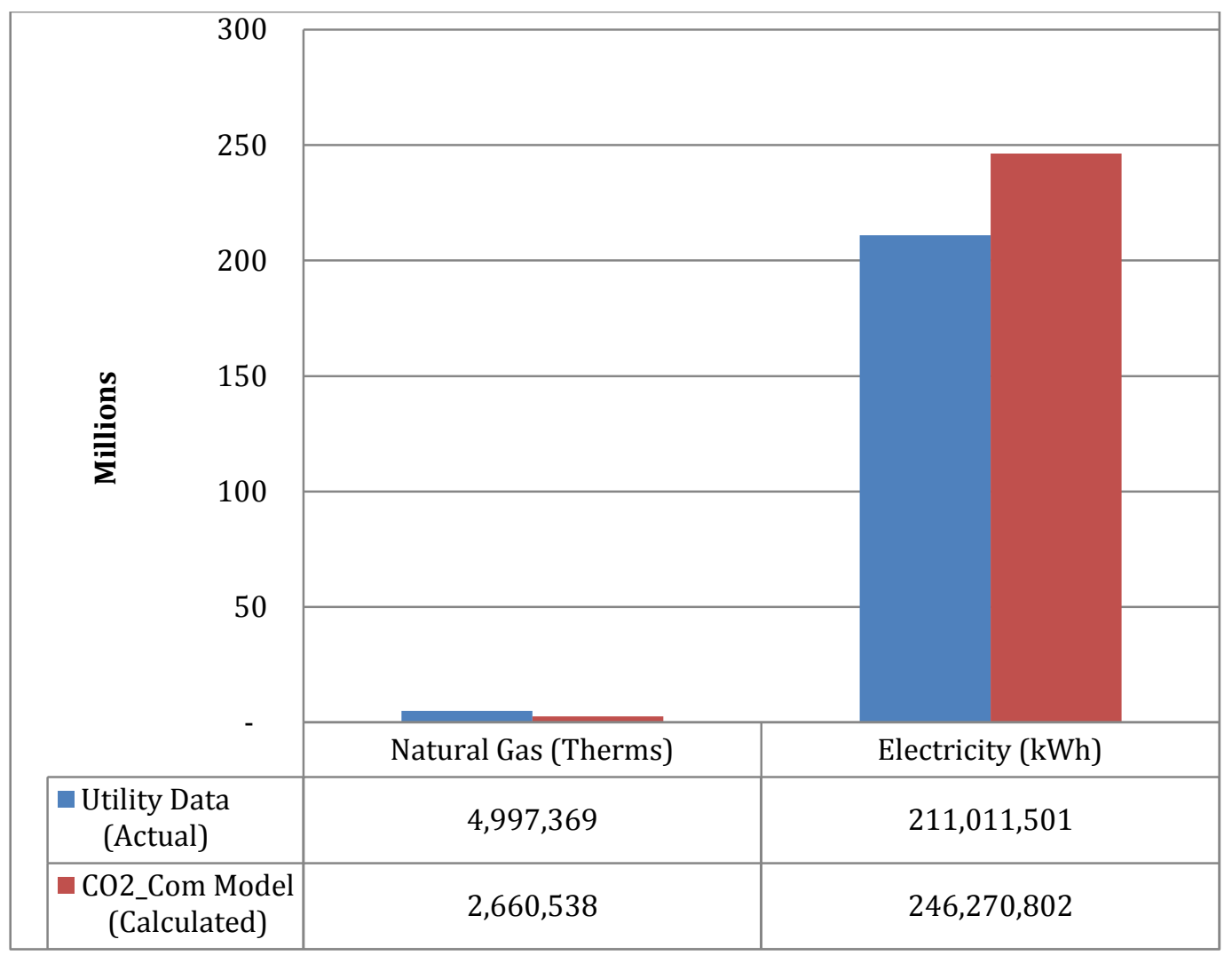

Figure 6-3: Commercial model result validation

The 17 percent overestimation of electricity consumptions could be due to the generalization introduced by the electricity intensity values used in the model to predict the annual electricity consumptions; or it could be due to the different aggregation schema used by the utility company when they provided the total consumption data. The model does not differentiate between vacant and used buildings and also could be a potential reason for overestimation.

There are several potential factors that may account for underestimating natural gas consumptions. First, the Commercial End-Use Survey focused on electricity consumptions more than natural gas consumptions. Therefore, the electricity intensities are more accurate than gas intensities. Second, the natural gas consumptions for 2008 were provided by the utility company according to NAICS (North American Industry Classification System) codes. The consumption data for 2008 included all the SoCalGas (Southern California Gas Company) accounts with city as Redlands. There are several parcels which fall outside the city limits but are under the influence of the City of Redlands that were actually included in the utility-provided data. However, they were excluded from the model as the city boundary was used to select the relevant parcels. The electricity consumption estimation may suffer a similar inconsistency while aggregating annual consumption data for the city. It is important to find a consistent way to aggregate energy consumption data so that the model calculated data can be validated.

Third, the accuracy of natural gas intensities across different categories may vary. To examine this, the estimated annual natural gas consumptions for restaurants and lodgings 
(hotels and motels) were compared to their actual values provided by the SoCalGas (Table 8). These two building types were appropriate for the examination because both categories had the most complete floor space data in the database, with only one missing record for each of them, and all records in these two categories are located within the Redlands city limits. The model yielded much more accurate predictions for the lodging category (only overestimated by 1 percent) compared to the restaurant category (underestimated by 50 percent). Therefore, this suggests that the natural gas intensities for several building types may not be as accurate as others.

Table 8. Comparison of actual and estimated natural gas consumptions

\begin{tabular}{|lccc|}
\hline & $\begin{array}{c}\text { Actual } \\
\text { Consumptions } \\
\text { Building Type }\end{array}$ & $\begin{array}{c}\text { Calculated } \\
\text { Consumptions }\end{array}$ & \\
All & $4,997,369$ & (Therms) & \%rror \\
Restaurant & $1,106,332$ & $2,660,538$ & $47 \%$ \\
Lodging & 102,402 & 558,404 & $50 \%$ \\
\hline
\end{tabular}

In summary, the estimates of carbon dioxide emissions from natural gas consumptions could be significantly improved when there are no missing value issues, the natural gas intensity values for some building type are improved, and the data provided by SoCalGas includes all commercial units within the city boundary.

\subsection{Residential Model Results}

This section provides the results and analysis of the $\mathrm{CO}_{2} \_\mathrm{SCE}$ and $\mathrm{CO}_{2}$ Zone10 models. Unlike the commercial model, floor space is not one of the factors to estimate carbon emissions for residential buildings because the electricity and gas intensity values for residential buildings were not available. Therefore, all the building units that belong to the same building type have the same carbon emissions according to the generalized approach. The building unit refers to the household; for example, a single family house is one unit, while a multifamily building contains multiple units. Obviously, this result cannot be accurate for estimating individual household energy consumption. It can only be used for very coarse estimation for the carbon emissions at the parcel level.

Figure 6-4 shows the distribution of carbon dioxide emissions estimated using these two models respectively. The variation in the distribution of carbon dioxide emissions predicted from the $\mathrm{CO}_{2}$ SCE model was largely dependent on the variation of building type and age. All buildings were divided into four categories in this model: new and old single family homes, and new and old multifamily homes. Unlike the results from the $\mathrm{CO}_{2} \_\mathrm{SCE}$ model, the variation in the distribution of carbon dioxide emissions predicted from the $\mathrm{CO}_{2}$ Z Zone 10 model was only determined by the building types. For the $\mathrm{CO}_{2}$ ZZone10 model, the building types were divided into four different categories: single family homes, 2-4 unit apartments, 5+unit apartments, and mobile homes. Since natural gas consumption data for the different building types were not available, all household annual gas unit energy consumption values were used for the $\mathrm{CO}_{2}$ Zone10 model. The 
analysis was performed at the parcel scale because the building type data existed in the parcel database.
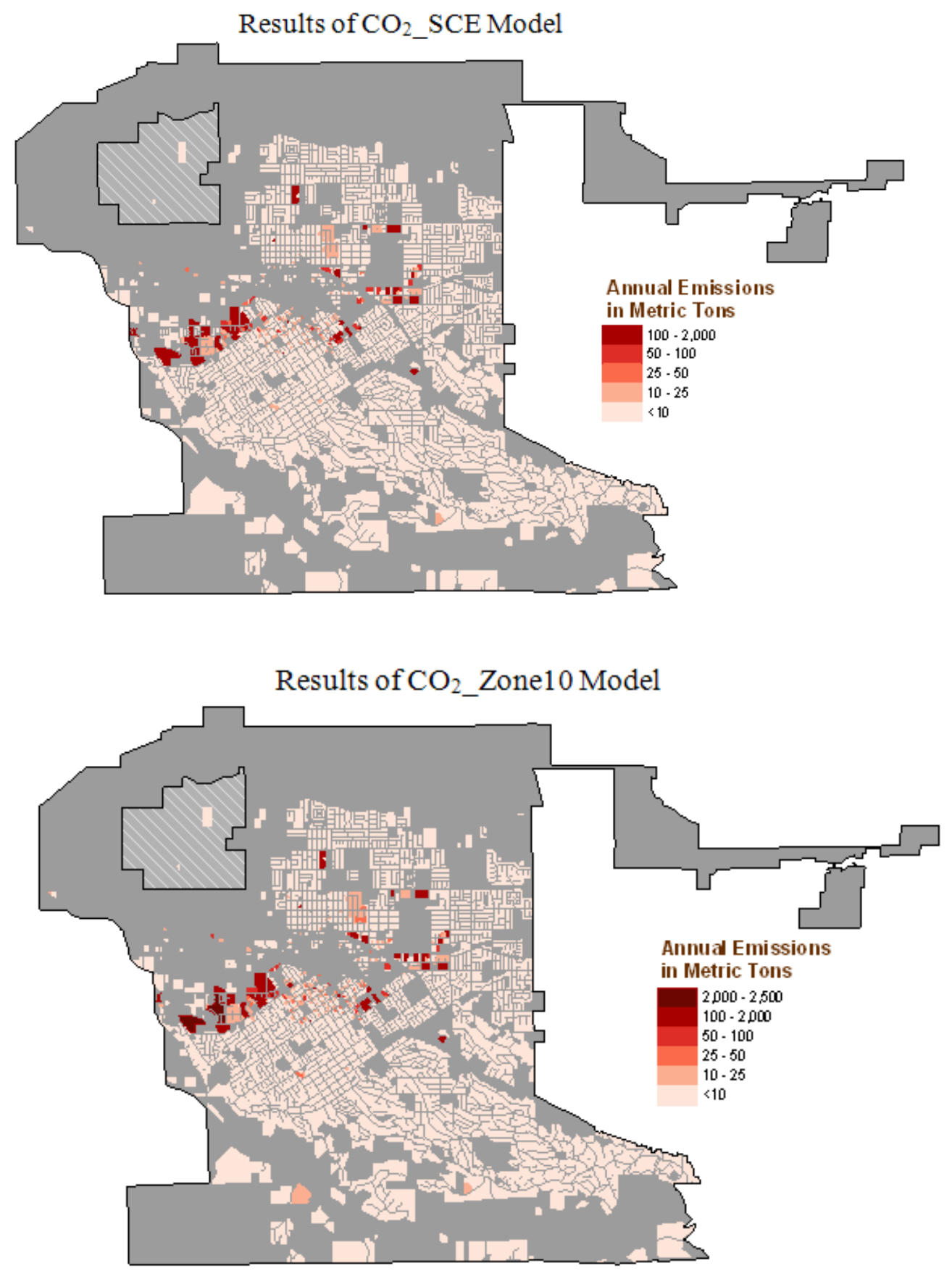

Figure 6-4: Carbon dioxide emissions distribution for residential sector predicted using $\mathrm{CO}_{2} \_\mathrm{SCE}$ Model and $\mathrm{CO}_{2} \_\mathrm{Zone10}$

It appears that these two models generated very similar carbon emission patterns. The residential areas in the northwest section of the city have high carbon emissions 
compared to other residential areas. This is because the majority of the residential buildings in that area are multifamily buildings with an average age of 30 years and an average number of units per parcel greater than 100. The large value in the number of units makes these parcels stand out, even though the UECs for old multifamily homes is relatively low compared to single family homes. However, a closer look at the map shows that the carbon emission for every parcel estimated from the $\mathrm{CO}_{2}$ SCE model is less than 2000 metric tons, while the $\mathrm{CO}_{2}$ Zone 10 model yields values greater than 2000 metric tons. This is because the UECs used in the $\mathrm{CO}_{2}$ Zone10 are generally greater than those applied in the $\mathrm{CO}_{2} \_\mathrm{SCE}$ model.

Figure 6-5 compares the proportion of carbon dioxide emissions estimated for certain types of buildings to the proportion of that type of building in the total residential buildings in the city. Seventy-eight percent of residential buildings are old single family buildings, which contributed 66 percent of the total carbon dioxide emissions. The second largest contributor, old multifamily homes ( 22 percent), only constitutes 10 percent of all residential buildings, which is reasonable when considering the number of units in those buildings. New single and multifamily homes constitute 11 percent of the residential buildings and the carbon dioxide emissions from these homes are not significant because they only constitute 10 percent of the total estimated carbon dioxide emissions for all residential buildings. Therefore, significant amount of carbon dioxide emissions could be reduced by focusing on improving the energy efficiency of the older buildings, particularly the multifamily homes.

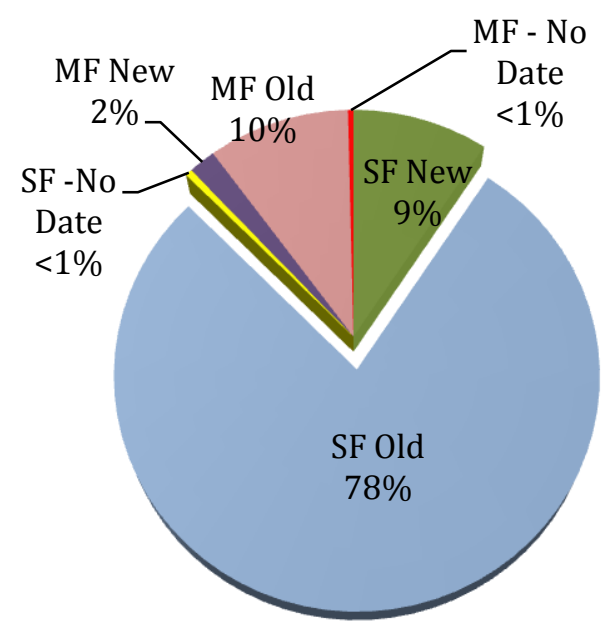

$\%$ Building Type

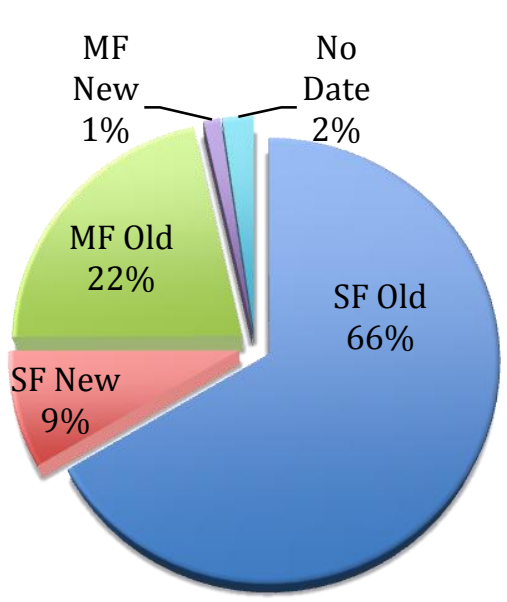

\% Emissions

Figure 6-5: Percent of residential building type and carbon dioxide emissions

To validate the results from the two residential models, the total annual electricity and gas consumptions calculated from the models were aggregated at the city level and compared to the actual electricity and gas consumptions provided by the utility companies for the year 2008. Both residential models underestimated the electricity and gas consumptions, as show in Figure 6-6. 


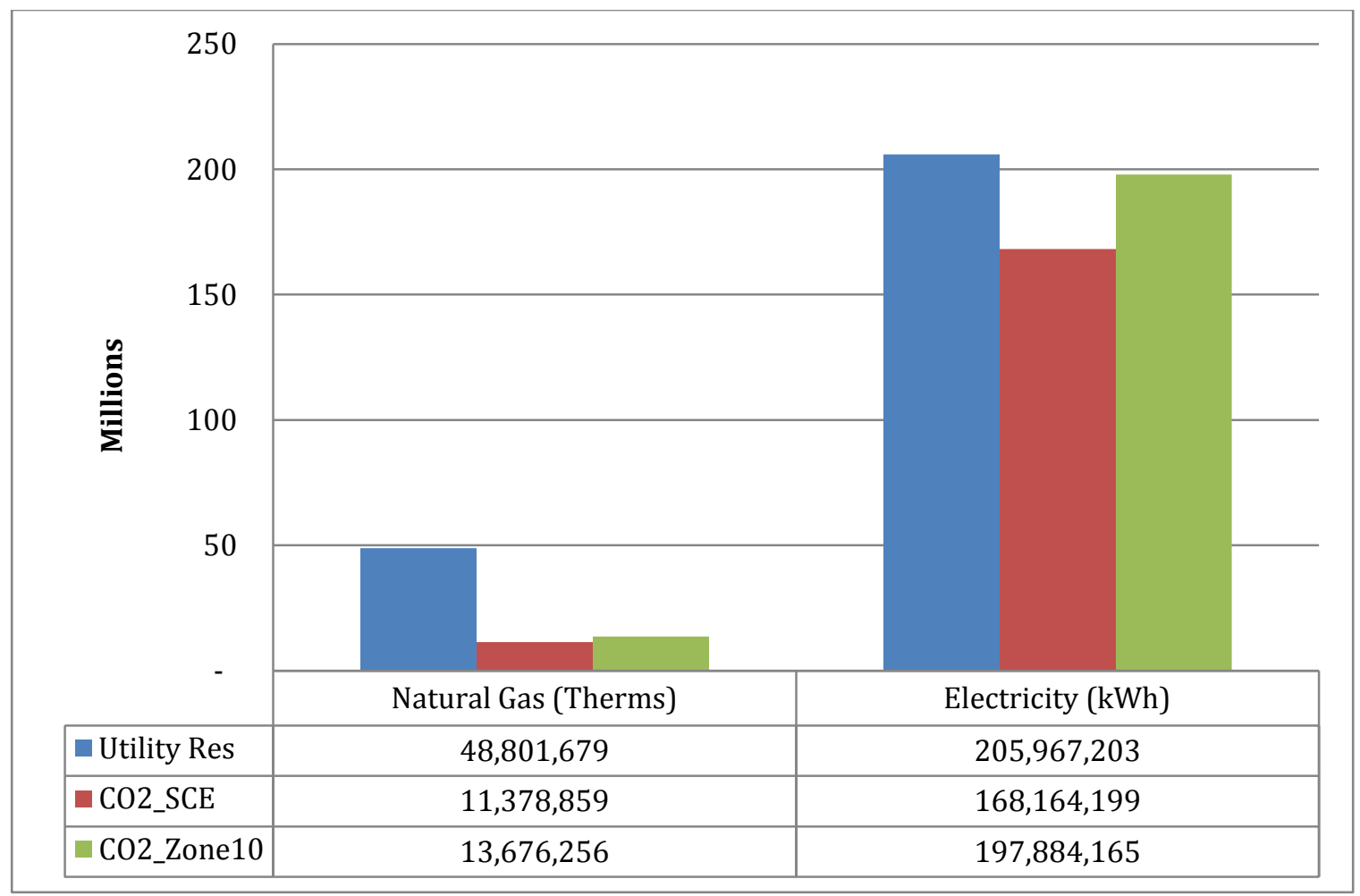

Figure 6-6: Residential model result validation

As with the commercial model results, the electricity consumption estimates are much more accurate than the gas consumptions. Both residential models underestimated the gas consumption by more than 70 percent (Table 9).

Table 9. Percent error for electricity and natural gas for the residential sector

\begin{tabular}{|lcc|}
\hline & \% Error Gas & \% Error Electricity \\
$\mathrm{CO}_{2} \_\mathrm{SCE}$ & $77 \%$ & $18 \%$ \\
$\mathrm{CO}_{2}$ ZZone 10 & $72 \%$ & $4 \%$ \\
\hline
\end{tabular}

There are a few reasons for this large discrepancy. Due to the unavailability of enduse gas UECs data according to building type for climate zone 10, all household values were used to calculate the end-use gas consumption. Therefore, the $\mathrm{CO}_{2}$ Zone10 model doesn't accurately predict annual gas consumptions when compared to the annual electricity consumptions.

As mentioned earlier in section 6.1 (Commercial Model Results), one of the possibilities for the larger error for end-use gas consumptions may have been the annual gas UEC values used. The results of the Residential Appliance Saturation Study (RASS) for predicting the gas UEC values at the household level may not be accurate, especially for the SCE utility region or climate zone 10, because the survey population of the households served by the SoCalGas utility was not as complete as the survey population of the households served by the SCE (California Energy Commission, 2004). The 
electricity and natural gas UEC values are considered more accurate for the utility regions with one utility provider, such as the Pacific Gas and Electric Company, which provides both electricity and natural gas to its customers.

As far as electricity consumption estimation is concerned, there was only 4 percent error generated by the $\mathrm{CO}_{2} \_$Zone10 model, suggesting that the annual electricity UEC values for Zone 10 should be used for electricity consumptions calculation. This is because the RASS survey focused specifically on the Inland Empire and is weathernormalized using conditions from the closest weather stations. Therefore, CEC (California Energy Commission) forecast climate zone 10 electricity UECs are more representative of the UECs for City of Redlands households, compared to the electricity UECs produced for the entire SCE utility region.

\subsection{Summary}

The total carbon dioxide emissions estimated by the model for commercial and residential sectors from end-use energy consumption of natural gas were approximately 232,000 metric tons. In Redlands, 87 percent of the total carbon dioxide emissions generated from end-use energy consumption in the residential and commercial sectors were contributed by electricity consumption. The carbon dioxide emissions were underestimated due to several reasons, including missing data, inaccuracy, and inconsistency in energy consumptions data aggregated by the model and utility company, and inaccuracy in gas intensity and gas UEC values predicted by the CEC study for the SoCalGas population. The accuracy of the model could be improved considerably with more accurate input variables. The commercial predictions would be more accurate if the usable square feet of office building types were identified for the commercial buildings at the parcel level. 


\section{Chapter 7 - Conclusions and Future Work}

Obtaining actual energy consumption data from a utility company at the parcel level is not possible due to customer confidentiality issues. Conducting parcel level surveys to analyze the carbon dioxide emissions is both very time consuming and costly. Therefore, an alternative approach was used to estimate the carbon dioxide emissions from the enduse energy consumption in the residential and commercial sectors. ESRI's ArcGIS 9.3 ModelBuilder platform helped design and model the $\mathrm{CO}_{2}$-Model application to calculate the indirect carbon dioxide emissions for the City of Redlands. Using energy intensity and Unit Energy Consumption (UEC) values with GIS parcel data is a cost effective way to estimate and visually analyze the distribution of carbon dioxide emissions from enduse energy consumptions for commercial and residential sectors. This study revealed that using annual electricity intensity, electricity consumed per square foot floor space, and annual UECs per household can better estimate electricity consumption than natural gas consumption. Although the $\mathrm{CO}_{2}$-Model was developed to work for the City of Redlands, it can be customized to work for other cities, as well.

\subsection{Model Summary}

Three models were implemented to calculate the carbon dioxide emissions from the commercial and residential sectors: the $\mathrm{CO}_{2}$ Com model for the commercial sector, and the $\mathrm{CO}_{2} \_\mathrm{SCE}$ and $\mathrm{CO}_{2}$ ZZone10 models for the residential sector. Annual electricity and gas intensity data provided by the Commercial End-Use Survey of 2006 for the SCE utility region was used to estimate the total energy consumption per parcel in the $\mathrm{CO}_{2}$ Com model. Electricity and gas annual UECs data provided by the RASS study (2006) for the SCE utility region and climate zone 10 region were used to estimate the total energy consumptions per parcel in the $\mathrm{CO}_{2} \_\mathrm{SCE}$ model and $\mathrm{CO}_{2}$ Zone10 model, respectively.

The calculated electricity and gas consumptions from the models were aggregated and compared to the actual data provided by the utility company for the year 2008 to ensure the accuracy of the models. All three models provided better accuracy in predicting electricity consumptions compared to gas consumptions. The higher errors in predicting gas consumption were due to the variables used to estimate gas consumption. As better energy intensities and UEC values are calculated by the CEC, the model can be used by cities to estimate the carbon dioxide emissions and monitor the changes over time in a consistent manner.

The model can be updated easily when input variables such as annual electricity and gas intensities, UECs, and carbon dioxide emissions factors for natural gas or electricity are updated by the CEC or the California Climate Action Registry. The model can also be easily updated every year when the city's parcels data is updated and carbon emissions can be calculated and compared year after year to gauge the effects of population growth and new development.

Based on the results of the three models $-\mathrm{CO}_{2} \_\mathrm{Com}, \mathrm{CO}_{2} \_\mathrm{SCE}$, and $\mathrm{CO}_{2}$ ZZone10 - the objective of this project to estimate the carbon dioxide emissions and display it at the parcel level was achieved. However, it is important to note that the 
volume of carbon dioxide results produced from the $\mathrm{CO}_{2}$-Model at parcels level does not indicate the carbon dioxide concentration for that area and should not be used for assessing local air quality. However, focusing on reducing energy consumption at the parcel level, the local air quality, as well as regional quality, can be improved. The purpose of the $\mathrm{CO}_{2}$-Model is simply to estimate carbon dioxide emissions for inventory purposes. The results of the model should be validated every year by requesting energy consumption data from the utility company in a consistent manner.

\subsection{Model Enhancement and Future Studies}

The carbon dioxide emissions estimations can be improved with the improvement of the UEC and energy intensity values. Since SoCalGas has provided gas consumption data by NACIS codes, the gas intensities for the different types of commercial buildings can be improved. Natural gas intensities for specific business types at the city level can be calculated by dividing the aggregated gas consumption data provided by the SoCalGas Company by the total square feet of floor space of a particular building type aggregated at city level. This can be done if all the commercial buildings square feet of floor space data were populated in the parcel feature class. For example, since the restaurant and lodging square feet data at parcels level were complete, comparing the gas consumptions for these building types helped identify that the gas intensity data provided by the CEC study was lower than the calculated gas intensity for the city. The calculated natural gas intensity for restaurants (4.97) was double the natural gas intensity predicted by the CEC study for the SCE area (2.49). However, the calculated natural gas intensity (.41) for lodging was similar to the predicted natural gas intensity (.40) by the CEC survey study for the SCE area. Hence, gas intensities can be improved using the data provided by SoCalGas and by populating the floor space of buildings in the parcels database.

Future research should focus on using simulation software such as EQUEST, DOE2, or Energy Plus to simulate daily and seasonal energy consumption loads at the building level for the residential and commercial sectors. This is one of the bottom-up approaches, used for estimating individual building energy consumption. Buildings are divided into different categories based on their characteristics and the simulation software is used to predict the energy consumption for a set of similar buildings representative of buildings in a particular city (Heiple \& Sailor, 2008). Using simulation software to estimate residential and commercial energy consumption was considered as an alternative. However, since the different types of buildings representative of the buildings for the City of Redlands were not available, the simulation approach was abandoned. Simulation methods should be used in the future to compare the level of energy consumption predicted by the $\mathrm{CO}_{2}$-Model and validate it by requesting energy bills from different building types when the direct energy consumption data is hard to acquire.

If data for similar buildings could be identified at city level, the future study could be built upon Heiple and Sailor (2008) approach and case study for the City of Houston, Texas. It could provide a basis to analyze carbon emissions from the daily and peak hour energy consumption, as well as seasonal energy consumption effects. The energy consumptions calculated using the simulation methods could be used to estimate the carbon dioxide emissions and analyze the change in trend over time.

Finally, with the $\mathrm{CO}_{2}$-Model outputs, the client can examine the distribution of the carbon emission of different types of buildings and estimate the total carbon emission of 
the entire city for commercial and residential sectors. Along with the $\mathrm{CO}_{2}-\mathrm{Model}$ output, the documentation of this GIS desktop application was also delivered to the client. Overall, the $\mathrm{CO}_{2}$-Model application is easy to work with and can be used to inventory other greenhouse gases with minimal changes to the models. 



\section{Works Cited}

Arronruengswat, A., \& Auffhammer, M. (2009, March). Impacts of climate change on residential electricity consumption: evidence from billing data. Retrieved May 2009, from California Energy Commission:

http://www.energy.ca.gov/2009publications/CEC-500-2009-018/CEC-500-2009018-D.PDF

California Climate Action Registry. (2009, January). General Reporting Protocol, Version 3.1. Retrieved June 15, 2009, from http://www.climateregistry.org/tools/protocols/general-reporting-protocol.html

California Energy Commission. (2004, June). California Statewide Residential Appliance Saturation Study. Retrieved November 04, 2009, from http://www.energy.ca.gov/reports/400-04-009/2004-08-17_400-04009VOL1.PDF

California Energy Commission. (2006, March). California Commercial End-Use Survey. Retrieved April 2009, from http://www.energy.ca.gov/ceus/

California Energy Commission. (2006, March). California Commercial End-Use Survey. Retrieved June 20, 2009, from http://www.energy.ca.gov/2006publications/CEC400-2006-005/CEC-400-2006-005.PDF

California Energy Commission. (2006, June). California Statewide Residential Appliance Saturation Study Updated to Air Conditioning Unit Energy Consumption Estimates Using 2004 Billing Data. Retrieved November 8, 2009, from http://websafe.kemainc.com/RASSWEB/uploads/060510-CA-RASS-follow-onFINAL.pdf

California Environmental Protection Agency Air Resources Board. (2006). Assembly Bill 32. Retrieved from http://www.arb.ca.gov/cc/ab32/ab32.htm

California Public Utilities Commission. (2008, September). California Long Term Energy Efficiency Strategic Plan. Retrieved from www.CaliforniaEnergyEfficiency.com

City of Redlands. (2006, July). General Plan. Retrieved from http://www.ci.redlands.ca.us/plans/general_plan1.htm

Energy Information Administration. (2007). Emissions of Greenhouse Gases in the United States. Washington DC: U.S. Department of Energy.

Environmental Systems Research Institute. (2009). ArcGIS Diagrammer. Retrieved November 10, 2009, from ESRI Support Center: http://arcscripts.esri.com/details.asp?dbid=15166

Heiple, S., \& Sailor, D. J. (2008). Using Building Energy Simulation and Geospatial Modeling Techniques to Determine High Resolution Building Sector Energy Consumption Profiles. Energy and Buildings, 1426-1436.

Kates, R. W., Mayfield, M. W., Torrie, R. D., \& Witcher, B. (1998). Methods for estimating greenhouse gases from local places. Local Environment, 279-297.

Paltsev, S., Reilly, J. M., Jacoby, H. D., Eckaus, R. S., McFarland, J., Sarofim, M., et al. (2005, August). The MIT Emissions Prediction and Policy Analysis (EPPA) Model: Version 4. Retrieved May 2009, from MIT Joint Program on the Science and Policy of Global Change:

http://web.mit.edu/globalchange/www/MITJPSPGC_Rpt125.pdf 
Python Software Foundation. (2009). Python TM. Retrieved October 07, 2009, from Python Programming Language: http://python.org/

SCAG. (n.d.). Southern California Association of Governments. Retrieved October 17, 2009, from http://www.scag.ca.gov/planning.htm

Schmalensee, R., Stoker, T. M., \& Judson, R. A. (1998). World Carbon Dioxide Emission:1950-2050. The Review of Economics and Statistics, 80, 15-27.

U.S. Department of Energy. (2003). Energy Indicators System: Index Construction Methodology. Retrieved October 24, 2009, from http://www.eere.energy.gov/ba/pba/intensityindicators/pdfs/index_methodology.p df

University of California at Davis. (2008, August 11). Information Center for the Environment. Retrieved April 7, 2009, from http://ice.ucdavis.edu/doc/uplan 


\title{
Appendix A. Python Script
}

Python 2.5.1 (r251:54863, Apr 18 2007, 08:51:08) [MSC v.1310 32 bit (Intel)] on win32 Type "copyright", "credits" or "license()" for more information.

************************************************************************

Personal firewall software may warn about the connection IDLE makes to its subprocess using this computer's internal loopback interface. This connection is not visible on any external interface and no data is sent to or received from the Internet.

$* * * * * * * * * * * * * * * * * * * * * * * * * * * * * * * * * * * * * * * * * * * * * * * * * * * * * * * * * * * * * * * *$

\author{
AddFields_Pipeline.py \\ \# Description: Adds fields from value table. \\ \# NOTES: Fields are only added if they don't exist. \\ \# Requirements: ArcView or ArcInfo license. \\ \# User must code in input layer. \\ \# User must code in value table (see comments for format). \\ \# $\quad$ Should be used as script tool in ArcCatalog toolbox. \\ \# Assumes active doc is a data frame (uses layers). \\ \# See http://www.python.org/doc/current/lib/contents.html for Python Reference \\ \# Author: Sabina Giri, adapted from Ruth Bowers script \\ \# Date: September, 2009 \\ \# \\ \# IMPORT SYSTEM MODULES \\ import sys, string, os, win32com.client \\ \# CREATE THE GEOPROCESSOR OBJECT \\ $\mathrm{gp}=$ win32com.client.Dispatch("esriGeoprocessing.GpDispatch.1") \\ \# Create Arguments Feature Class (1) \& Name of the Output (2) \\ \# CREATE LOCAL VARIABLES \\ $\mathrm{InFC}=$ sys.argv[1] \\ \# Output Feature Class \\ OutFC $=$ sys.argv[2] \\ \# CREATE VALUE TABLE (FIELDS TO ADD) \\ try: \\ vtab = gp.CreateObject("ValueTable",5) \\ \# ADDROW FORMAT: Name Type Prec Scale Length \\ vtab.AddRow("Electric_kwh DOUBLE \# 2 \#")
}




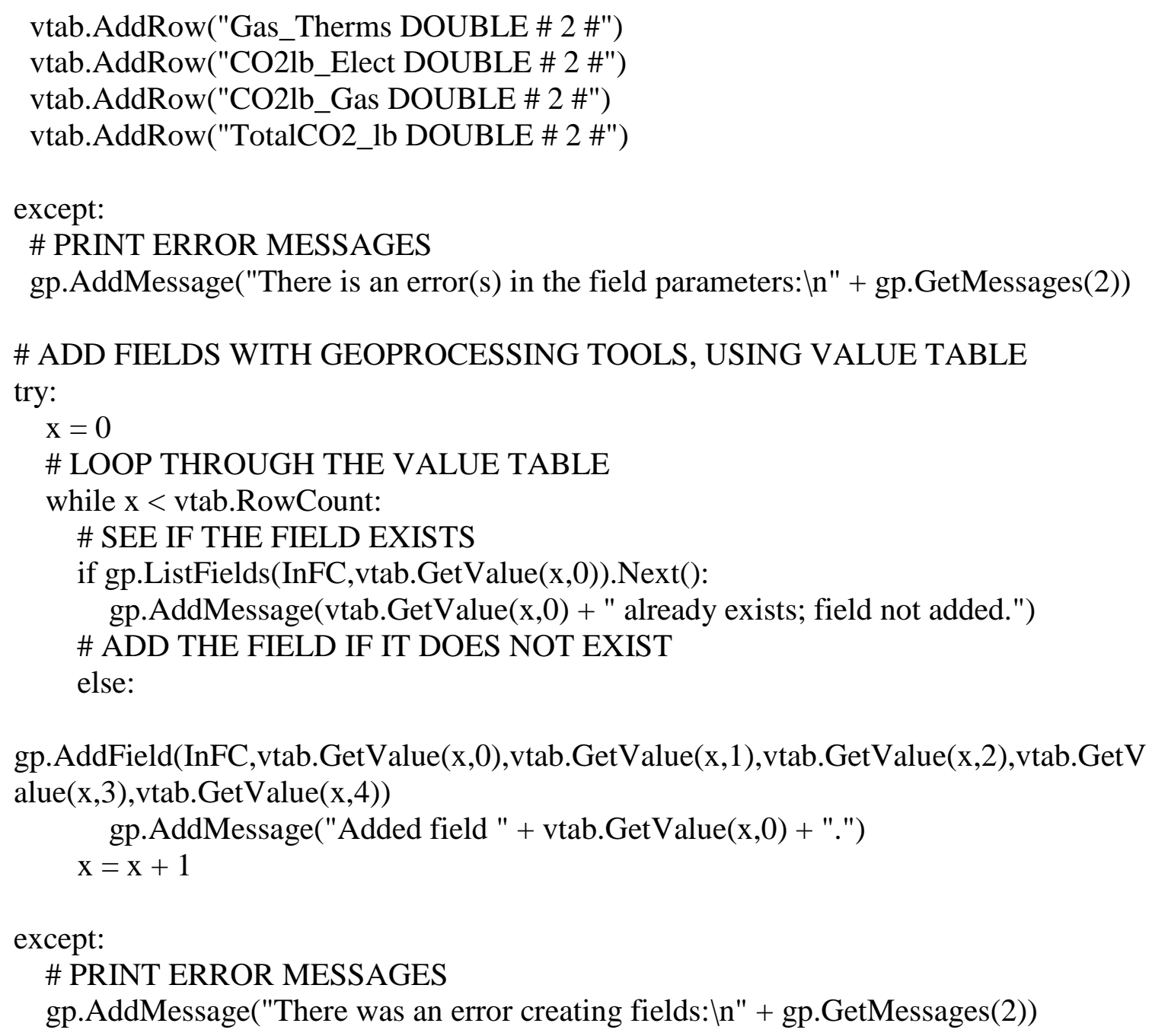




\section{Appendix B. Criteria for dividing parcels dataset into different land use}

Selection for Commercial parcels in A2P_LandUse feature class

Commercial:

USECODE" = 'ADULT SCHOOL' OR "USECODE" = 'AIRPORT' OR "USECODE" = 'ASSOCIATE' OR "USECODE" = 'ASSTLIVING' OR "USECODE" = 'AUTO DEALER' OR "USECODE" = 'AUTO STG' OR "USECODE" = 'AUTO WASH' OR "USECODE" = 'BANK/S\&L' OR "USECODE" = 'BOARD/CARE' OR "USECODE" = 'BOWLING' OR "USECODE" = 'BUSINESSPRK' OR "USECODE" = 'CAR LOT' OR "USECODE" = 'CAR WASH' OR "USECODE" = 'CELL TOWER' OR "USECODE" = 'CEMETERY' OR "USECODE" = 'CITY CLUB' OR "USECODE" = 'CITY YARD' OR "USECODE" = 'CIVIC CENTER' OR "USECODE" = 'CLUBHOUSE' OR "USECODE" = 'CO SCHOOL' OR "USECODE" = 'COIN WASH' OR "USECODE" = 'COLLEGE' OR "USECODE" = 'COMMON' OR "USECODE" = 'COMMON C/I' OR "USECODE" = 'COMMUNITY CENTER' OR "USECODE" = 'CONV HOSP' OR "USECODE" = 'CONV STORE' OR "USECODE" = 'CONV/GAS' OR "USECODE" = 'DAIRY/GAS' OR "USECODE" = 'DEN OFFICE' OR "USECODE" = 'DEPARTMENT' OR "USECODE" = 'DISCOUNT' OR "USECODE" = 'DIST WHSE' OR "USECODE" = 'EDUCATION' OR "USECODE" = 'ELEM SCHOOL' OR "USECODE" = 'ENG/RESRCH' OR "USECODE" = 'FAST FOOD' OR "USECODE" = 'FIRE STATION' OR "USECODE" = 'FRATERNAL' OR "USECODE" = 'GEN OFFICE' OR "USECODE" = 'HEALTH CLB' OR "USECODE" = 'HIGH SCHOOL' OR "USECODE" = 'HOSPITAL' OR "USECODE" = 'HOTEL' OR "USECODE" = 'IND LOFT' OR "USECODE" = 'IND CONDO' OR "USECODE" = 'JUNK YARD' OR "USECODE" = 'LAUNDROMAT' OR "USECODE" = 'LIBRARY' OR "USECODE" = 'MARKET' OR "USECODE" = 'MED CONDO' OR "USECODE" = 'MED OFFICE' OR "USECODE" = 'MEDICAL' OR "USECODE" = 'MINI LUBE' OR "USECODE" = 'MINI STG' OR "USECODE" = 'MORTUARY' OR "USECODE" = 'MOTEL' OR "USECODE" = 'OFF CONDO' OR "USECODE" = 'OFFICE' OR "USECODE" = 'OIL \& GAS' OR "USECODE" = 'POLICE ANNEX' OR "USECODE" = 'PRE SCHOOL' OR "USECODE" = 'PUBLIC FACILITY' OR "USECODE" = 'PUBLICUTIL' OR "USECODE" = 'RECT/CONV' OR "USECODE" = 'REDLANDS BOWL' OR "USECODE" = 'RESTAURANT' OR "USECODE" = 'RET STRIP' OR "USECODE" = 'RET WHSE' OR "USECODE" = 'RETAIL' OR "USECODE" = 'SCHOOL' OR "USECODE" = 'SECOND SCHOOL' OR "USECODE" = 'SENIOR CENTER' OR "USECODE" = 'SERVICE STATION' OR "USECODE" = 'SHOP CTR' OR "USECODE" = 'SRVICE GAR' OR "USECODE" = 'STG WHSE' OR "USECODE" = 'STG YARD' OR "USECODE" = 'STORAGE' OR "USECODE" = 'SUPER MKT' OR "USECODE" = 'THEATER' OR "USECODE" = 'VET OFFICE' OR "USECODE" = 'WAREHOUSE' 
Single Family Residential: All Single family detached buildings on a parcel

1. $\quad 1$ st Selection based on LANDUSE

"USECODE" = 'SFR' OR "USECODE" = 'MHM 18551' OR "USECODE" = 'DEMIN PUD' OR "USECODE" = 'QUAD' OR "USECODE" = 'MISC RES'

2. $\quad 2^{\text {nd }}$ selection based on LANDUSE

"LANDUSE" = 'RES,SINGLE FAMILY RESIDENCE' OR "LANDUSE" = 'RES,PUD' OR "LANDUSE" = 'PUD,DEMINIMUS' OR "LANDUSE" = 'MHM,18551 MANUF HM ON PERM FOUND'

Multifamily Residential: includes all single family attached buildings and multifamily buildings

1. 1st Selection based on LANDUSE

"USECODE" = 'SFR 2' OR "USECODE" = 'SFR 3' OR "USECODE" = 'SFR 4' OR "USECODE" = 'SFR 5-14' OR "USECODE" LIKE '\%APT\%' OR "USECODE" = 'DUPLEX' OR "USECODE" = 'QUAD' OR "USECODE" = 'TRIPLEX' OR "USECODE" = 'BOYS \& GIRLS CLUB' OR "USECODE" = 'CONDO' OR "USECODE" = 'MISC RES' OR "USECODE" = 'PUD' OR "USECODE" = 'REST HOME' OR "USECODE" = 'SR APT 15+'

2. $\quad 2^{\text {nd }}$ selection based on LANDUSE

"LANDUSE" LIKE 'RES,MULTI-FAM\%' OR "LANDUSE" = 'RES,PUD' OR "LANDUSE" = 'RES,CONDOMINIUM' 


\title{
Appendix C. Utility provided data and $15 / 15$ rule
}

\author{
1. Information provided by: Southern California Edison
}

\author{
CITY OF REDLANDS \\ LAND USE ZONE \\ CALENDAR YEAR 2008
}

\begin{tabular}{|l|r|r|}
\hline Zone & $\begin{array}{c}\text { NUMBER OF } \\
\text { ACCOUNTS }\end{array}$ & ANNUAL KWH \\
\hline $\mathrm{Ag}$ & 1,732 & $80,578,093$ \\
\hline Com1 & 1,354 & $101,528,365$ \\
\hline Com2 & 1,646 & $109,483,136$ \\
\hline Res 1 & 16,639 & $164,174,436$ \\
\hline Res 2 & 7,537 & $41,792,767$ \\
\hline Other & 853 & $50,666,174$ \\
\hline Total & $\mathbf{2 9 , 7 6 1}$ & $\mathbf{5 4 8 , 2 2 2 , 9 7 1}$ \\
\hline
\end{tabular}

Application of 15/15 Rule (Release of Aggregated Customer Information)

Ag Zone includes the following categories: Orchards \& Vineyards, Commercial Recreation, Dairy \& Intensive Livestock, Developed Local Parks and Recreation, Golf Courses, Horse Courses, Irrigated Cropland, Non-Irrigated Cropland, Nurseries, Other Agriculture, Other Open Space \& Recreation, Rural Residential Low Density, Rural Residential High Density, Trailer Parks High Density, Vacant Undifferentiated, and Vacant with Limited Improvement

Com 1 Zone includes the following categories: Cemeteries, Commercial Storage, Communication Facilities, Elementary Schools, Hotels \& Motels, Junior High Schools, Non-Attended Public Parking, Open Storage, Police \& Sheriff Stations, Pre-Schools/Day Care Centers, Religious Facilities, Retail Centers, Senior High Schools, and Special Care Facilities.

Com2 Zone includes the following categories: Colleges \& Universities, Fire Stations, Government Offices, Low-Med Rise Major Office, Major Medical Health Care, Mixed Commercial \& Industrial, Modern Strip Development, Older Strip Development, Packing Houses \& Grain Elevators, Regional Shopping Center, and Wholesaling \& Warehousing.

Res1 Zone includes the following categories: High Density, and Low Density.

Res2 Zone includes the following categories: Duplexes \& Triplexes, Low-Rise Apartments \& Condos, Med-Rise Apartments \& Condos, and Mixed Residential.

Other Zone includes the following categories: Airports, Freeways \& Major Roads, Maintenance Yards, Manufacturing \& Assembly, Mixed Urban, Other Public Facilities, Other Special Care Use, Under Construction, Water Storage Facilities, Water Transfer Facilities and Unmapped. 
From: Estrella, Becky R.

Sent: Wednesday, August 19, 2009 3:58 PM

To: Giri, Sabina

Subject: RE: Energy Data Request

\section{5/15 Rule:}

The 15/15 Rule is intended to protect customer confidentiality by reducing the possibility of identifying customers through the release of usage information. SCE will apply the 15/15 Rule in releasing aggregated customer information. The rule was initially implemented by the California Public Utilities Commission during Direct Access proceedings in 1997 and was adopted through D. 97-10-031.

The 15/15 rule requires that any aggregated information provided by the Utilities must be made up of at least 15 customers, and a customer's load must be less than $15 \%$ of an assigned category. If the number of customers in the compiled data is below 15, if a single customer's load is more than $15 \%$ of the total data, categories (e.g., rate classes) must be combined before the information is released. The rule further requires that if the $15 / 15$ rule is triggered for a second time after the data has been screened once already using the 15/15 rule, then the customer is dropped from the information provided.

\section{Information provided by: Southern California Gas Company (SoCalGas)}

\begin{tabular}{|lcc|}
\hline 2008 Natural Gas Consumption-City of Redlands & \\
& & \\
Commercial Accounts (All Rates) & $484,241,552$ & Therms \\
Residential Accounts (GR) & $43,314,763$ & Therms \\
Residential Accounts (GM) & $5,486,916$ & Therms \\
Total & $\mathbf{5 3 3 , 0 4 3 , 2 3 1}$ & Therms \\
& & \\
Commercial Account (excludes & 5134794 & \\
Manufacturers) & 5 & \\
\hline
\end{tabular}

Detailed natural gas consumption according to NAICS codes and GR/GM Rate can be found in the project CD.

For the codes and rate: http://www.socalgas.com/regulatory/tariffs/tariffs rates.shtml 
Appendix D. $\mathrm{CO}_{2}$-Model Application ModelBuilder Diagrams 


\section{Commercial: $\mathrm{CO}_{2}$ Com Model}

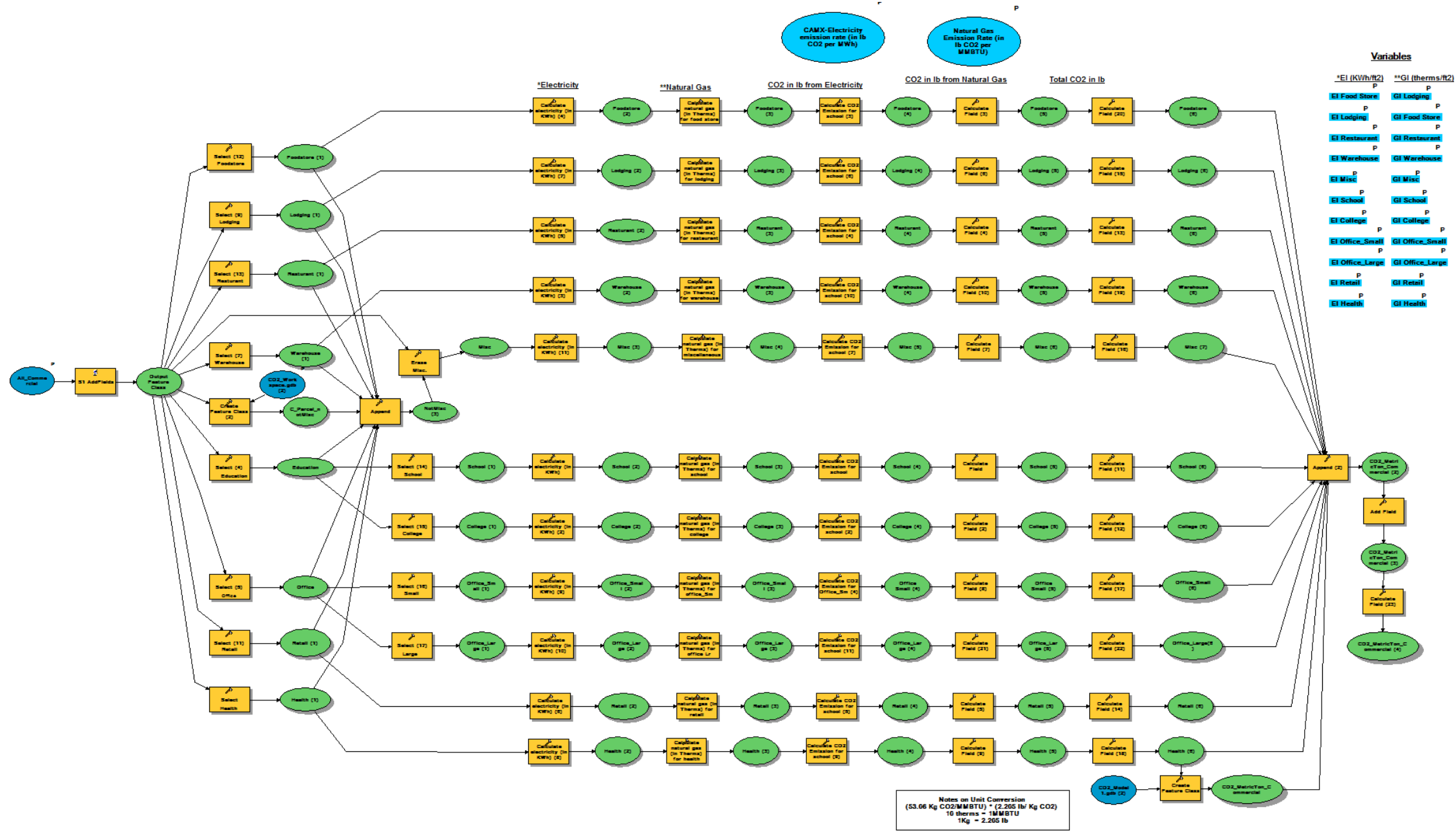




\section{Residential: $\mathrm{CO}_{2}$ SCE Model}

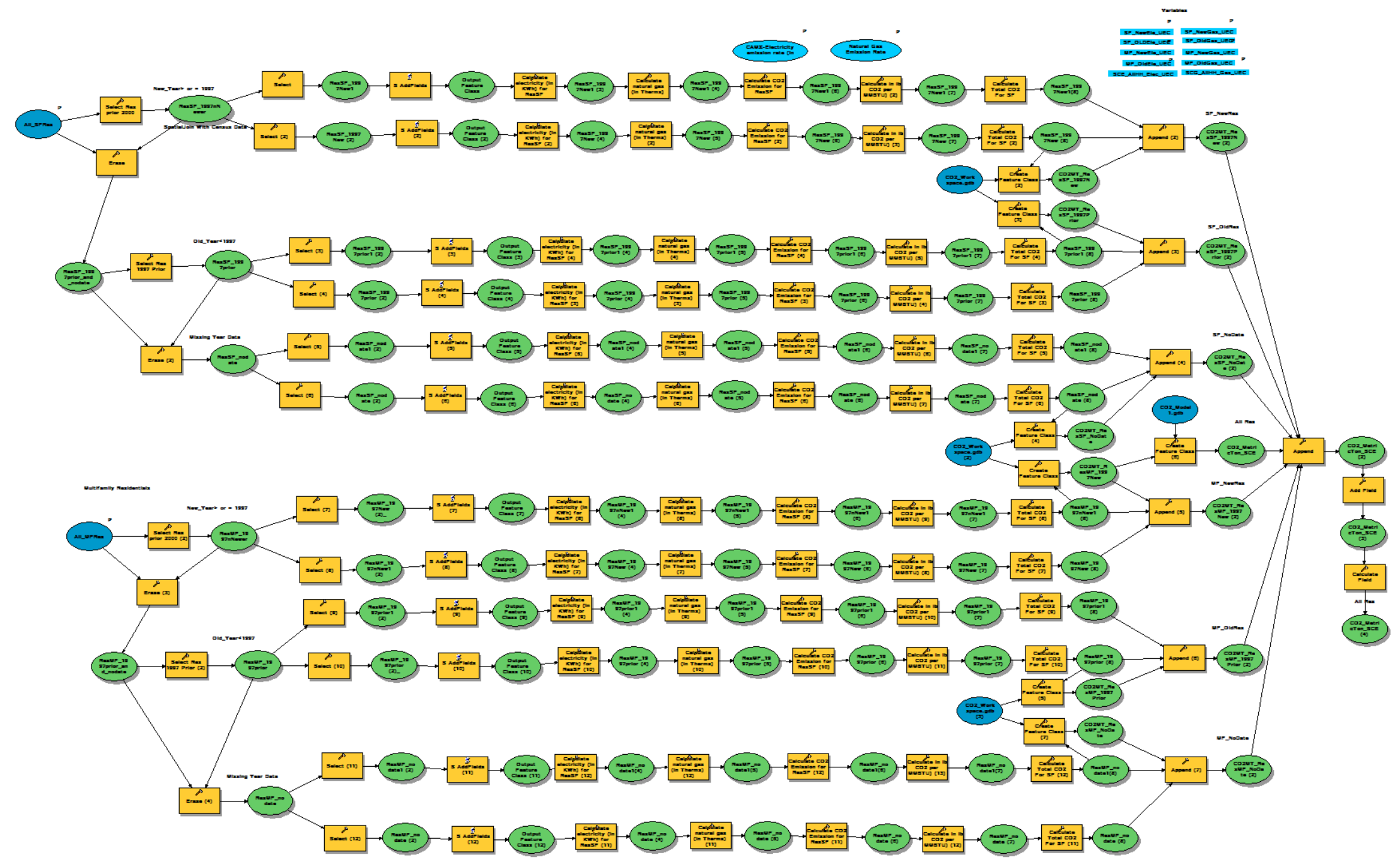




\section{Residential: $\mathrm{CO}_{2} \_$Zone10 Model}

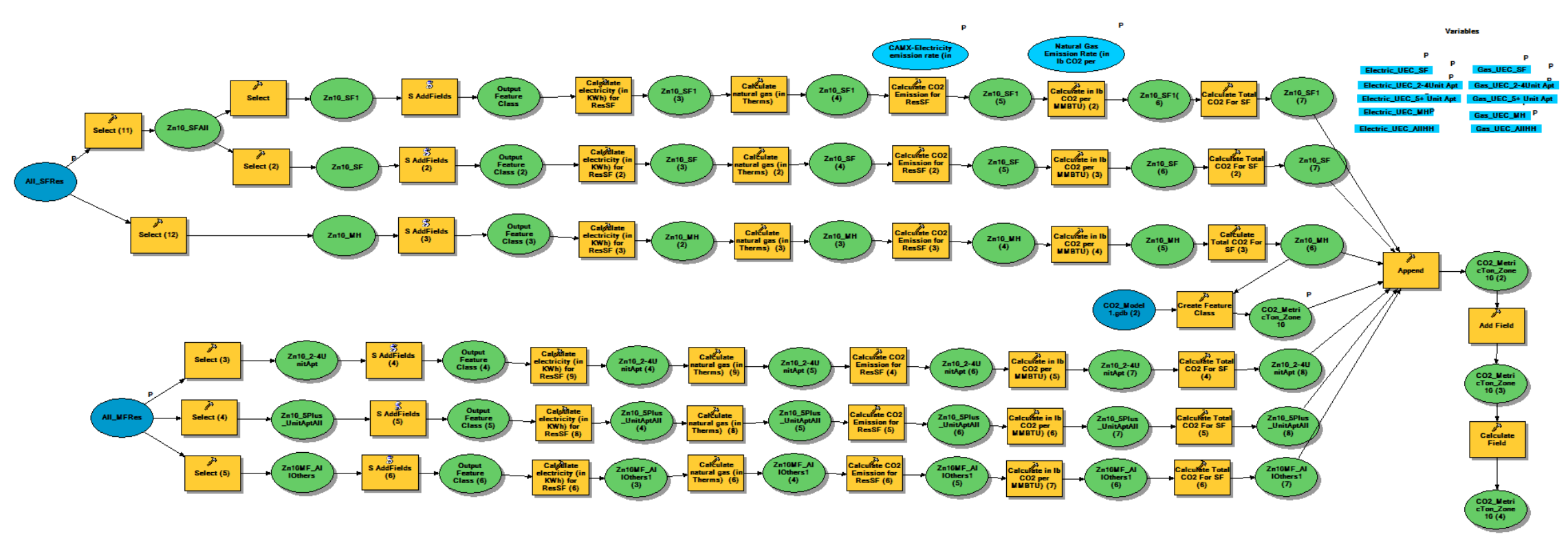




\section{Appendix E. Workflow for $\mathrm{CO}_{2}$ Com model}

\begin{tabular}{|c|c|c|c|c|}
\hline \multicolumn{5}{|c|}{ Add Multiple Fields } \\
\hline \multicolumn{3}{|c|}{5 fields added } & \multicolumn{2}{|c|}{ Type: Double } \\
\hline \multicolumn{5}{|c|}{ Select } \\
\hline \multicolumn{5}{|c|}{$\begin{array}{c}\text { LandUse and UseCode to divide parcels data into } 11 \text { building types as shown in } \\
\text { Table } 5\end{array}$} \\
\hline \multicolumn{5}{|c|}{ Calculate Field } \\
\hline $\begin{array}{l}\text { Annual electricity } \\
\text { consumption (KWh) }\end{array}$ & $=$ & $\begin{array}{l}\text { Electricity intensity } \\
\text { (KWh/Sqft) }\end{array}$ & $\mathrm{X}$ & $\begin{array}{l}\text { Building floor space } \\
\text { (Sqft) }\end{array}$ \\
\hline \multicolumn{5}{|c|}{ Calculate Field } \\
\hline $\begin{array}{c}\text { Annual gas } \\
\text { consumption (Therms) }\end{array}$ & $=$ & Gas intensity & $\mathrm{X}$ & $\begin{array}{l}\text { Building floor space } \\
\text { (Sqft) }\end{array}$ \\
\hline \multicolumn{5}{|c|}{ Calculate Field } \\
\hline $\begin{array}{l}\text { Annual } \mathrm{CO} 2 \text { emissions } \\
\text { from electricity }\end{array}$ & $=$ & $\begin{array}{c}\text { Annual electricity } \\
\text { consumption (KWh) }\end{array}$ & $\mathrm{x}$ & $\begin{array}{l}\text { Electricity emissions } \\
\text { factor }\end{array}$ \\
\hline \multicolumn{5}{|c|}{ Calculate Field } \\
\hline $\begin{array}{l}\text { Annual CO2 emissions } \\
\text { from gas consumption (lb) }\end{array}$ & $=$ & $\begin{array}{l}\text { Annual gas consumption } \\
\text { (Therms) }\end{array}$ & $\mathrm{x}$ & Gas emissions factor \\
\hline \multicolumn{5}{|c|}{ Calculate Field } \\
\hline $\begin{array}{l}\text { Annual CO2 Emissions } \\
\text { (lb) }\end{array}$ & $=$ & $\begin{array}{l}\text { Annual CO2 emissions } \\
\text { from electricity (lb) }\end{array}$ & + & $\begin{array}{l}\text { Annual CO2 emissions } \\
\text { from gas (lb) }\end{array}$ \\
\hline \multicolumn{5}{|c|}{ Append } \\
\hline \multicolumn{5}{|c|}{ Appends 11 tables to a single new feature class - "CO2_MetricTon_Commercial" } \\
\hline \multicolumn{5}{|c|}{ Calculate Field } \\
\hline $\begin{array}{l}\text { Annual CO2 Emissions } \\
\text { (Metric Tons) }\end{array}$ & $=$ & Annual CO2 Emissions (lb) & & $\begin{array}{c}(2,204.62 \mathrm{lb} / \text { Metrci } \\
\text { Tons })\end{array}$ \\
\hline
\end{tabular}




\section{Appendix F. Workflow for $\mathrm{CO}_{2} \_\mathrm{SCE}$ and $\mathrm{CO}_{2}$ ZZone10 model}

\begin{tabular}{|c|c|c|c|c|c|}
\hline \multicolumn{6}{|c|}{ Select } \\
\hline \multicolumn{3}{|c|}{$\begin{array}{c}\text { CO2_SCE: LandUse and UseCode to divide SF } \\
\text { parcels data into old SF, or new SF, or no date } \\
\text { SF and MF parcels data into old MF or new MF } \\
\text { or no date MF }\end{array}$} & \multicolumn{3}{|c|}{$\begin{array}{l}\text { CO2_Zone10: LandUse and UseCode to } \\
\text { divide parcels into SF, 2-4 unit apt, 5+ unit } \\
\text { Apt, mobile homes or others }\end{array}$} \\
\hline \multicolumn{6}{|c|}{ Following stepsare followed in both sub-models } \\
\hline \multicolumn{6}{|c|}{ Add Multiple Fields } \\
\hline \multicolumn{3}{|c|}{5 fields added } & \multicolumn{3}{|c|}{ Type: Double } \\
\hline \multicolumn{6}{|c|}{ Calculate Field } \\
\hline $\begin{array}{c}\text { Annual electricity } \\
\text { consumption (KWh) }\end{array}$ & $=$ & \multicolumn{2}{|c|}{ Number of Units } & & $\begin{array}{c}\text { annual electricity UEC } \\
\text { (KWh/unit) }\end{array}$ \\
\hline \multicolumn{6}{|c|}{ Calculate Field } \\
\hline $\begin{array}{l}\text { Annual gas consumption } \\
\text { (Therms) }\end{array}$ & $=$ & \multicolumn{2}{|c|}{ Number of Units } & \multicolumn{2}{|r|}{$\begin{array}{l}\text { annual gas UEC } \\
\text { (Therms/unit) }\end{array}$} \\
\hline \multicolumn{6}{|c|}{ Calculate Field } \\
\hline $\begin{array}{c}\text { Annual CO2 emissions } \\
\text { from electricity } \\
\text { consumption (lb) }\end{array}$ & $=$ & $\begin{array}{l}\text { Annual el } \\
\text { consumptic }\end{array}$ & $\begin{array}{l}\text { tricity } \\
\text { (KWh) }\end{array}$ & $\mathrm{X}$ & $\begin{array}{l}\text { Electricity emissions } \\
\text { factor }\end{array}$ \\
\hline \multicolumn{6}{|c|}{ Calculate Field } \\
\hline $\begin{array}{l}\text { Annual CO2 emissions } \\
\text { from gas consumption (lb) }\end{array}$ & $=$ & $\begin{array}{r}\text { Annual gas } \\
\text { (The }\end{array}$ & $\begin{array}{l}\text { nsumption } \\
\text { ms) }\end{array}$ & $\mathrm{X}$ & Gas emissions factor \\
\hline \multicolumn{6}{|c|}{ Calculate Field } \\
\hline Annual CO2 Emissions (lb) & $=$ & $\begin{array}{l}\text { Annual } \mathrm{CO} 2 \\
\text { from elect }\end{array}$ & $\begin{array}{l}\text { emissions } \\
\text { icity (lb) }\end{array}$ & + & $\begin{array}{l}\text { Annual CO2 emissions } \\
\text { from gas (lb) }\end{array}$ \\
\hline \multicolumn{6}{|c|}{ Append } \\
\hline \multicolumn{6}{|c|}{ Appends all SF and MF tables to a single new feature class - "CO2_MetricTon_SCE" } \\
\hline \multicolumn{6}{|c|}{ Calculate Field } \\
\hline $\begin{array}{c}\text { Annual CO2 Emissions } \\
\text { (Metric Tons) }\end{array}$ & $=$ & Annual CO2 Er & issions (lb) & $\div$ & $\begin{array}{c}(2,204.62 \mathrm{lb} / \text { Metrci } \\
\text { Tons })\end{array}$ \\
\hline
\end{tabular}




\section{Appendix G. eGRID Subregions}

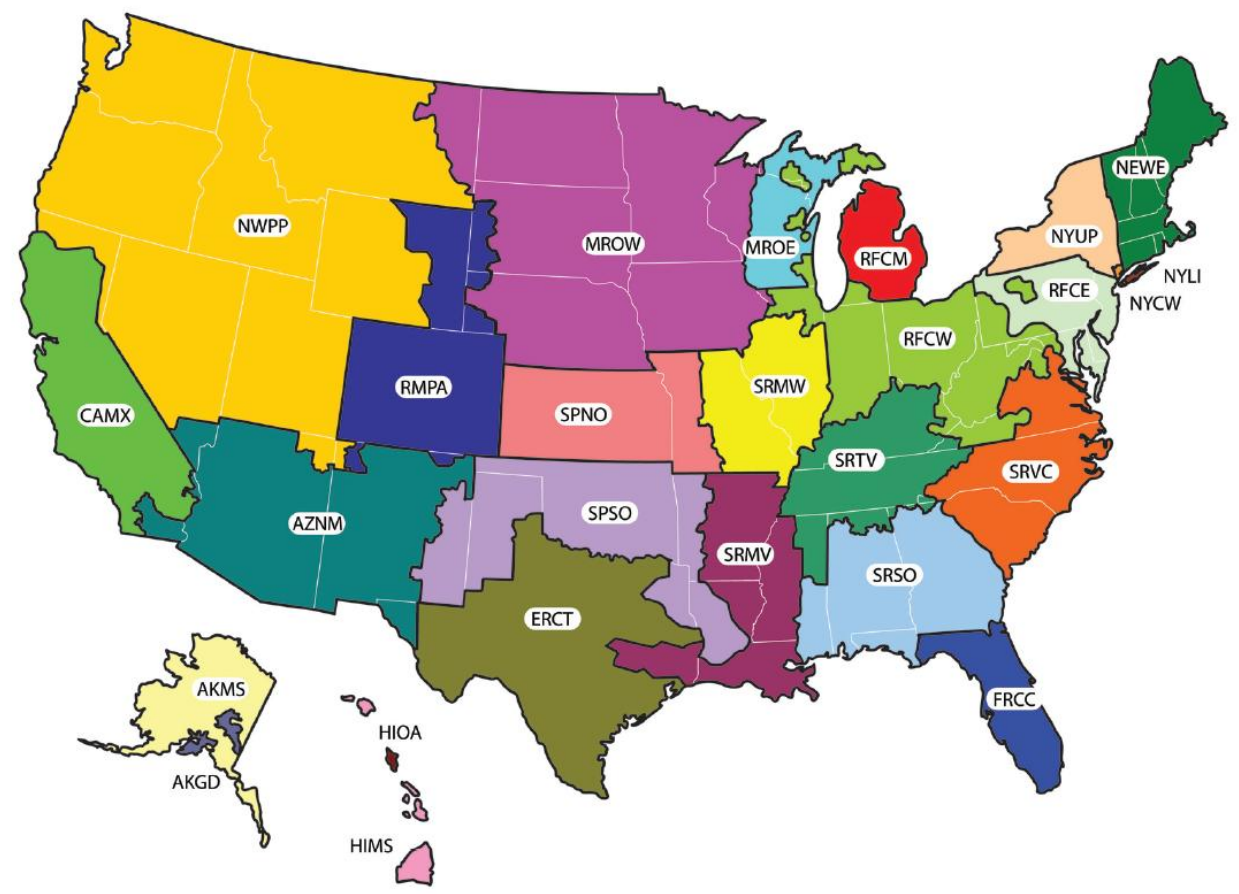

Source: (California Climate Action Registry, 2009) 